\title{
Cavity-shaped Ligands for Asymmetric Metal Catalysis
}

Zeyneb Kaya ${ }^{\mathrm{a}}$, Embarek Bentouhami ${ }^{\mathrm{b}}$, Katrin Pelzer $^{\mathrm{a}}$ and Dominique Armspach $^{\mathrm{a} *}$

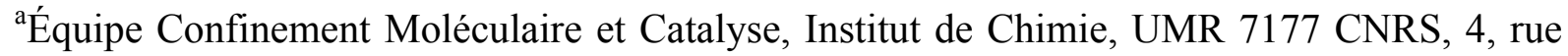
Blaise Pascal, CS90032, 67081 Strasbourg Cedex, France, E-mail: d.armspach@unistra.fr

${ }^{b}$ Laboratoire de Chimie Inorganique et Nanostructures, Faculté de Technologie, Université Ferhat Abbas, Sétif-1, Campus El Bez, Sétif, 19000, Algeria

\section{Contents}

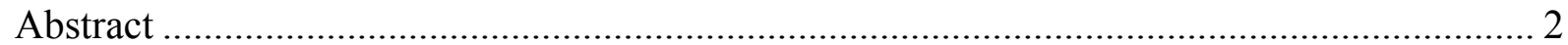

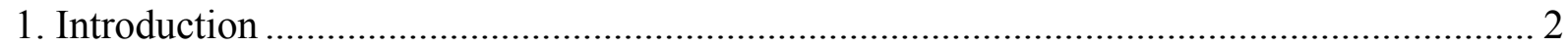

2. Chiral cavity-shaped ligands derived from calixarenes .................................................. 3

3. Chiral cavity-shaped ligands derived from cyclodextrins ................................................ 16

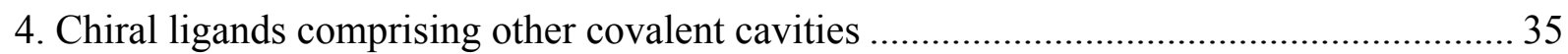

5. Chiral cavity-shaped supramolecular assemblies with metal coordinating ability ............. 44

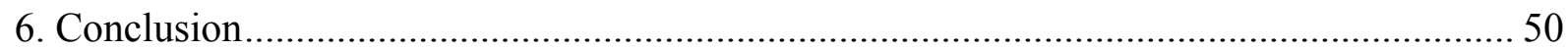

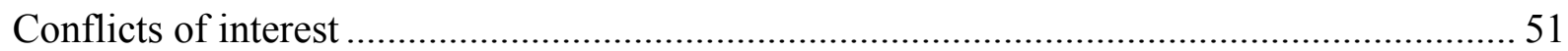

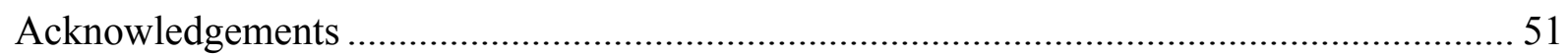

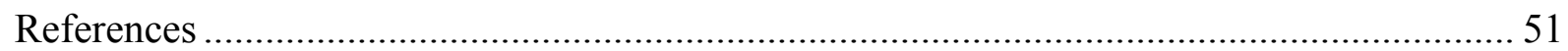

*Corresponding author. Tel.: ++33 368851621 (D.Armspach)

E-mail address: d.armspach@unistra.fr (D. Armspach) 


\begin{abstract}
Cavity-shaped ligands offer unique opportunities for influencing the first sphere of coordination of metals because of their capacity to act as containers for metal centers and/or preorganization platforms. These unique properties are of particular importance in asymmetric metal catalysis where spatial control around the coordinated substrate is of paramount importance for reaching high ee values. This perspective article describes the different approaches, whether covalent or supramolecular, that have so far been used for achieving enantiodiscrimination in asymmetric metal-catalyzed reactions thanks to metal complexation within or near chiral capsular environments.
\end{abstract}

Keywords: Ligand, Cavity, Asymmetric catalysis, Metal

\title{
1. Introduction
}

Most asymmetric metal-catalyzed reactions require the use of optically active ligands. These are often rigid and chelating in order to control access of the substrate to the coordinated metal. Enantiodiscrimination relies therefore in most cases on the existence of repulsive steric interactions between a prochiral substrate and the metal-bound chiral ligands. A wealth of ligands have so far been prepared according to these principles, amongst them the ones designed and tested by William S. Knowles, [1] Ryoji Noyori [2] and K. Barry Sharpless [3] who received the Nobel price for their seminal contributions in the field of asymmetric metal catalysis in 2001, as well as those of Henri Kagan [4] who perfected the art of ligand design in order to achieve optimal enantiodiscrimination. To date most ligands used in asymmetric catalysis, whether monodentate or bidentate, are devoid of a molecular cavity capable of hosting both a metal center and a reacting substrate in order to achieve high enantioselectivity by sterical control even if such a design is widely present in Nature's own metal catalysts, e.g. metalloenzymes [5]. Unlike cavity-free designs, metal confining cavityshaped ligands have the ability to fully embrace the catalytic center so that substrate-ligand interactions, whether repulsive or attractive, are present in every single portion of space surrounding the metal center. Amongst the readily available macrocyclic platforms that can be turned into chiral cavity-shaped ligands, two classes of molecules are clear frontrunners. These are the calixarenes and the cyclodextrins [6,7]. However, more original designs have emerged in recent years, including capsular ligands assembled by supramolecular means [810]. This perspective article focuses on the design and synthesis of this particular class of chiral ligands as well as their applications in asymmetric metal catalysis. It is divided into four sections, the first two dealing respectively with calixarenes and cyclodextrins and the last 
two with other designs including supramolecular ones. Note that macrocyclic ligands devoid of well-defined cavities are beyond the scope of this review [11], but cavity-shaped ligands for which the cavity acts only as a preorganization platform will be included. MOF-like asymmetric catalysts will also be excluded from this article as they have already been reviewed on several occasions [12-17].

\section{Chiral cavity-shaped ligands derived from calixarenes}

Calixarenes are oligophenolic compounds that have been popularized at the end of the 1970 s by Gutsche and are probably the most studied synthetic macrocycles [18-20]. Such a rich chemistry is a result of the ease with which they can be prepared in large quantities, at least for the most common ones, from simple phenolic derivatives and aldehydes, in particular formaldehyde. The fact that the small members of the family, in particular calix[4]arene, can be functionalized at will in a regioselective manner and the presence of a well-defined molecular cavity in the cone conformers, which can be easily stabilized, make them very attractive preorganization platforms onto which various substituents, including chiral ones, can be grafted, if applicable, in an orthogonal manner. The way chirality can be introduced in the conical structure is two-fold. The first one consists in substituting phenolic units with different groups on precise locations of the macrocyclic structure, e.g. two different groups on proximal positions. If the substitution pattern results in a $C_{1}$-symmetric molecule, the calixarene is "inherently chiral" [21,22]. More classically, chirality can be introduced by grafting enantiopure fragments, whether with stereogenic centers or displaying planar or axial chirality, onto the calixarene skeleton. To date, the number of examples of calixarenes made chiral using the second strategy far exceeds those displaying inherent chirality, including for applications in asymmetric metal catalysis. Noticeably, all examples of calixarene-based asymmetric metal catalysts are constructed from calix[4]arenes, despite the fact their rather small cavity restricts their use as molecular receptors. In these systems, the calix[4]arene core acts as a preorganization platform rather than a metal encapsulating unit. Larger analogs such as chiral calix[6]arenes have not been used so far in asymmetric metal catalysis because the control of their conformation and their regiofunctionalization are far more challenging. In 2001, Matt was the first to synthesize chiral ligands built from a calix[4]arene platform [23]. They comprise two phosphine units located on the proximal positions of a calix[4]arene lower rim and an enantiopure amide unit. Because of the inherent chirality of the macrocycle, two diastereomers $(\mathbf{1} \mathbf{a}, \mathbf{b})$ are formed when grafting the chiral unit on the di(phosphine oxide) platform. These can be easily separated by column chromatography. Following reduction of 
the phosphine oxide units with phenylsilane, enantiopure diphosphines $\mathbf{2 a}$ and $\mathbf{2 b} \mathbf{2} \mathbf{2} \mathbf{b}$ is present in solution as a 10:1 mixture of cone/partial cone conformations) were obtained. They display both inherent chirality and classical C-centrochirality. Further derivatization of one of the diastereomeric diphosphines (2a) afforded ligand $\mathbf{3}$ with a larger substituent size at the fourth phenolic unit (Scheme 1). While preformed cationic palladium complexes incorporating ligands $\mathbf{2 a}$ and $\mathbf{3}$ were tested in asymmetric Tsuji-Trost allylic alkylation, their rhodium analogs acted as catalysts for dimethyl itaconate hydrogenation (Scheme 1).

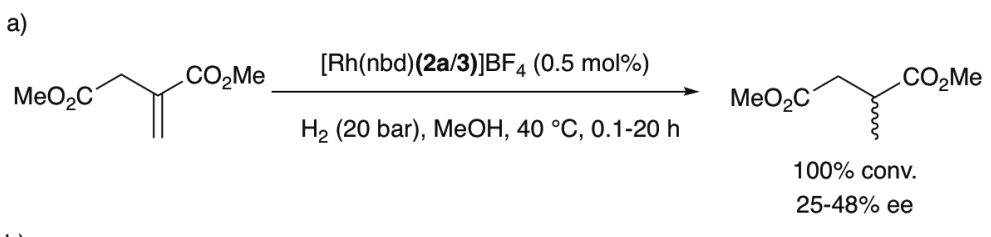

b)

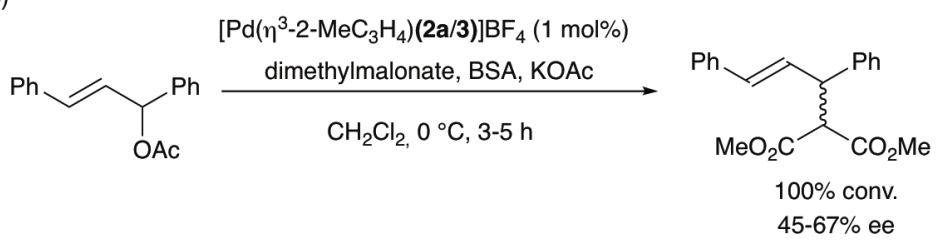

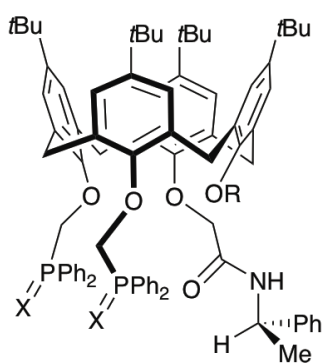

1a, $X=O, R=H$

2a, $\mathrm{X}=$ lone pair, $\mathrm{R}=\mathrm{H}$

3, $\mathrm{X}=$ lone pair, $\mathrm{R}=\mathrm{SiMe}_{3}$

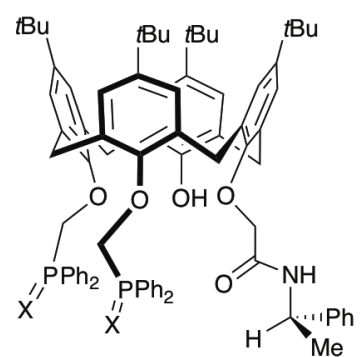

$1 b, X=0$

2b, $X=$ lone pair

Scheme 1. Asymmetric alkylation and hydrogenation of functional olefins catalyzed by diphosphines based on chiral calix[4]arene platforms.

Moderate to average ee values (25-67\%) were observed for all these catalysts. The best results were obtained when the fourth phenolic unit remains unsubstituted as in 2a both in terms of activity and enantioselectivity (TOF up to $2000 \mathrm{~h}^{-1}$ and $48 \%$ ee for the hydrogenation of itaconate using $\left.[\mathrm{Rh}(\mathrm{nbd})(\mathbf{2 a} / \mathbf{3})] \mathrm{BF}_{4}\right)$ as catalyst and TOF of $30 \mathrm{~h}^{-1}$ and $67 \%$ ee for the alkylation of 1,3-diphenylprop-2-enyl acetate using $\left[\mathrm{Pd}\left(\eta^{3}-2-\mathrm{MeC}_{3} \mathrm{H}_{4}\right)(\mathbf{2 a})\right] \mathrm{BF}_{4}$ as catalyst). Interestingly, analogous complexes lacking inherent chirality with the two phosphine units in either proximal or distal positions (not drawn) produced much lower enantioselectivities (ee values between $0-16 \%$ ) proving that enantiodiscrimination occurs mainly as a result of the inherent chirality of the calix[4]arene platform. Other enantiopure bidentate P(III) ligands 
built on the lower rim of a calix[4]arene platform 4a-d were designed by Kamer and van Leeuwen in 2007 (Scheme 2) [24]. They were synthesized by first monosubstituting a p-tertbutylcalix[4]arene with an enantiopure BINOL or TADDOL unit. The resulting triphenols were then capped with $\mathrm{PCl}_{3}$ to afford very rigid chelating diphosphites, which were then tested in rhodium-catalyzed asymmetric hydrogenation of dimethyl itaconate and methyl $\alpha-$ acetamidoacrylate (Scheme 2). These catalytic systems were found to be comparable to cavity-free analogs both in terms of activity (usually $100 \%$ conversion in $4 \mathrm{~h}$ ) and enantioselectivity (up to $94 \%$ for the bulkier TADDOL-based ligand $\mathbf{4 c}$ ).

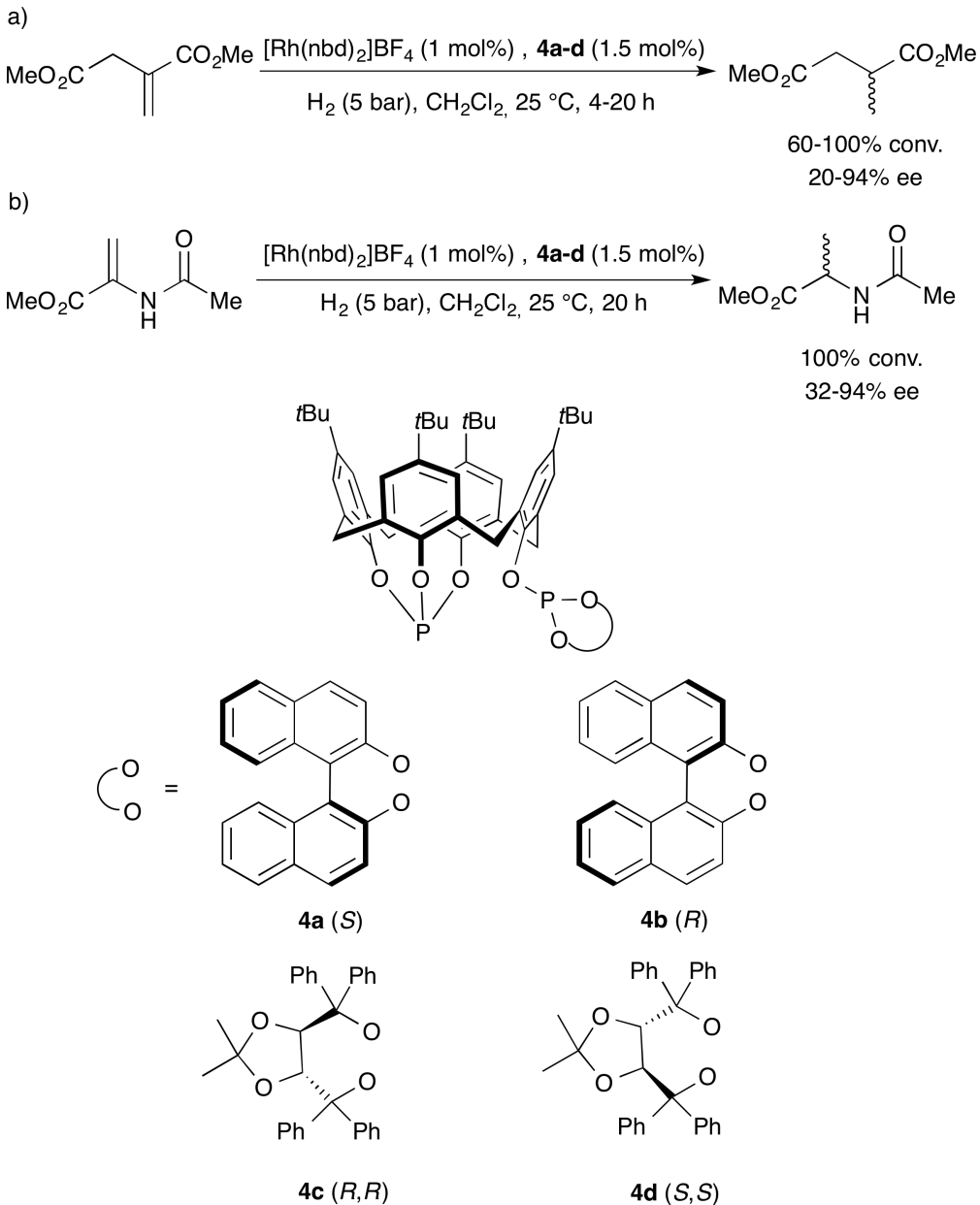

Scheme 2. Use of enantiopure calix[4]arene-based diphosphites in asymmetric hydrogenation of prochiral olefins.

In 2010, Jugé and Harvey [25] managed to graft a single P-chirogenic aminophosphanephosphinite chelating unit onto a calix[4]arene upper rim. The ligand 5 was tested in the rhodium-catalyzed hydrogenation of various prochiral olefins and ee values as high as $98 \%$ were obtained in the case of (R)- $N$-acetylphenylalanine methyl ester (Scheme 3). In this catalytic system, the chirogenic $\mathrm{P}$ atom is very close to the bulky cavity-shaped platform, 
which is key for reaching high ee values. In contrast, analogous ligands equipped with less bulky substituents systematically perform more poorly. Theoretical calculations indicated that an outer conformation whereby the metal center points away from the cavity is slightly preferred over an inner one. It is therefore likely that the cavity itself plays little role in the enantiodiscrimination process, but it is the sheer size of the calix[4]arene unit that leads to effective enantiodiscrimination.

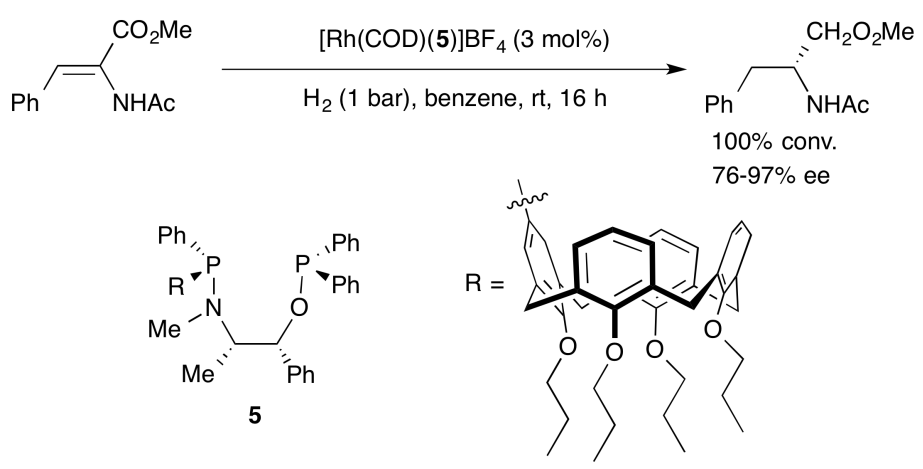

Scheme 3. Asymmetric hydrogenation of a dehydroamino acid methyl ester by a calix[4]arene bonded to a Pchirogenic aminophosphane phosphinite $\mathrm{Rh}$ metallo-organic unit.

Much more rigid $C_{2}$-symmetric diphosphines 6a-c together with their monophosphine analogs 7a-c were devised by the same authors three years later using $(+)-$ or $(-)$-ephedrine as chiral auxiliaries for accessing stereogenic $\mathrm{P}(\mathrm{III})$ atoms with a given configuration [26]. The $C_{2^{-}}$ symmetric ligands performed much better in terms of enantioselectivity than their $C_{1}$ monophosphine counterparts in the Pd-catalyzed alkylation of dimethyl malonate using $(E)$ $( \pm$ )-1,3-diphenylprop-2-en-1-yl acetate as the allylic substrate (up to $82 \%$ ee for $\mathbf{6 a} v s .5 \%$ ee for 7a). However, such a difference of performance was generally less pronounced when dimethyl malonate was replaced with benzylamine as the nucleophile (up to $79 \%$ ee for the chelate complex obtained in situ from 6a and $\left[\mathrm{Pd}\left(\eta^{3-}\left(\mathrm{C}_{3} \mathrm{H}_{5}\right) \mathrm{Cl}\right]_{2}\right.$ vs. up to $76 \%$ ee for the $\mathrm{Pd}$ complex comprising monophosphine $7 \mathbf{c}$ but surprisingly $0 \%$ for the chelate complex based on 6b) (Scheme 4). Again the bulky calix[4]arene plays only the role of preorganization platform and/or provides steric bulk, the enantiodiscriminating process taking place outside the cavity. In addition, theoretical calculations point to the fact that the chelate $6 \mathbf{6} / \mathrm{Pd}($ allyl) complex has a dissymmetric LUMO that is compatible with a complexed $\eta^{1}$-allyl moiety instead of the more common $\eta^{3}$-allyl coordination mode. According to the authors such a feature is responsible for efficient regio- and enantioselectivity. 


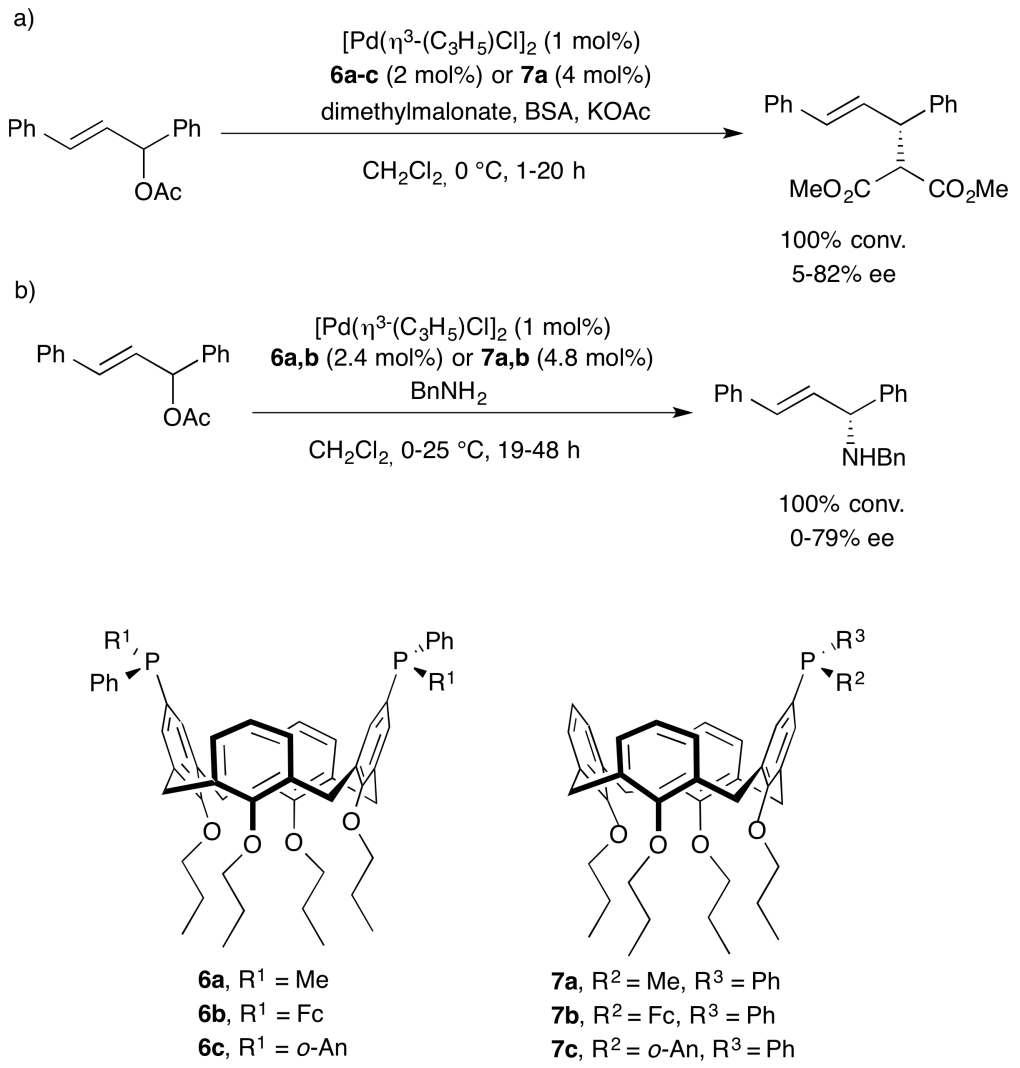

Scheme 4. Use of P-chirogenic mono- and diphosphines built on a calix[4]arene platform for Pd-catalyzed asymmetric allylic substitution.

More recently, Voitenko, Kalchenko and Manoury have synthesized calix[4]arenes substituted at the lower rim with an enantiomerically pure phosphinoferrocenyl unit $(\mathbf{8 a}, \mathbf{b})$ [27]. They have been tested in the asymmetric palladium-catalyzed Suzuki-Miyaura crosscoupling of naphthalene derivatives. The rather flexible asymmetric catalysts showed good activities when using the $[\mathrm{PdCl}(\text { allyl })]_{2}$ metal precursor, but much lower ee values $(<5 \%)$ than to those measured with other ferrocene-based catalysts. Clearly, the calix[4]arene unit does not bring any added value for this particular reaction. However, the $\mathrm{C}_{2}$-symmetric diphosphine 9 showed much higher potential in the asymmetric allylic alkylation of 1,3diphenylprop-2-enyl acetate with dimethyl malonate, probably because of its chelating nature although the formation of a rigid Pd(II) chelate complex has not been established so far (Scheme 5). Furthermore, the alkaline cation of the acetate used in conjunction with $\mathrm{N}, \mathrm{O}$ bis(trimethylsilyl)acetamide (BSA) probase has a strong influence on enantioselectivity with the potassium cation leading to highest ee value $(86 \%$ ee). It seems that in the presence of the potassium cation, the dimethyl malonate anion interacts more strongly with the two hydroxyl groups of ligand 9 to selectively direct the nucleophile towards one carbon atom of the $\pi$-allyl 
intermediate. This work exemplifies the fact that more rigid systems are better suited for effective enantiodiscrimination.

a)

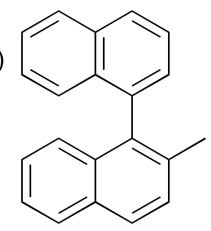

up to $100 \%$ conv.

$<5-100 \%$ yield

b)

$<5-37 \%$ ee
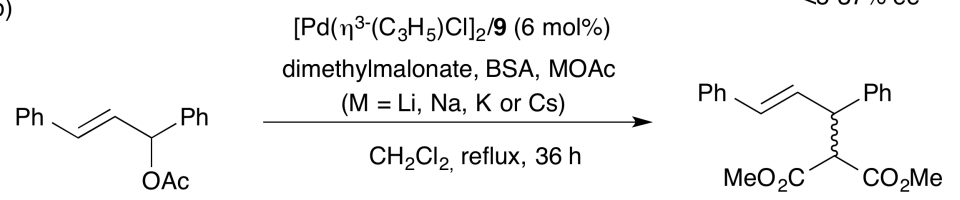

$100 \%$ conv.

$75-88 \%$ yield

$14-86 \%$ ee

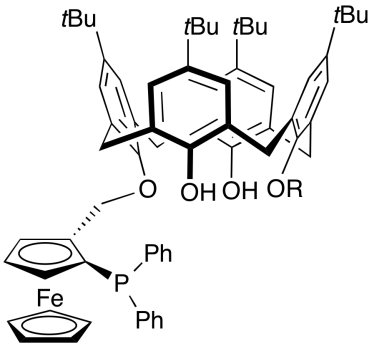

$8 \mathrm{a}, \mathrm{R}=\mathrm{Bn}$

$8 b, R=H$

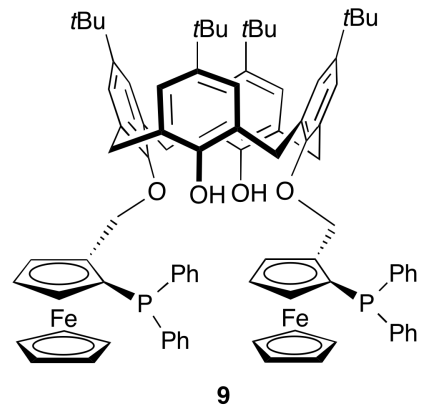

9

Scheme 5. Use of enantiopure mono-and di(ferrocenylphosphine)-calixarenes in asymmetric Pd-catalyzed Suzuki-Miyaura cross coupling and allylic substitution.

In 2009, Matt and Sémeril tested the ability of a calix[4]arene-diphosphite rhodium complex 10 to catalyze the asymmetric hydroformylation of styrene and norbornene in a micellar aqueous medium [28]. Thus, in the presence of various surfactants derived from sulfonated calixarenes 11a-d, up to $100 \%$ diastereoselectivity was achieved in favor of the endo isomer in the case of norbornene and enantioselectivity, although moderate (up to $39 \%$ ee), proved to be highly dependent of the type of tenside present in the aqueous reaction mixture (Scheme 6). In the case of styrene, a regioselectivity up to $79 \%(b: l=0.27)$ in favor of the linear isomer was observed, the chiral, branched isomer being produced with low ee values $(21-27 \%$ ee). 
a)

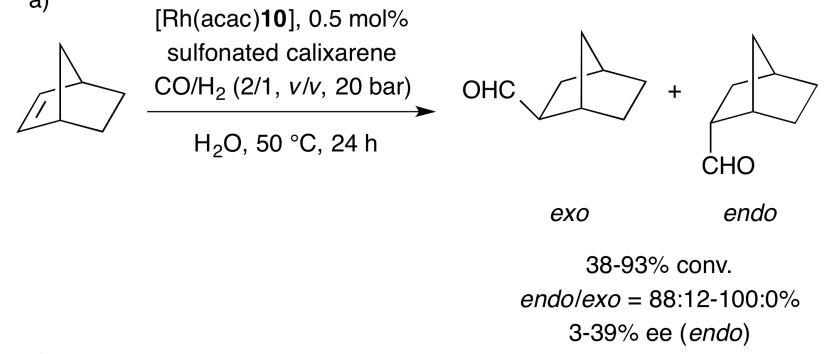

b)
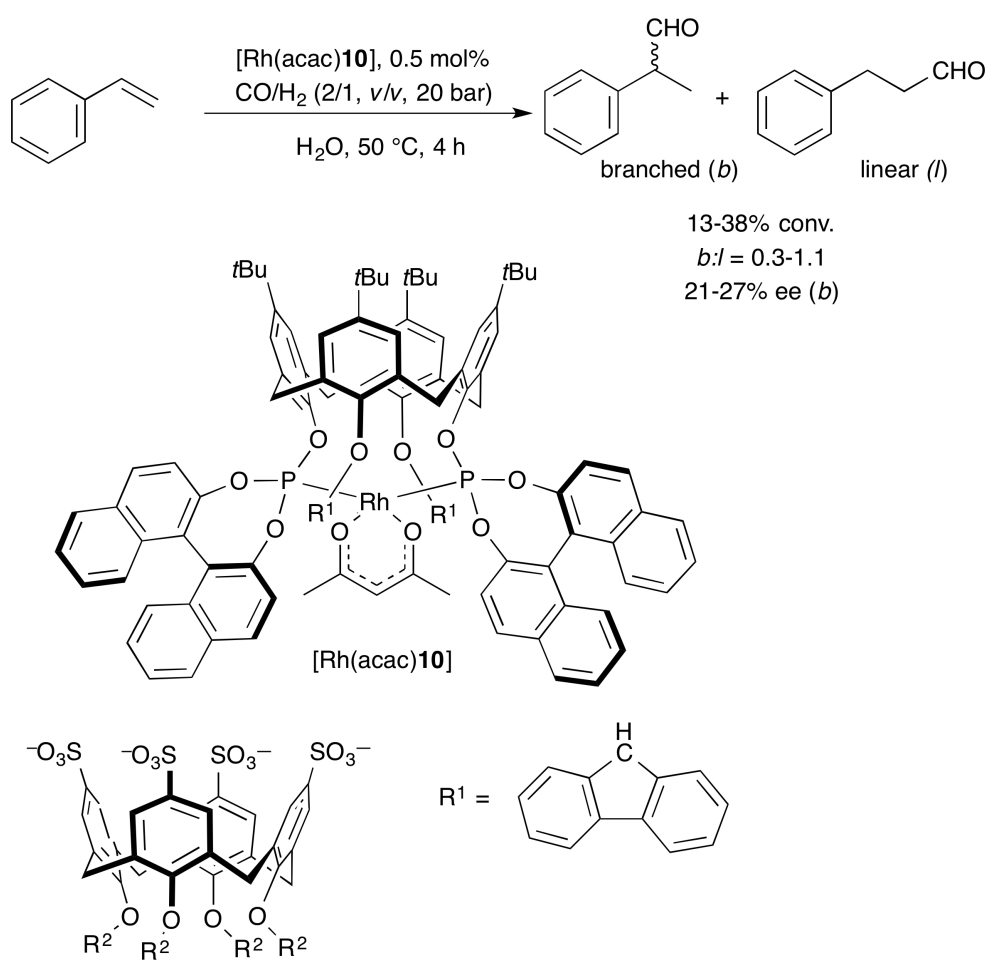

$11 \mathrm{a}, \mathrm{R}^{2}=\mathrm{H} \quad 11 \mathrm{c}, \mathrm{R}^{2}=n-\mathrm{C}_{6} \mathrm{H}_{13}$

11b, $\mathrm{R}^{2}=n-\mathrm{C}_{4} \mathrm{H}_{9} 11 \mathrm{~d}, \mathrm{R}^{2}=n-\mathrm{C}_{8} \mathrm{H}_{17}$

Scheme 6. Use of calix[4]arene-diphosphite rhodium complexes in asymmetric olefin hydroformylation.

Very recently, the same group synthesized two additional diphosphite ligands incorporating two (S)-BINOLate units 12a,b [29]. While 12a is derived from a calix[4]arene 1,3disubstituted at the upper ring, 12b comprises an 1,2-substituted resorcin[4]arene unit. Unlike 12a, which is sufficiently flexible, to allow for the formation of large chelate rings and therefore very rigid complexes, resorcin[4]arene-based ligand $\mathbf{1 2 b}$ has two phosphite units rigidly held apart and is unable to form such chelates so that dimeric species and possibly higher oligomers tend to form. Overall, the chelating properties of 12a make it better suited for enantiodiscrimination by creating a very rigid chiral pocket around the metal center as postulated for the rhodium-catalyzed hydroformylation of styrene (Scheme 7). While ee values as high as $89 \%$ with excellent concomitant regioselectivity towards the branched isomer $(b: l>99)$ could be reached with 12a for this reaction, ee values not exceeding $50 \%$ 
and with lower regioselectivity $(b: l=6.7)$ were observed with $\mathbf{1 2 b}$ under the same reaction conditions. Only with a bulkier substrate such as 2 -vinylnaphtalene ( $86 \%$ ee) could a high ee be attained in the case of $\mathbf{1 2 b}$. Other vinylarenes led to lower enantioselectivities with both 12a and 12b. Note that for achieving optimal enantiodiscrimination, an excess ligand had to be used in both cases to prevent ligand dissociation and catalysis by phosphite-free rhodium complexes.

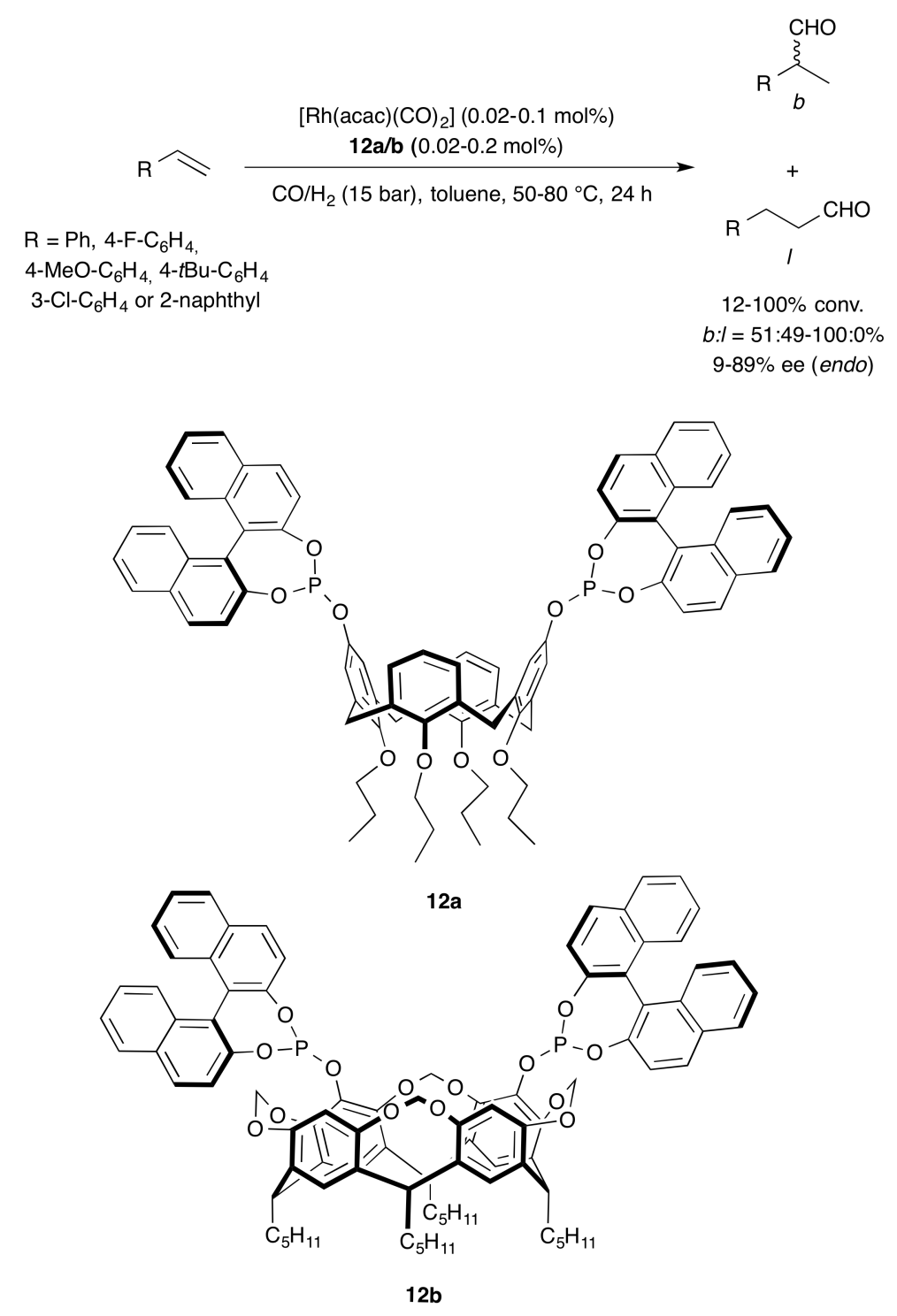

Scheme 7. Use of diphosphites based on upper rim substituted calix[4]arenes and resorcin[4]arenes in asymmetric Rh-catalyzed hydroformylation of styrene.

Phenate functions of calix[4]arenes act as excellent coordinating groups for early transition metals [30]. Upon grafting one or two enantiopure units on the lower rim of a p-tertcalix[4]arene, the remaining hydroxyl groups should still be able to chelate early transition metals such as titanium when deprotonated as in the phenolic ligands 13a-e [31]. However, it 
seems that a minimum of three contiguous $\mathrm{OH}$ groups are necessary to strongly coordinate Ti(IV) cations as in ligands $\mathbf{1 3 a}, \mathbf{b}$. All ligands were tested in the asymmetric aldol reaction of diene 14 with $p$-nitrobenzaldehyde (15) but produced low enantioselectivity (up to $28 \%$ ee for the monosubstituted calix[4]arene 13a), most probably as a result of the lack of rigidity of the pendant chiral groups (Scheme 8). Moreover, the more sterically crowded 13c-e apart from producing even poorer ee values on average than their monosubstituted analogs, also led to lower yields.
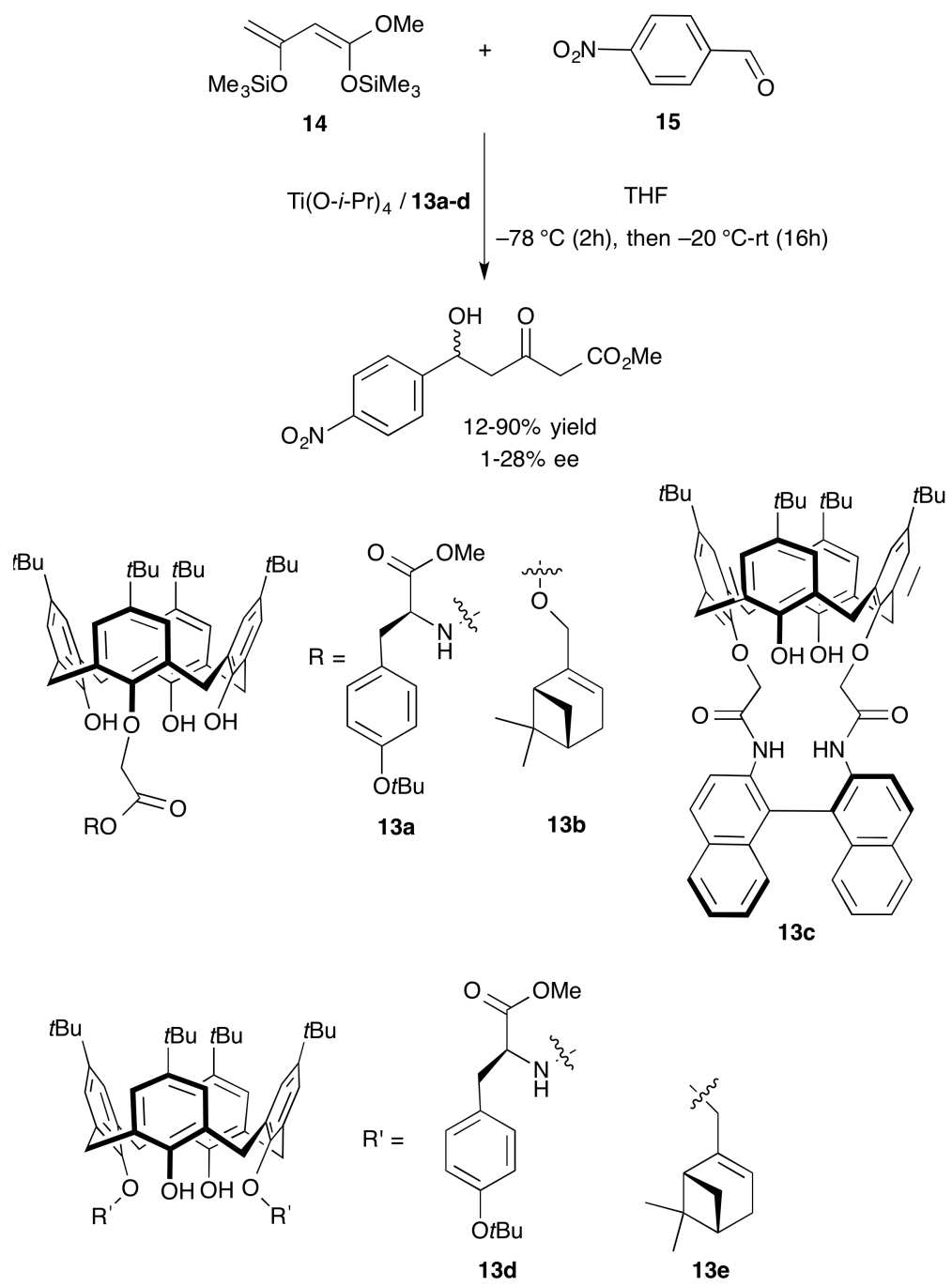

Scheme 8. Asymmetric aldol reactions catalyzed by Ti(IV)-complexed calix[4]arenes substituted with enantiopure amino acid and pinene-like units at the lower rim.

In the same vein, Nandi and Katz have managed to create a chiral pocket on the lower rim of a calix[4]arene platform by grafting on the distal positions of the macrocyclic structure either two enantiopure fragments each comprising a single stereogenic carbon atom (Scheme 9) or two bulky enantiopure phosphite units (Scheme 10) [32]. In both cases, the remaining hydroxyl groups on the calix[4]arene platform are able to chelate an Al(III) cation to generate 
respectively complexes 16a-c and 17a-e. Both types of complex were engaged in Meerwein-Ponndorf-Verley (MPV) reductions of ketones using a chiral secondary alcohol as reductant for complexes 16a-c and an achiral one for 17a-e. Only moderate enantioselectivities were achieved using the first strategy (up to $40 \%$ ee), while the second one proved to be much more successful. Indeed, the two bulky phosphite units in complexes 17a-e do not act as ligands but constitute Lewis bases capable of enhancing asymmetric transfer during the reaction. In addition, the presence of a rigid calix[4]arene platform together with the bulky side groups is crucial for avoiding aggregation of Al-alkoxide-type complexes, which lead to catalytically inactive hexacoordinate species. According to the authors, the whole system in $\mathbf{1 7 a - e}$ behaves as a frustrated Lewis pair, which ensures efficient enantioselective hydride transfer. Ee values as high as $99 \%$ have been measured for BINOLbased 17a but only at a very low conversion (1\%) and with no reaction time mentioned, which makes these Al(III) complex systems the most enantioselective ones in Al-catalyzed asymmetric MPV reduction catalysis, when using an achiral alcohol as a hydride donor. However, at higher conversions (80\%), the ee value drops to $80 \%$ ee with the same system.
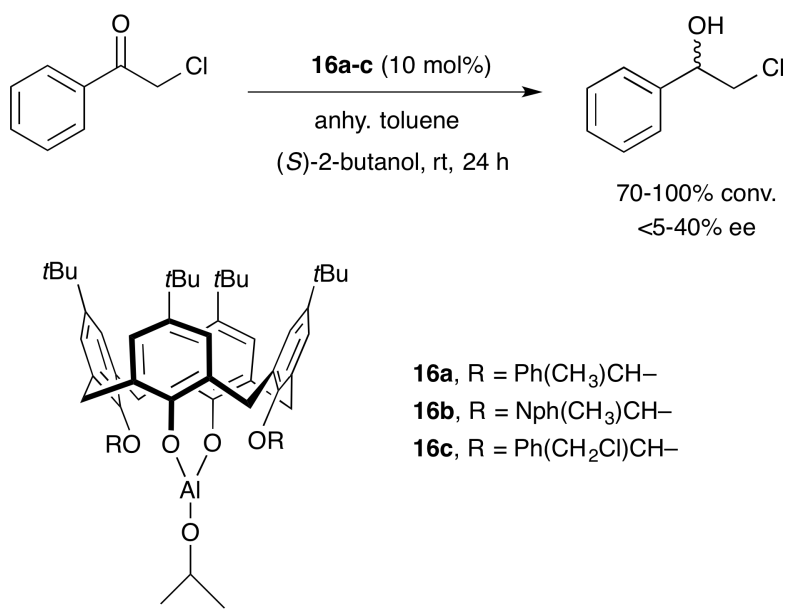

$16 a, \mathrm{R}=\mathrm{Ph}\left(\mathrm{CH}_{3}\right) \mathrm{CH}-$
$16 \mathbf{b}, \mathrm{R}=\mathrm{Nph}\left(\mathrm{CH}_{3}\right) \mathrm{CH}-$
$16 c, \mathrm{R}=\mathrm{Ph}\left(\mathrm{CH}_{2} \mathrm{Cl}\right) \mathrm{CH}-$

Scheme 9. Asymmetric MPV reduction of chloroketones with chiral Al(III)-calix[4]arene complexes. 

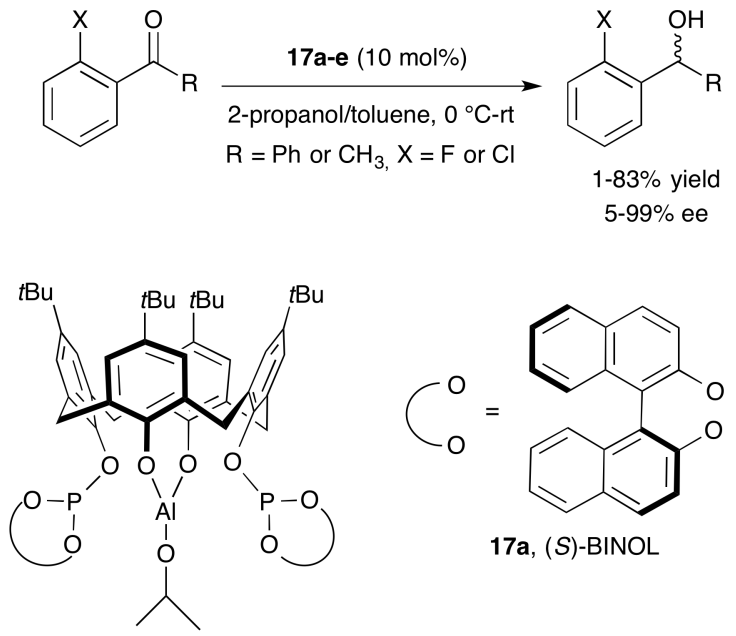

17a, (S)-BINOL
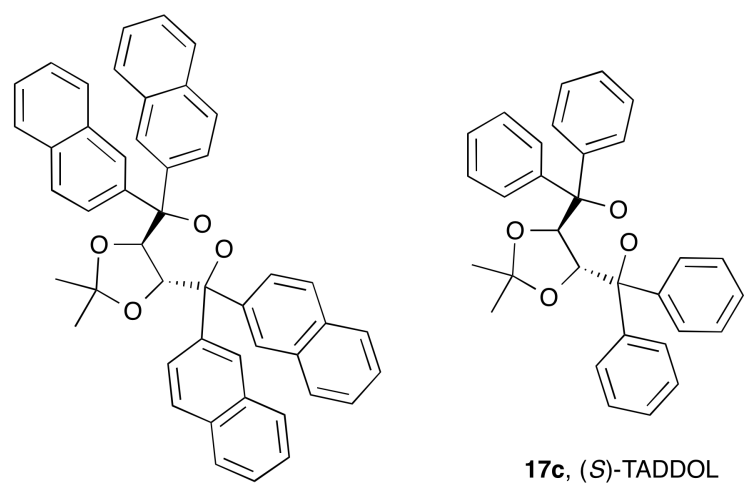

17c, (S)-TADDOL

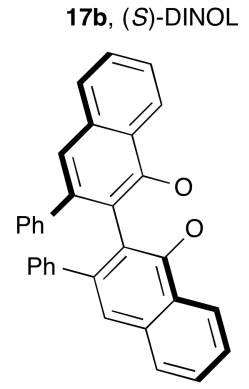

17d, (S)-VANOL

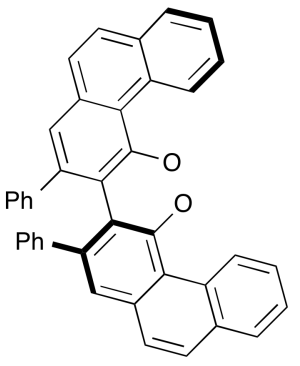

17e, $(R)$-VAPOL

Scheme 10. Al(III)-catalyzed asymmetric MPV reduction with enantiopure calix[4]arenes ligands having distally positioned chiral substituents.

Enantiopure salen-type ligands have also been used to create a chiral environment above the lower rim of a calix[4]arene cavity. A first series of cone-calix[4]arenes bearing a single pendant salen unit were synthesized by Tomaselli in 2005 [33]. Because of the inherent chirality of the aldehyde starting material 18a,b condensation with imino-amino intermediates 19 and 20 produced in each case two separable diastereomers. Complexation of these with $\mathrm{Mn}(\mathrm{OAc})_{3} \cdot 2 \mathrm{H}_{2} \mathrm{O}$ afforded $\mathrm{Mn}(\mathrm{III})$ complexes 21a,b and 22a,b (Scheme 11), which were tested as asymmetric catalysts in the epoxidation of cis- $\beta$-alkystyrenes using sodium 
hypochlorite $(\mathrm{NaClO})$ as oxygen donor and 4-phenylpyridine $N$-oxide (4-PPNO) as co-ligand

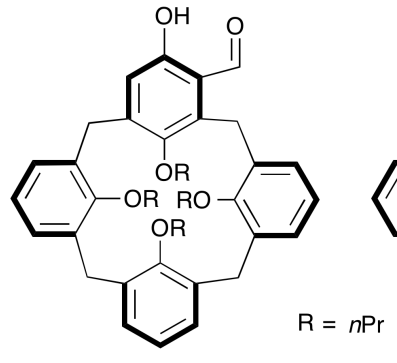

$18 \mathrm{a}$

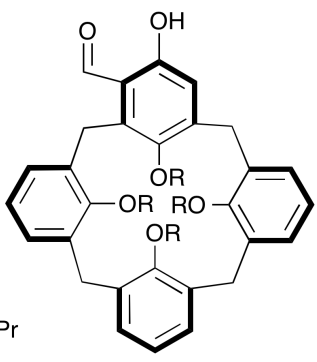

$18 b$

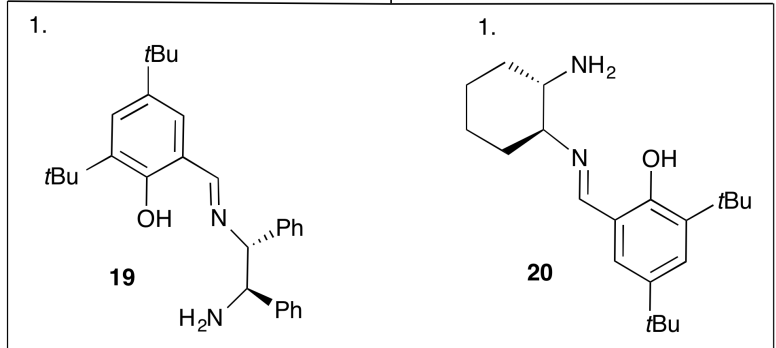

2. $\mathrm{Mn}(\mathrm{OAc})_{3} \cdot 2 \mathrm{H}_{2} \mathrm{O}$

2. $\mathrm{Mn}(\mathrm{OAC})_{3} \cdot 2 \mathrm{H}_{2} \mathrm{O}$
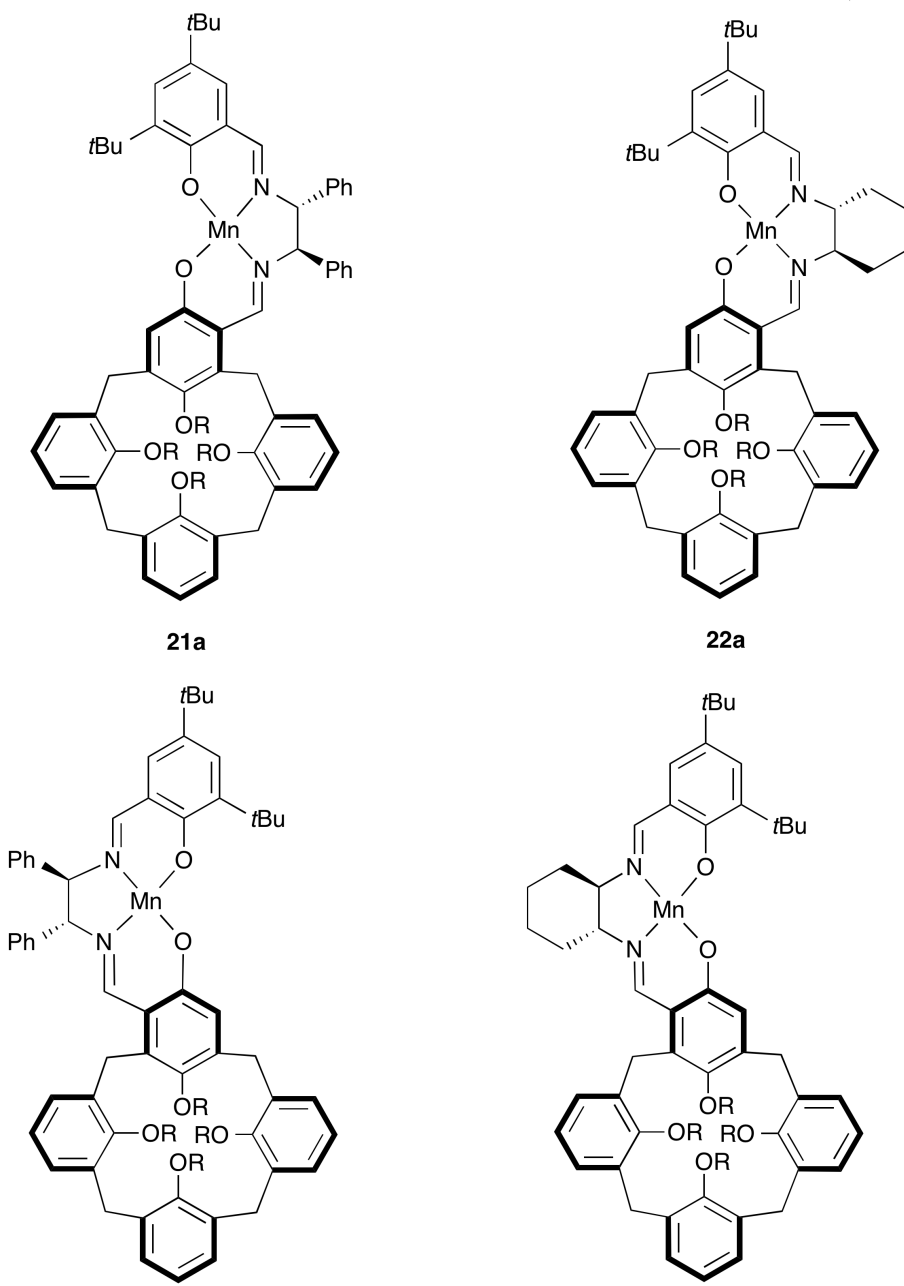

21b

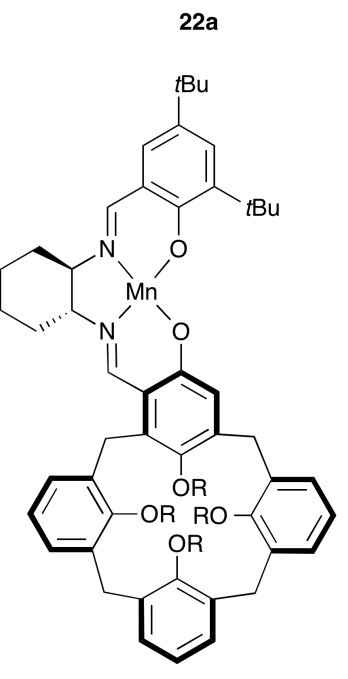

22b

Scheme 11. Enantiopure (salen)Mn(III) complexes containing a calix[4]arene as catalysts for enantioselective epoxidation reactions. 
(Scheme 12). Low to average ee values for the major cis epoxide (up to 72\%) were measured. Enantioselectivity is here highly substrate dependent, the more sterically crowded alkyl styrenes giving rise to higher ee values than a terminal alkene such as styrene, albeit with a much lower reaction rate. According to the authors, the relatively low enantioselectivity results from a nonstereospecific mechanism of epoxidation. Furthermore, the presence of a calix[4]arene cavity displaying inherent chirality has no effect on enantiodiscrimination. In order to increase stereoinduction, the same group has bridged two distal phenolic units of a calix[4]arene in its 1,3-alternate conformation with an enantiopure salen unit having various degrees of flexibility owing to spacers of different chain length that link the coordinating salen unit to the calix[4]arene platform (Figure 1) [34]. As for the previous catalytic systems, $\mathrm{NaClO}$ was used as oxygen donor and 4-phenylpyridine $\mathrm{N}$-oxide (4-PPNO) as co-ligand (Scheme 12). The higher rigidity and compactness of complex 23a allow a better chirality transfer from the salen unit to the dioxyalkyl linkers, hence a superior stereoinduction for 23a (up to $93 \%$ ee) compared to only $66 \%$ ee for $\mathbf{2 3 b}$. Surprisingly, despite its compactness, $\mathbf{2 3 a}$ is also more active than $\mathbf{2 3 b}$. Again, the catalytic performances are very sensitive to the nature of the alkene, the highest ee values being obtained with electron-rich cyclic alkenes.

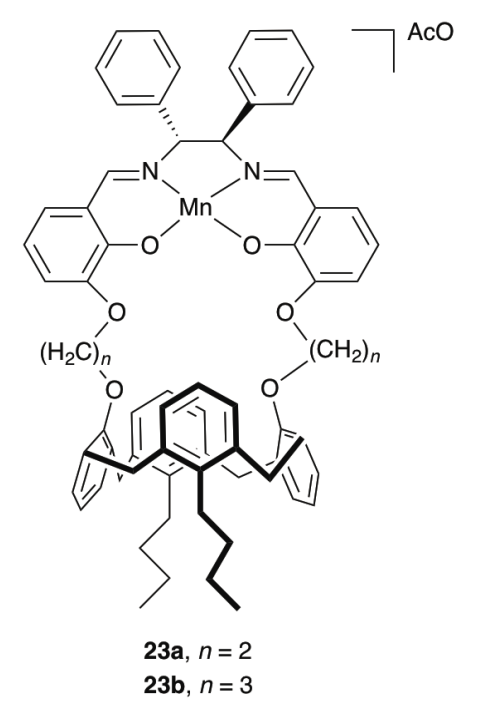

Figure 1. Calix[4]arenes in a 1,3-alternate conformation with an enantiopure (salen)Mn(III) capping unit. 

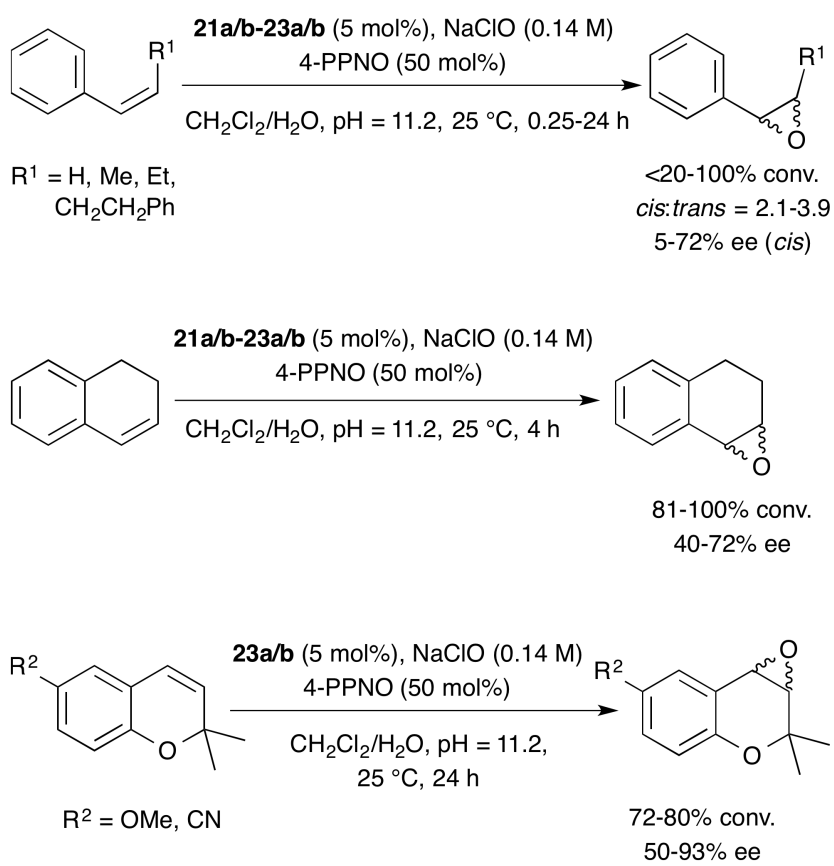

Scheme 12. Enantioselective epoxidation of alkenes by enantiopure (salen)Mn(III) calix[4]arenes.

\section{Chiral cavity-shaped ligands derived from cyclodextrins}

Cyclodextrins (CDs) act as ubiquitous water-soluble host molecules towards hydrophobic guest molecules and as such have been widely used in host-guest chemistry. Unlike the rather small calix[4]arenes, the three commercially available CDs $(\alpha-\beta$ - and $\gamma$-CDs) have large enough inner space (diameters ranging from $5.7 \mathrm{~nm}$ to $9.5 \mathrm{~nm}$ ) to accommodate a variety of guests of different size and shape (Figure 2). The outstanding supramolecular properties of these cheap, naturally occurring cyclic oligosaccharides have been harnessed in many application fields [35]. In particular, their chiral character makes them prime candidates for use in asymmetric catalysis [36] although they have often been portrayed in the past as unsuitable for achieving a high degree of stereocontrol. Indeed, despite their numerous stereogenic centers, their conformational rigidity combined with their high degree of symmetry make stereodifferentiation of prochiral substrates very challenging. However, with the advent of powerful functionalization methods [37], it is now possible to introduce various donor atoms e.g. nitrogen, phosphorus, sulfur, NHC, etc. at given locations of the CD platform [38]. This in turn makes the macrocyclic structure much less symmetrical, in particular in persubstituted CD derivatives, which lacks the hydrogen-bond network involving secondary hydroxyl groups. Furthermore, by forcing the donor atom(s) to point towards the $\mathrm{CD}$ interior whether by controlling the orientation of the donor atom lone pair or by 
supramolecular means, it is possible to perform enantioselective reactions inside the chiral cavity where the possibilities of stereoinduction are maximized.

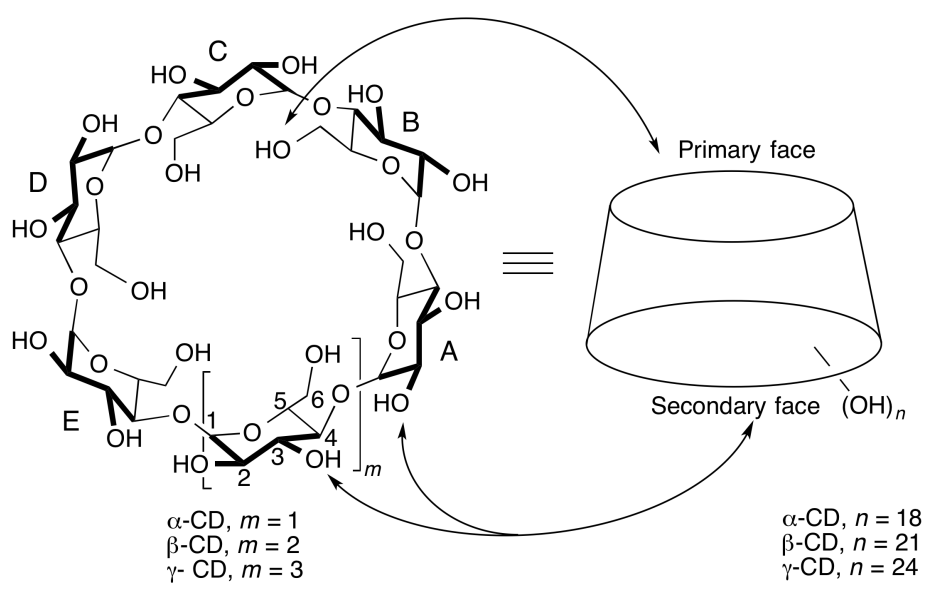

Figure 2. Schematic description of CDs

The first report of a metalloCD used as a catalyst for an enantioselective transformation dates from 1992 by Weber [39]. The catalytic system consists of a monosubstituted 2,6permethylated $\beta-\mathrm{CD}$ with a dangling iron or manganese porphyrin unit $(\mathbf{2 4 a}, \mathbf{b})$ that photocatalyzes the oxidation of racemic $\alpha$-pinene in various organic solvents using molecular oxygen as terminal oxidant (Scheme 13). A mixture of oxidized chiral products, amongst them epoxide 25a as the major product but also unsaturated ketones $25 \mathbf{b}, \mathbf{c}$ and unsaturated alcohols 25d-f with moderate to low ee's and a maximum value of $67 \%$ ee for epoxide $\mathbf{2 5 a}$ was produced. This reaction relies on the enantiodiscrimination between the two enantiomers of $\alpha$-pinene and as such cannot be considered as an asymmetric catalytic process. 


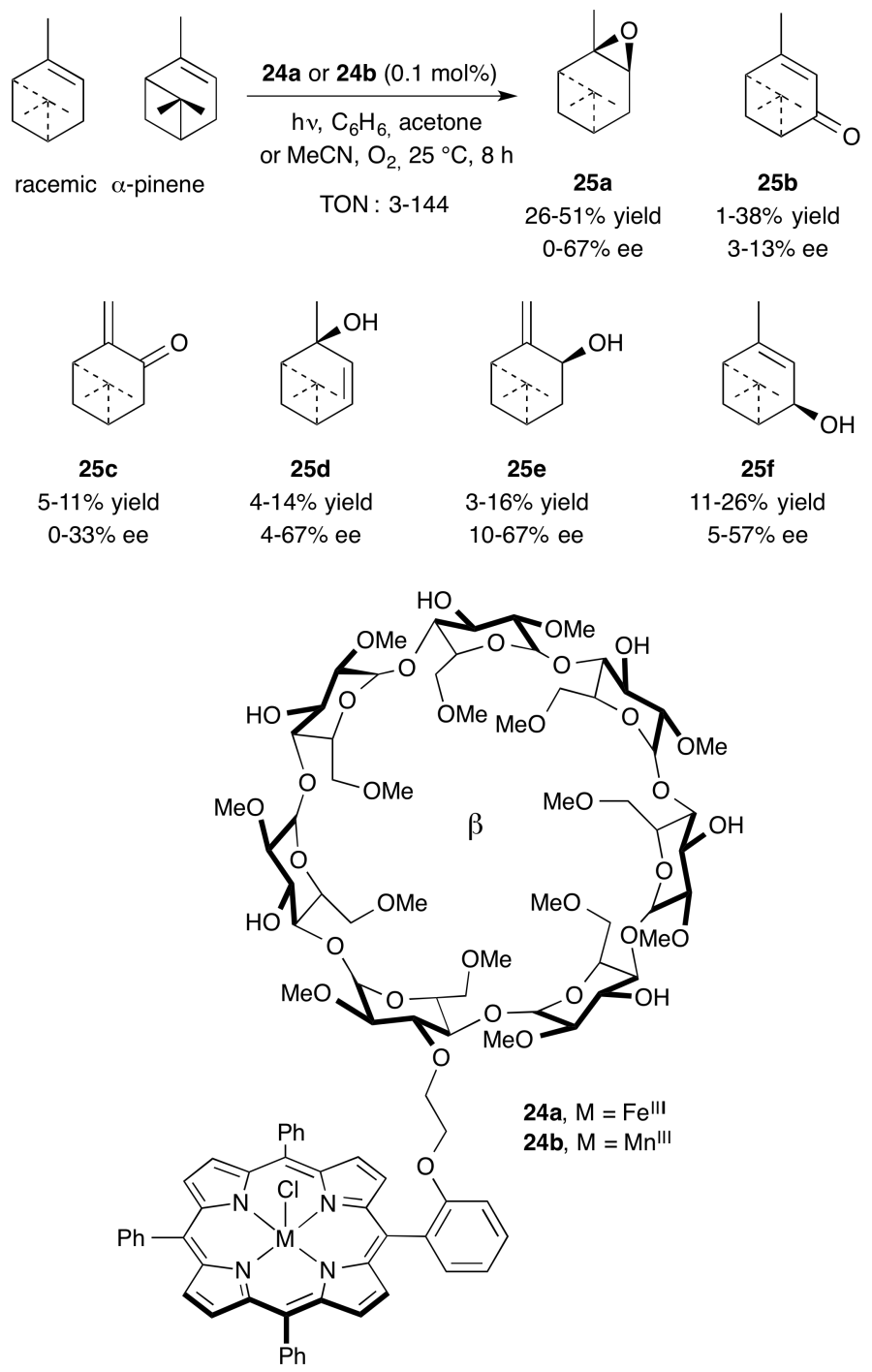

Scheme 13. Photocatalytic oxygenation of a racemic $\alpha$-pinene mixture by cyclodextrin-linked porphyrins.

A true metalloCD-catalyzed asymmetric catalytic transformation was published as early as 1995 by Carofiglio [40]. Diamines 26a,b as well as diaminophenol 26c and iminoaminophenol 26d were used as chiral $\beta-C D$ ligands for the molybdenum-catalyzed asymmetric oxidation of thioethers with hydrogen peroxide as terminal oxidant in three different media containing HEPES (4-(2-hydroxyethyI)piperazine-1-ethanesulfonic acid) buffer solution at pH 7 - heterogeneous (pure HEPES acid buffer solution), biphasic (HEPES buffer solution and 1,2-dichloroethane) and homogeneous (HEPES buffer solution/methanol) (Scheme 14). Only 6-diamino- $\beta$-CD 26a produced ee values above 50\% whereas low ee values were observed with all other ligands. The fact that only small variations of ee values (between $53 \%$ and $60 \%$ ee) occur upon changing the reaction media most likely points to a scenario where the host-guest properties of the $\mathrm{CD}$ are not involved in enantiodiscrimination, 
although inclusion of the substrate in the $\beta$-CD cavity even in the presence of methanol (homogeneous case) cannot be totally ruled out.
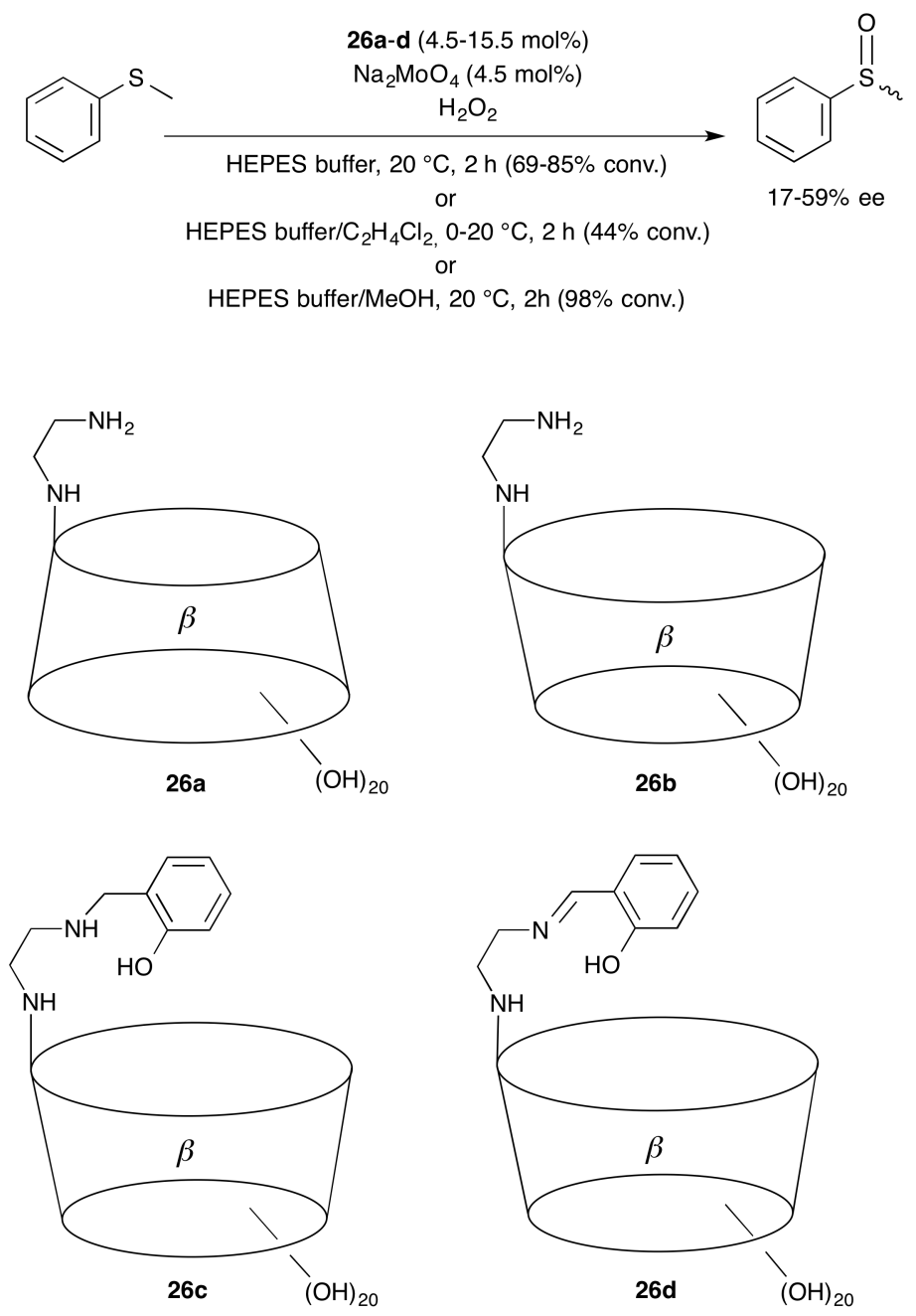

Scheme 14. Asymmetric oxidation of thioanisole in the presence of $\beta$-CD-based nitrogen ligands.

More recently, Ji has synthetized similar podands (27a-g) with an amino alcohol coordinating unit grafted onto a $\beta$-CD platform (Figure 3). As for the previous study, the ligands have been used for the molybdenum-catalyzed asymmetric oxidation of thioethers with hydrogen peroxide as terminal oxidant. Up to $56 \%$ ee values were measured with the simplest ligand 27a. Surprisingly, the presence of an extra stereogenic $(S)$ center in the coordinating arm as in 27e does not improve enantioselectivity. According to theoretical and NMR-based mechanistic studies performed on the molybdenum complex $\mathrm{Na}_{2}\left[\mathrm{MoO}_{4}(\mathbf{2 7 a})\right]$ (28), this moderate enantioselectivity reflects the fact that two competing catalytic processes take place within the CD cavity. One of them which involves a thioether group located near the metal unit at the primary face is intramolecular and highly enantioselective whereas the second one is intermolecular and poorly selective because the thiophenol function is upside down in the 
reacting inclusion complex, away from the primary face-grafted metal unit. Enantioselectivity proved to be also strongly $\mathrm{pH}$ dependent but no explanation was provided for this behavior.

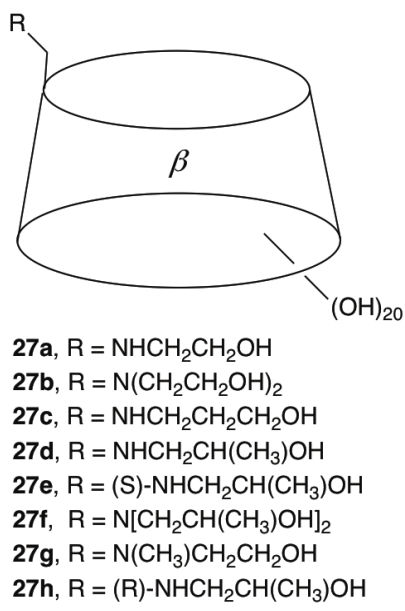

Figure 3. $\beta$-CDs substituted with a single aminoalcohol unit.

A third study on asymmetric oxidation of aromatic thioethers in aqueous solution relying on the use of native CDs $(\alpha-, \beta-$, or $\gamma$-CD) and $C D$-grafted catecholate ligands 29a,b in conjunction with molybdenum(V) chloride or copper(II) chloride was carried out by Sakuraba in 2006 (Scheme 15) [41]. Both native and modified CDs led to significant oxidation rate increase (3-9 fold), but only metal complexes of catecholate ligands 29a,b gave noticeable, albeit still moderate to average enantioselectivities (26-65\% ee). Surprisingly, opposite configurations were observed when switching from their $\mathrm{Mo}(\mathrm{V})$ complexes to their $\mathrm{Cu}(\mathrm{II})$ analogs. Clearly, the enantiodiscrimination process at work must be radically different for the two types of complexes, which indeed display induced circular dichroism (ICD) spectra with opposite signs but similar intensities in the $200-350 \mathrm{~nm}$ region. 


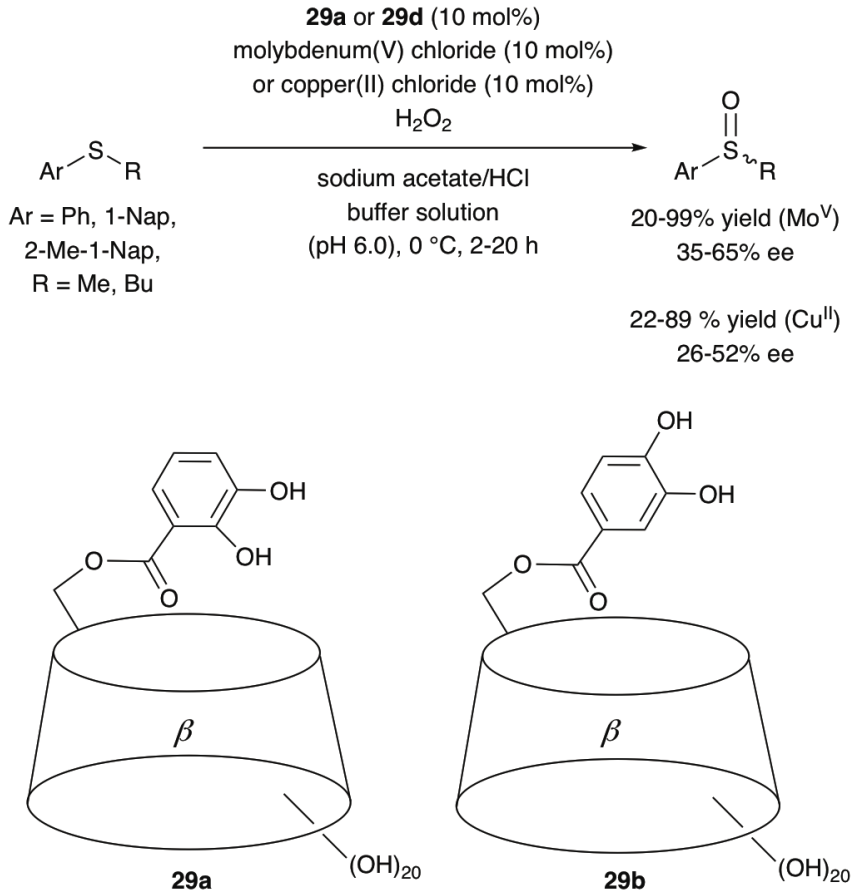

Scheme 15. Enantioselective oxidation of sulfides catalyzed by chiral $\mathrm{Mo}(\mathrm{V})$ and $\mathrm{Cu}(\mathrm{II})$ complexes of catecholfunctionalized $\beta-C D$ derivatives.

Woggon took also advantage of the host-guest properties of CDs equipped with aminoalcohol units $(\mathbf{2 7 a}, \mathbf{e})$ to prepare supramolecular Ru(II) catalysts 30a,b (Figure 4) capable of reducing both aliphatic and aromatic ketones with high enantioselectivities (up to 97\%) in a 3:1 $\mathrm{H}_{2} \mathrm{O} / \mathrm{DMF}$ mixture [42]. This is a perfect example of a CD-based system in which the chiral aminoalcohol coordinating unit and the $\mathrm{CD}$ receptor act in a synergistical way to produce high ee values. For comparison, the $\mathrm{CD}$-free analogous catalyst, which cannot encapsulate the prochiral guest only achieved $50 \%$ ee in favor of the same enantiomer.

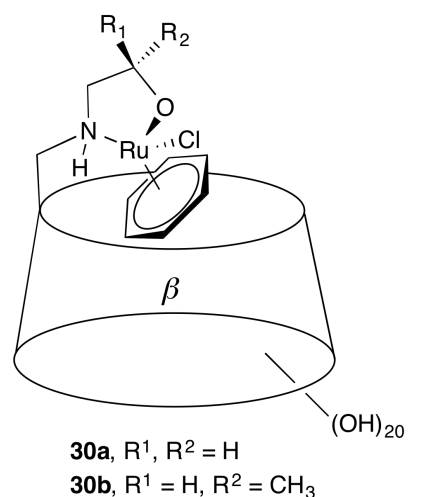

Figure 4. $\mathrm{Ru}(\mathrm{II})$ complexes of $\beta$-CDs substituted with a single amino alcohol unit. 
The presence of the NH group in the coordinating arm is crucial since its replacement with a tertiary amine led to an inactive system that is unable to activate the carbonyl group via proton transfer (Scheme 16).

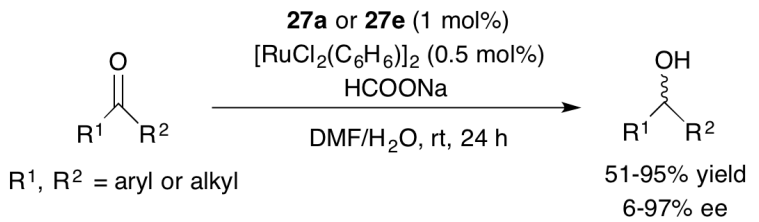

Scheme 16. Ru(II)-catalyzed asymmetric reduction of ketones using monosubstituted CDs $\mathbf{2 7} \mathbf{a}, \mathbf{b}$ as ligands.

In the same vein, the same CD-based ligands (see above) that were tested for the asymmetric oxidation of thioethers $(\mathbf{2 7} \mathbf{a}-\mathbf{h})$ were used by $\mathrm{Ji}$ to perform $\mathrm{Ru}(\mathrm{II})$-catalyzed asymmetric reductions of aromatic methyl ketones in DMF/water mixtures. Only ee values up to $80 \%$ could however be obtained and only with bulky ketones such as 2-acetylnaphtalene. As in Woggon's study, tertiary amine-based systems proved to be nonselective and poorly active. Catalysts with bulky aromatic ligands such as mesitylene bound to the metal tend to perform better in terms of enantioselectivity than less sterically crowded benzene analogs albeit with reduced activity (Scheme 17).

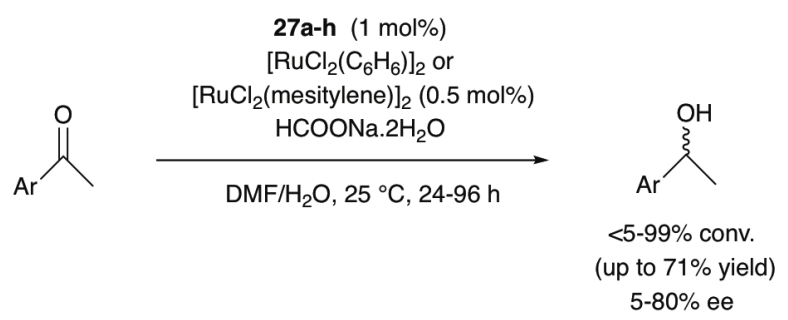

Scheme 17. Ru(II)-catalyzed asymmetric reductions of aromatic methyl ketones using monosubstituted CDs 27a-h as ligands.

Numerous examples of phosphorus containing CDs have been used as transition metal ligands for asymmetric catalytic reactions, usually associated with P(III) ligands [43,44], such as the hydrogenation and hydroformylation of prochiral alkenes, but also more recently the more challenging asymmetric gold(I)-catalyzed cycloisomerization reactions. Unlike the previous systems, these catalysts do not rely on the supramolecular properties of the CD host for effective enantiodiscrimination but on the ability of the phosphorus donor atom to direct the metal center in such a way that it can interact sterically with the chiral cavity. Although a phosphine-functionalized CD has been reported as early as 1993 [45], the first P(III)-based asymmetric catalysts were disclosed by Jia in 2002 [46] and shortly after by Armspach and Matt [47]. The former synthesized a cis-chelating diphosphine (31) in which two adjacent 
glucose units of a permethylated $\beta-\mathrm{CD}\left(6^{\mathrm{A}}-\right.$ and $6^{\mathrm{B}}$-positions $)$ are substituted with diphenylphosphino units. Reaction of the diphosphine with $\left[\mathrm{Rh}(\mathrm{COD})_{2}\right] \mathrm{BF}_{4}$ in dichloromethane produced a large chelate complex with a cis geometry (32). The authors suggest that the metal center sits above the $\beta-C D$ cavity despite the relative flexibility of the coordinating unit, the position of which with respect with the CD cavity in the complex was not substantiated with NMR or XRD studies. However, the close proximity of the metal center to the chiral cavity makes it possible to reach ee values up to $92 \%$ in the hydrogenation of unsaturated carboxylic acids and esters (Scheme 18).
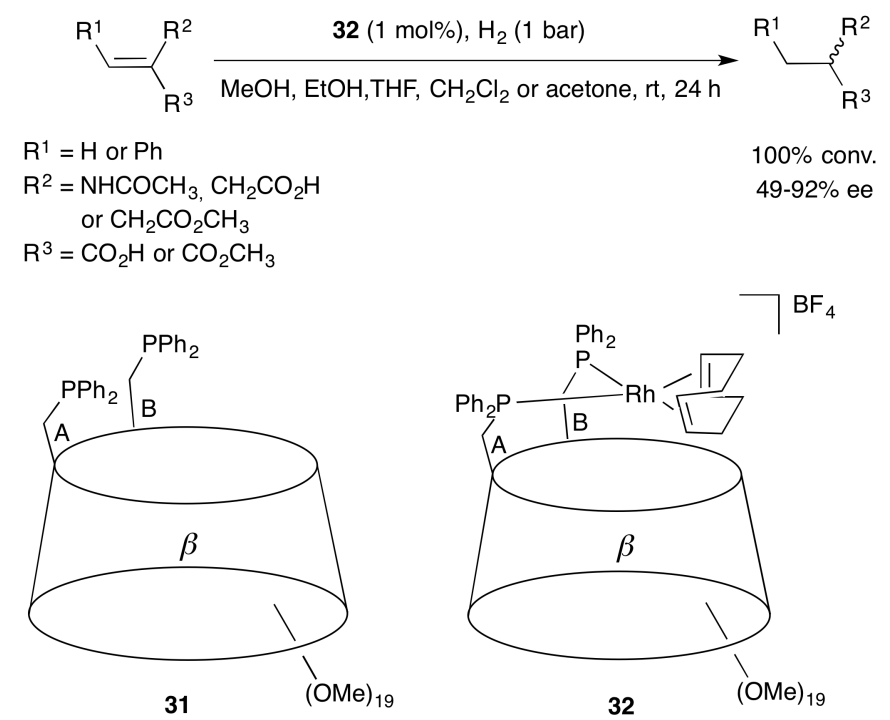

Scheme 18. $\beta$-CD-based diphosphine 31 and corresponding $\mathrm{Rh}(\mathrm{I})$ complex $\mathbf{3 2}$ for $\mathrm{Rh}(\mathrm{I})$-catalyzed asymmetric hydrogenation of functional olefins.

Larger chelate rhodium complexes were devised by Armspach and Matt from diphosphite ligands 33a,b [47]. Unlike Jia's diphosphine 31, these more flexible bidentate ligands can only form chelate complexes with cationic rhodium precursors, not neutral ones. Despite their higher flexibility, ee values up to $84 \%$ were obtained in the hydrogenation of dimethyl itaconate when using the preformed cis chelate complex 34, however with lower activities (17\% conv. after $24 \mathrm{~h}$ reaction) than with Jia's complex 32. In contrast, very poor enantioselectivities $(<17 \%$ ee) but higher activities were observed when the catalytic reaction was performed by reacting the ligands in situ with $\left[\mathrm{Rh}(\mathrm{COD})_{2}\right] \mathrm{BF}_{4}$ without isolating the chelate complexes (Scheme 19). 

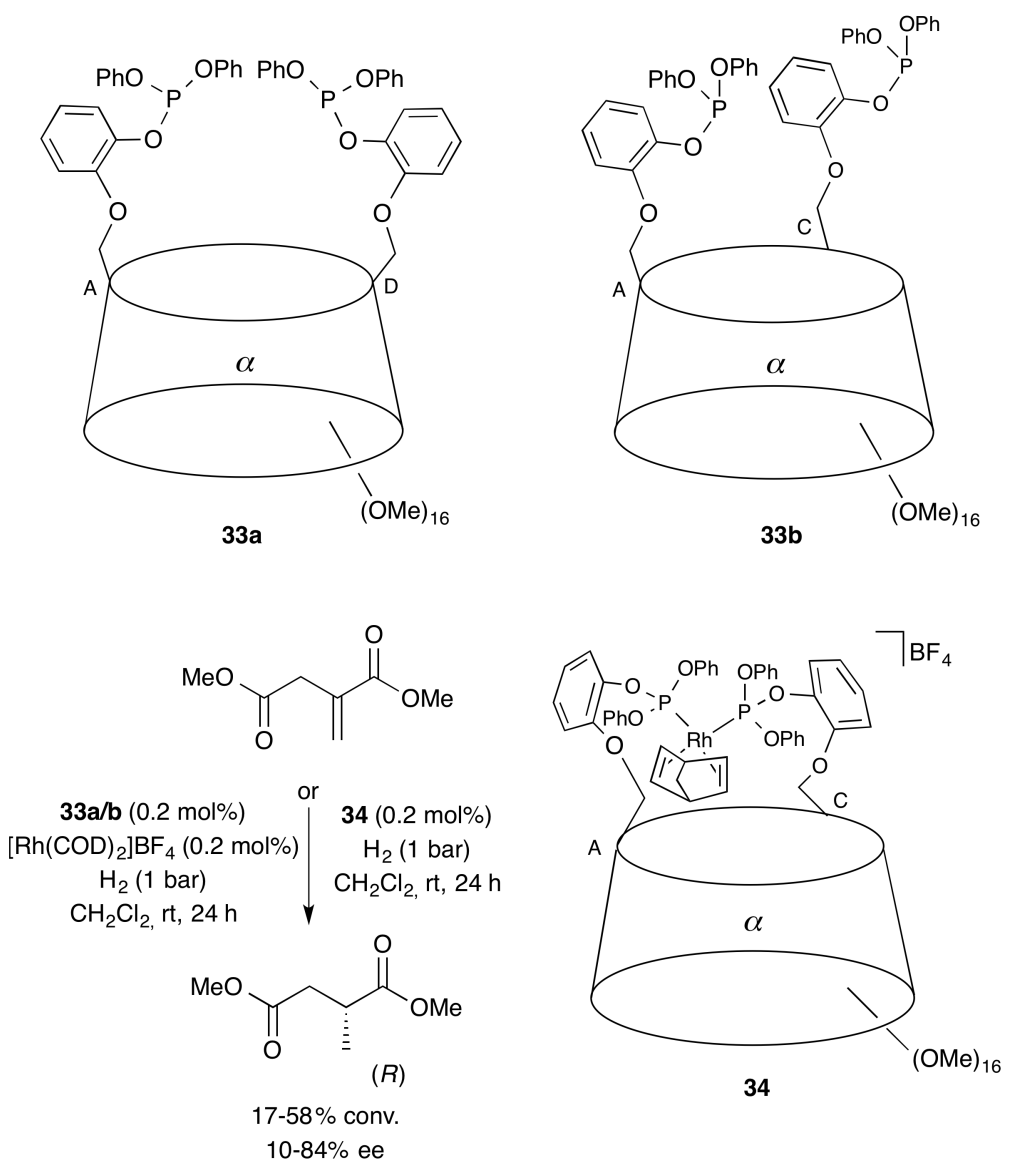

Scheme 19. Diphosphite functionalized $\alpha$-CDs in Rh catalyzed hydrogenation.

More recently, Sollogoub designed two pseudo-enantiomeric diphosphines (35a,b) the pseudo-inherent chirality of which is based on tridifferentiated CD platforms [48]. These were used in the palladium-catalyzed allylic alkylation of dimethylmalonate. Although enantioselectivities are modest (up to $30 \%$ ee), regioisomeric pseudo-enantiomeric ligands produced alkylated products with opposite configurations. In contrast, the $C_{2}$-symmetric ligand 35c, which lacks such pseudo-chirality did not induce any enantioselectivity, thus ruling out any asymmetric induction caused by the many stereogenic centers of the CD. Moreover, the complex resulting from the in situ reaction of $\mathbf{3 5 c}$ with $\left[\left\{\operatorname{Pd}\left(\eta^{3}-\mathrm{C}_{3} \mathrm{H}_{5}\right) \operatorname{Pd}(\mu-\right.\right.$ $\mathrm{Cl})\}_{2}$ ] proved to be much less active than those obtained from less sterically crowded 35a,b (Scheme 20). 

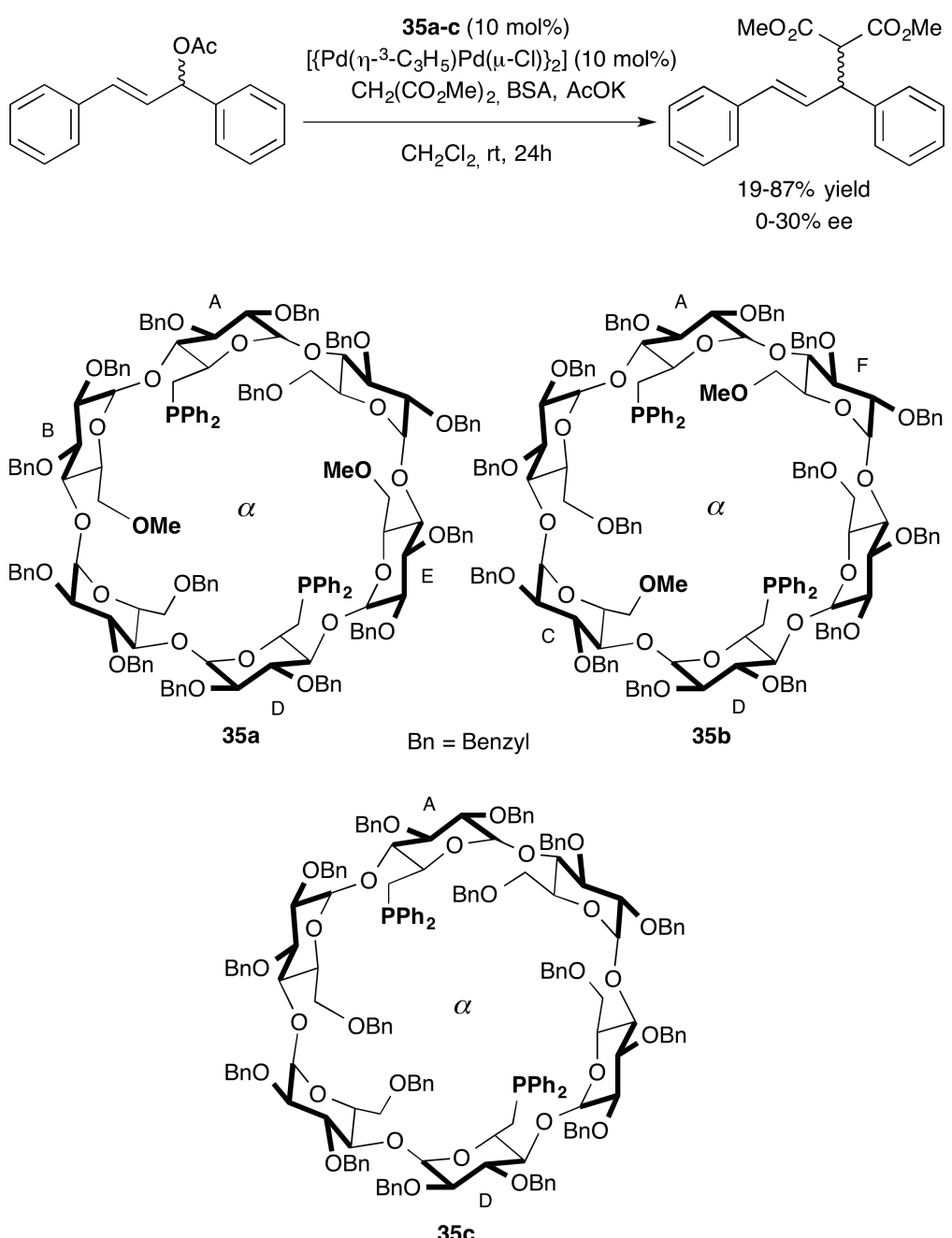

Scheme 20. $\operatorname{Pd}(0)$ catalyzed Tsuji-Trost substitution using pseudo-enantiomeric diphosphine CD ligands 35a-c.

The pseudo-enantiomeric environment around the metal was confirmed by a circular dichroism study on complexes 36a,b (Figure 5). Indeed these two complexes have opposite Cotton effects in the region above $350 \mathrm{~nm}$, where absorption bands originate from metalcentered $\mathrm{d}-\mathrm{d}$ transitions unlike their ligands, which have similar cotton effects as a result of stereogenic centers with identical configuration in the CD unit. 

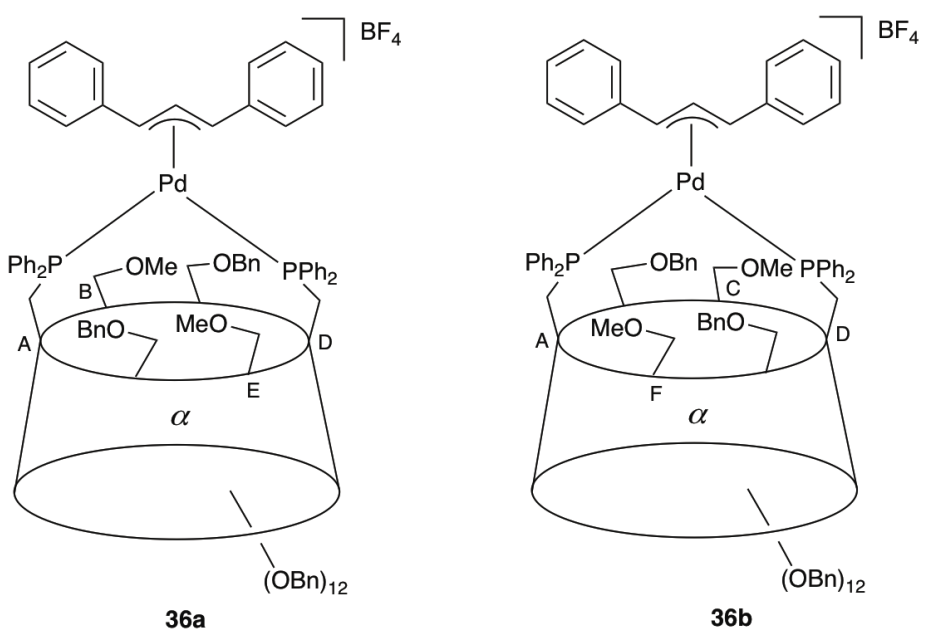

Figure 5. Pseudoenantiomeric $\mathrm{Pd}(\mathrm{II})-\mathrm{CD}$ complexes.

In order to take advantage on the potential enantioinduction caused by the pseudo inherent chirality of $C_{1}$-symmetric CDs, Armspach and Matt designed chelators (37a-d), in which two adjacent glucose units of a permethylated $\alpha-C D$ are substituted with both sterically and electronically different P(III) coordinating units [49]. These were tested in the rhodiumcatalyzed enantioselective hydrogenation of $\alpha$-dehydroamino esters (Scheme 21). Despite the flexibility of the rather large chelate rings, the bulkiest substrate (methyl 2-(acetylamino)-3naphthylpropenoate) and phosphine-phosphite $\mathbf{3 7 b}$ gave rise to the highest ee values (up to $60 \%$ ) with the $\mathrm{CD}$ as the only source of chirality. Whether enantiodiscrimination results from the inherent chirality of the CD platform, its numerous stereogenic centers and/or a particular conformation of the metallocycle could however not be settled. In addition, when a stereogenic $(R)$ - binapththyl unit was introduced in the phosphite part, ee values up to $92 \%$ could be reached, while those observed with the $(\mathrm{S})$ counterpart were much lower (up to $70 \%$ ee), clearly indicating a match/mismatch relationship. Rhodium-catalyzed hydroformylation of styrene was also tested with binaphthyl-free $\mathbf{3 7} \mathbf{b}$, but only moderate ee values $(50 \%$ ee) were measured together with standard regioselectivities $(b: l=3.3)$. 
a)

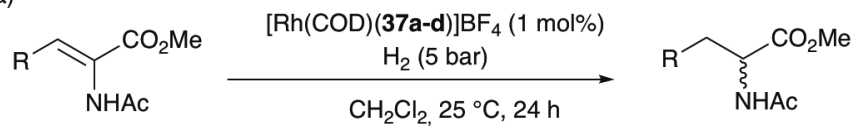

$$
\begin{aligned}
& \mathrm{R}=\mathrm{Ph}, 4-\mathrm{F}-\mathrm{C}_{6} \mathrm{H}_{4}, 4-\mathrm{Cl}-\mathrm{C}_{6} \mathrm{H}_{4} \quad 16-100 \% \text { conv. } \\
& \text { or 3,4- } \mathrm{Cl}_{2}-\mathrm{C}_{6} \mathrm{H}_{3} \text {, 2-naphthyl } \quad \text { 8-92\% ee }
\end{aligned}
$$

b)
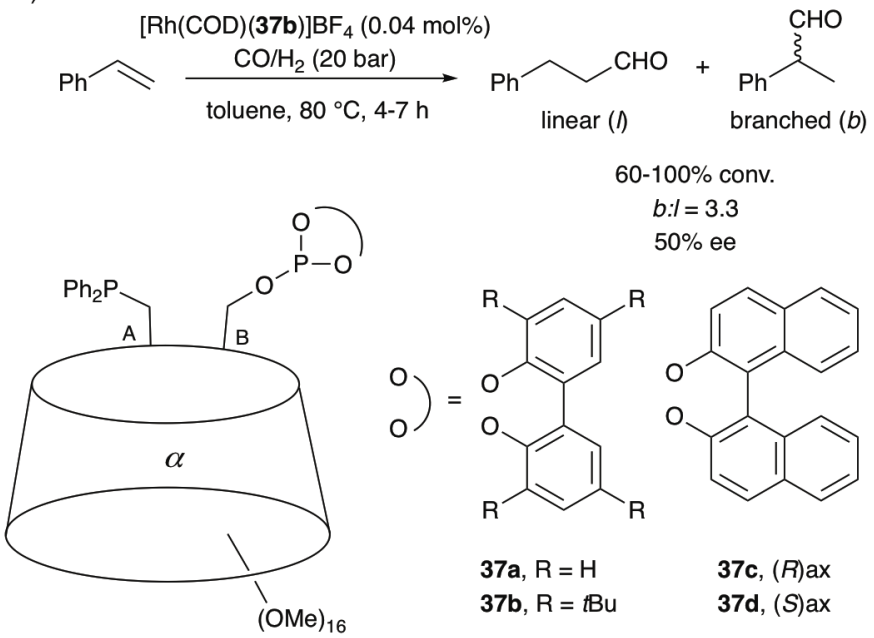

$$
\begin{aligned}
& b: l=3.3 \\
& 50 \% \text { ee }
\end{aligned}
$$

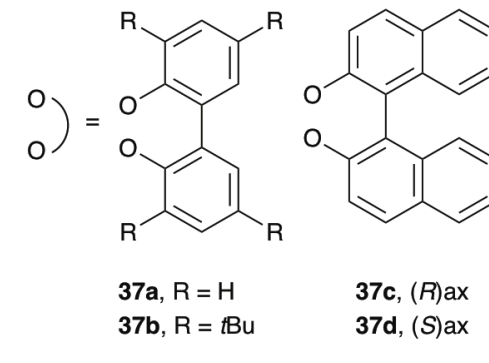

Scheme 21. Phosphane-phosphite chelators on an $\alpha$-CD scaffold and application in Rh(I)-catalyzed hydrogenation and hydroformylation of olefins

The strong directionality provided by a phosphorus donor atom incorporated in a cyclic structure offers unique opportunities for the use of CD-based monophosphines (Figure 6) in asymmetric catalysis. Armspach and Matt were the first to test such monoligands $(\mathbf{3 8 a}, \mathbf{b})$ in the asymmetric hydroformylation of styrene [50,51]. As a result of their metal confining properties, these can only form monophosphine complexes, which in turn favors the formation of the chiral, branched regiosiomer.

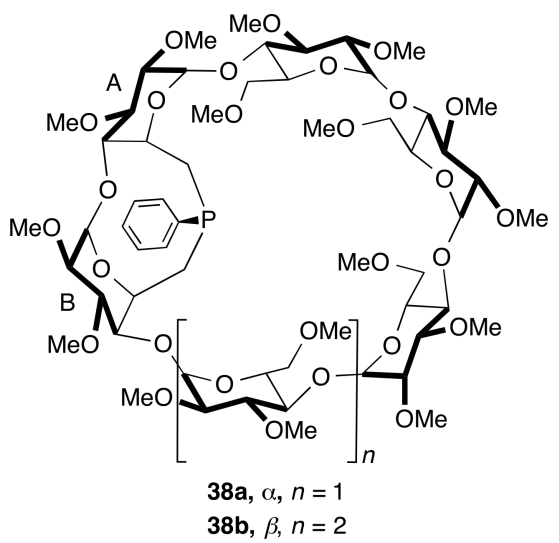

Figure 6. CD-based monophosphines with an inward-pointing phosphorus atom.

Because of the highly asymmetric environment surrounding the metal center, high enantioselectivity was also observed. These rhodium complexes $(\mathbf{3 9 a}, \mathbf{b})$ are the first examples 
of phosphine-based catalysts giving rise to both high regioselectivity $(b: l=58)$ and enantioselectivity (95\% ee) (Scheme 22).

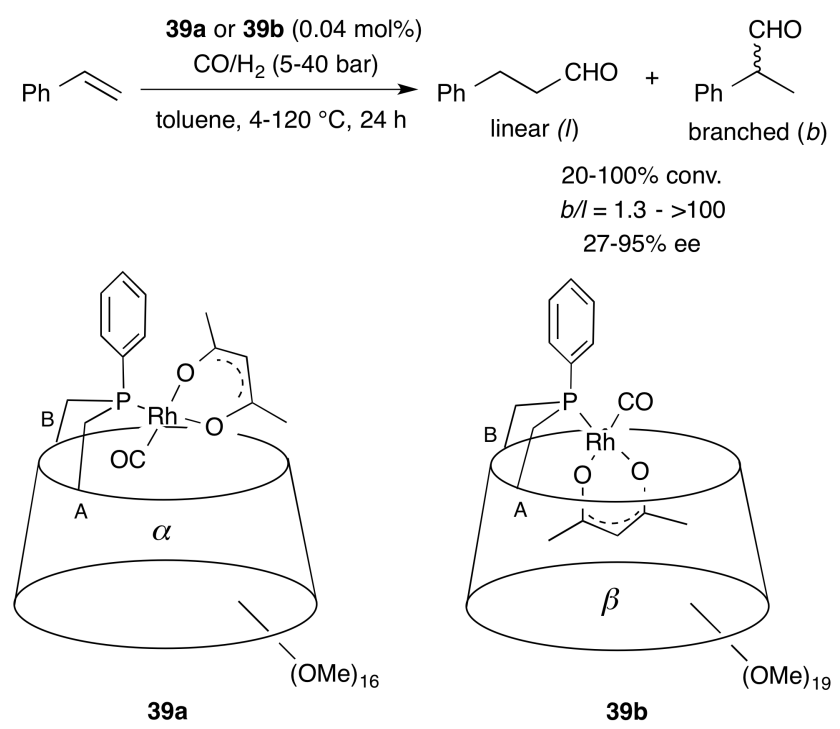

Scheme 22. Rh(I)-catalyzed hydroformylation of styrene using CD-based monophosphine complexes 39a,b.

Cationic Pd(II) monophosphine complexes derived from the same ligands (40a,b) act as precatalysts for the homopolymerization of styrene under CO pressure [52]. Although overall atactic, the resulting polymer features stereoregular sequences that are produced within the chiral environment of the CD cavity (Scheme 23).

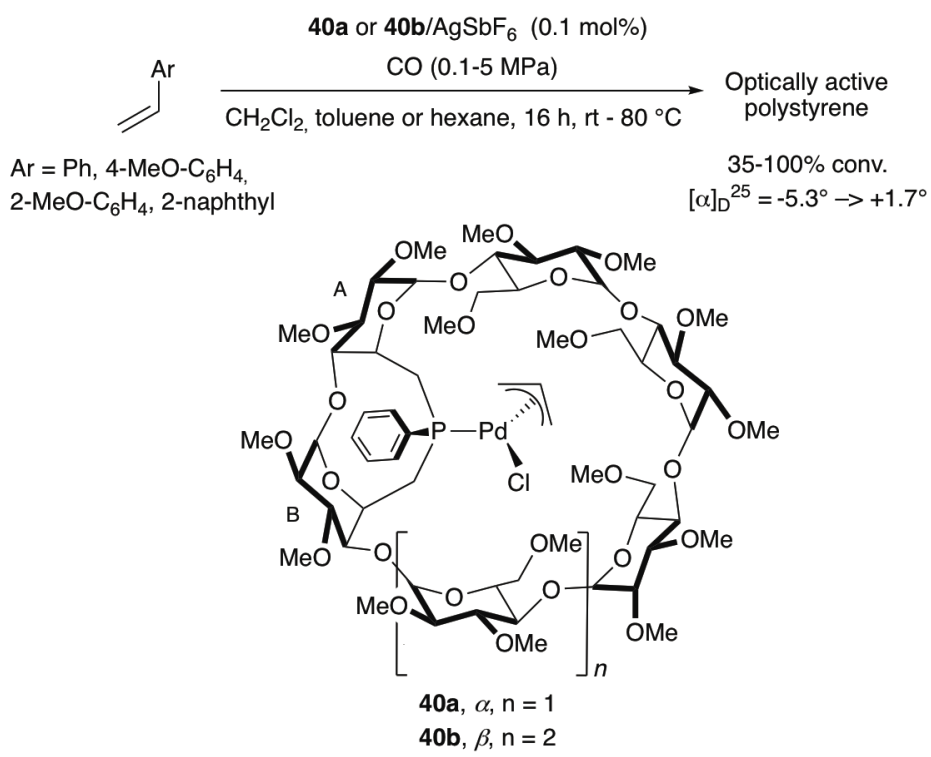

Scheme 23. Cationic Pd(II) allyl monophosphine complexes for the asymmetric polymerization of styrene.

Remarkably, $\mathrm{CO}$ is not incorporated into the macromolecule but has a strong influence on both optical activity and molecular weight. The highest optical activities (up to $-5.3^{\circ}$ ) were observed for polystyrene $\left(\mathrm{M}_{\mathrm{n}}=9100 \mathrm{~g} \cdot \mathrm{mol}^{-1}\right)$ produced under moderate CO pressure $(0.1$ 
$\mathrm{MPa}$ ) with a $>99 \%$ conversion, while higher $\mathrm{CO}$ pressure $(1 \mathrm{MPa}$ ) produced longer chains by suppressing $\beta$-hydrogen elimination $\left(\mathrm{M}_{\mathrm{n}}\right.$ up to $26400 \mathrm{~g}$. $\left.\mathrm{mol}^{-1}\right)$ albeit with no optical activity and low conversions $(<5 \%)$. In addition, the size of the cavity has little influence on the catalytic properties although $\alpha-C D$-based catalysts gave slightly higher optical activities, but lower molecular weights. Significantly lower optical activities were observed in the case of larger vinyl arenes (between -0.6 and $+1.7^{\circ}$ ). These monodendate ligands offer also unique opportunities in the notoriously challenging gold(I)-catalyzed asymmetric reactions because they provide a chiral environment at the backside of the metal-ligand bond. Again the same monophosphines $(\mathbf{3 8 a}, \mathbf{b})$ were used in the gold-catalyzed cycloisomerization of prochiral 1,6enynes. Compared to $\mathrm{Au}(\mathrm{I})$ precatalysts $\mathbf{( 4 1 a , b )}$ derived from CD-based $\mathrm{P}(\mathrm{III})$ phosphoramidite ligands equipped with an extra stereogenic binaphthyl unit but lacking the ability to confine metals, $\mathrm{Au}(\mathrm{I})$ precatalysts $(\mathbf{4 2 a}, \mathbf{b})$ based on $\mathbf{3 8 a}, \mathbf{b}$ gave rise to much higher albeit still moderate ee values (48\% vs. 9\% for respectively $\mathbf{4 2 b}$ and $\mathbf{4 1 b})$ at $70{ }^{\circ} \mathrm{C}$ (Scheme 24) [53]. Such a high temperature is required to ensure reasonable conversions, however at the expense of enantiodiscrimination. The use of an analogous digold(I) precatalyst (42c) did not improve enantioselectivity, whether with 1 or 2 equiv of silver salt (respectively 35 and $22 \%$ ee). The same catalytic reactions can be carried out at lower temperature $\left(25^{\circ} \mathrm{C}\right)$ using NHC-based complexes 43a,b, also derived from permethylated CDs, instead of monophosphine-based 38a,b [54]. However the same moderate ee values (50\%) were observed. Noteworthy is the fact that $C_{2}$-symmetric $\mathbf{4 3 b}$ leads to better enantiodiscrimination than the less symmetrical ligand 43a. 


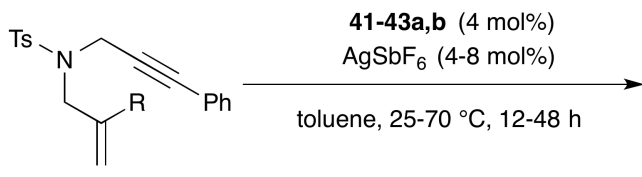

$\mathrm{R}=\mathrm{H}$ or $\mathrm{Me}$

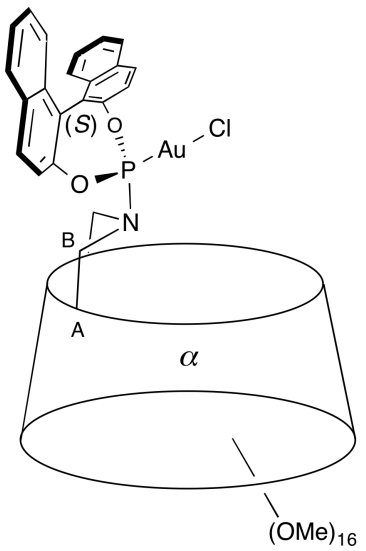

41a, $(S)$

41b, $(R)$ (not drawn)

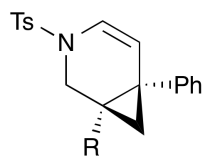

$\mathrm{R}=\mathrm{H}$ or $\mathrm{Me}$

$2-100 \%$ conv $0-50 \%$ ee

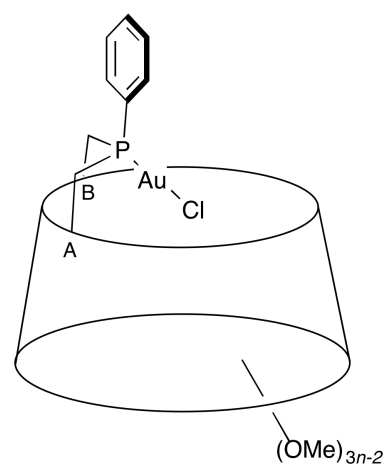

42a, $\alpha, n=6$

42b, $\beta, n=7$
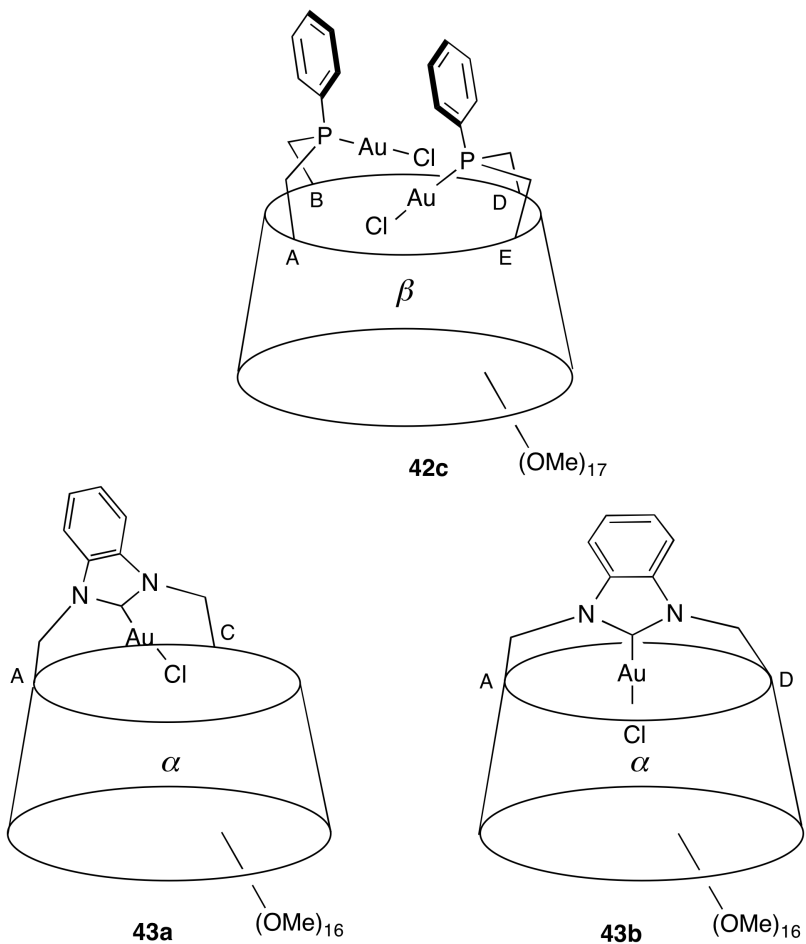

Scheme 24. $\mathrm{Au}(\mathrm{I})$ complexes derived from CD-based monodentate $\mathrm{P}(\mathrm{III})$ and $\mathrm{NHC}$ as well as diphosphine ligands for the asymmetric cycloisomerization of 1,6-enynes.

Slightly higher ee values (up to 59\% ee) were reached upon replacing the benzimidazolyl NHC cap with an imidazolyl one (44a,b) (Scheme 25) for a similar cycloisomerization reaction [55]. Performing asymmetric cycloisomerization reactions in water instead of an organic solvent such as $\mathrm{CH}_{2} \mathrm{Cl}_{2}$ with $44 \mathbf{a}, \mathbf{b}$ as precatalysts led to even higher enantiodiscrimination (up to $81 \%$ ee) and is noticeably possible without preactivation with 
silver salts, although the presence of silver salts is necessary to achieve reasonable conversions pointing to an active role of silver cations in the catalytic cycle and not only as a ionization agent.

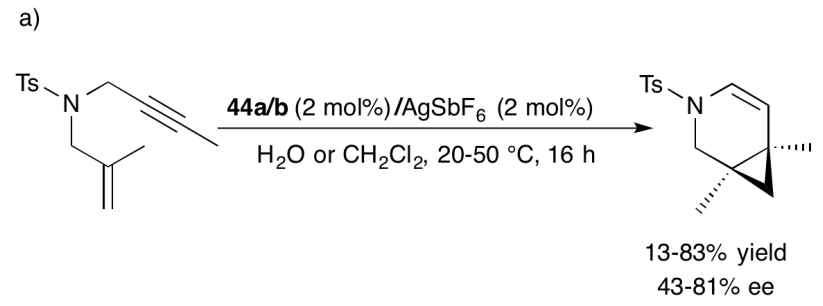

b)

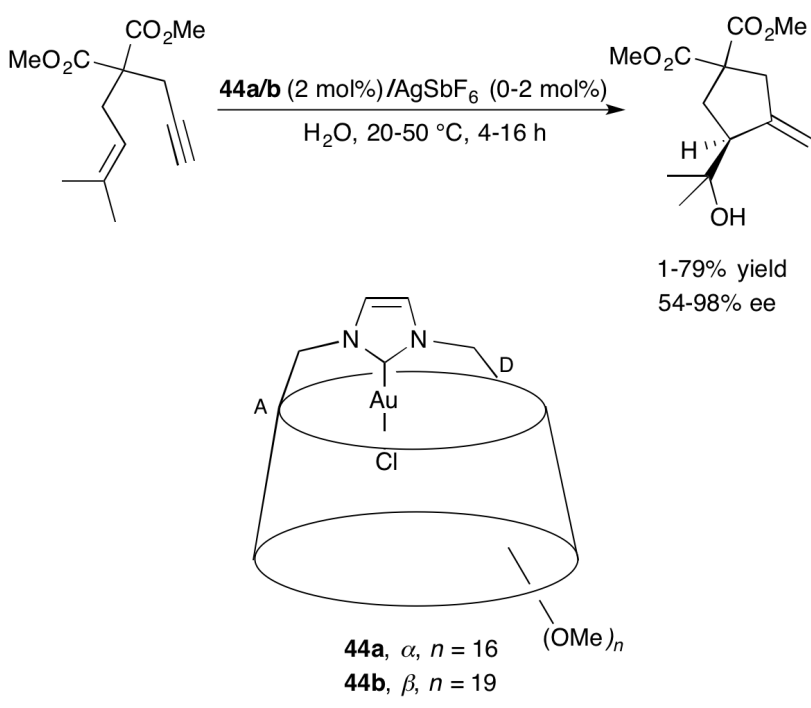

Scheme 25. NHC-capped $\alpha$ - and $\beta$-CDs $44 \mathbf{a}, \mathbf{b}$ for asymmetric gold catalysis.

However, no silver salts were required with $\beta$-CD-based 44b unlike $\alpha$-CD-based 44a in an analogous hydroxylation-cyclization reaction of 1,6-enynes (Scheme 25), which led to very high ee values and but low activity at $20{ }^{\circ} \mathrm{C}(98 \%$ ee and $79 \%$ yield after $45 \mathrm{~h})$. Raising the temperature to $50^{\circ} \mathrm{C}$ hardly affected the enantioselectivity of the reaction $(96 \%$ ee) but considerably increased activity (74\% yield after $4 \mathrm{~h}$ ). These results are in stark contrast with those obtained from monosubstituted permethylated CD 45, in which the NHC-gold unit is dangling (Scheme 26) [56]. When the cycloisomerization of prochiral $\gamma$ - or $\delta$-hydroxyallenes to tetrahydrofurans or -pyrans were performed in pure water without the presence of silver salts as above, only racemic products were obtained. Only by performing the cycloisomerization in organic solvents in the presence of silver salts could moderate enantioselectivities be obtained (18-38\%) at low conversions (up to $37 \%$ after $24 \mathrm{~h}$ ). 
a)

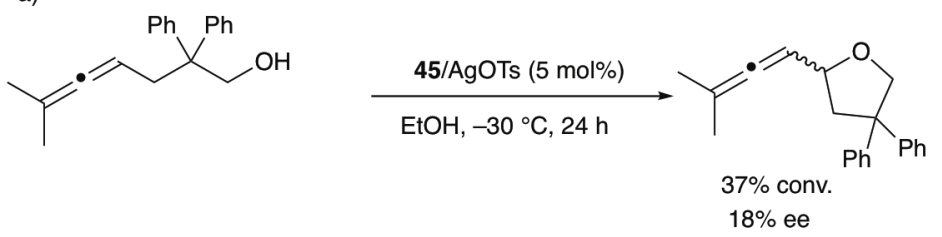

b)
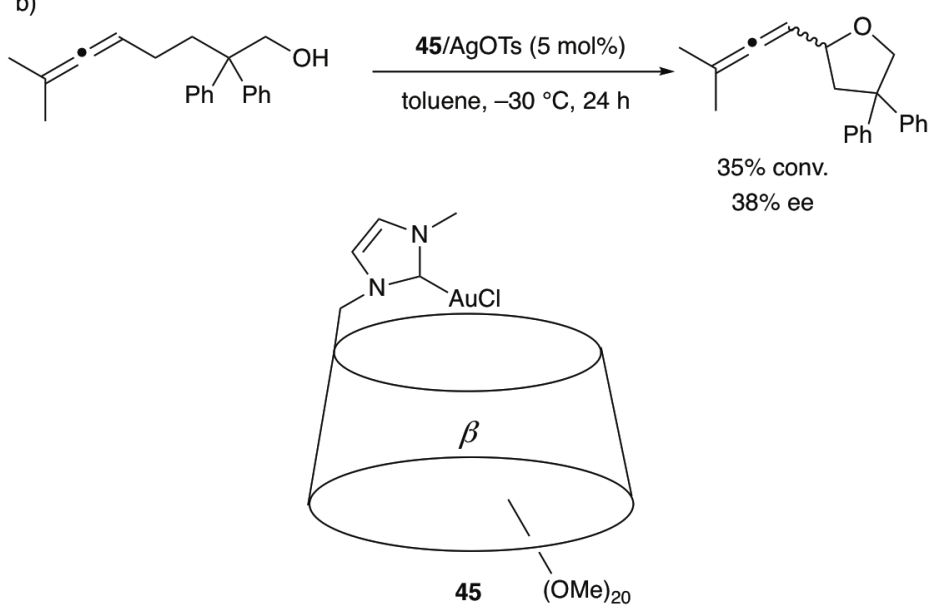

Scheme 26. NHC-appended $\beta$-CD 45 for asymmetric gold catalysis.

Perbenzylated analogs (46a-g) of the aforementioned NHC ligands (Scheme 27) were also tested with success in various asymmetric gold(I)-catalyzed reactions involving silver salt additives, including cycloisomerization and alkoxycyclisation of 1,6-enynes [57-59]. Ee values up to $80 \%$ were measured for the former, while an unprecedented ee value $(94 \%$ ee) was reached for the later reaction. Surprisingly, the use of $\mathbf{4 6 g}$ and the $\gamma$-CD-based precatalyst 46d provided either racemic mixtures or with the more bulky phenyl containing substrate the $(S, S)$ enantiomer during the cycloisomerization of enynes contrary to all other precatalysts, thus pointing to a very different stereodifferentiation process. Moreover, Sollogoub, Fensterbank and Mouriès-Mansuy showed that the outcome of the gold(I)-catalyzed reaction could be switched from cycloisomerization to alkoxycyclization just by adding an alcohol of reasonably small size. Apart from enantioselectivity, ring-size selectivity was also shown to take place for some cycloisomerization reactions, unusual 6-membered rings being favored within the capsular environment of $\beta$-CD-based catalysts. In terms of cavity size, it seems that $\beta$-CD-based catalysts are generally the best performing ones both in terms of enantioselectivity and activity. 
<smiles>[R]C(=C)CN([As])CC#CC</smiles>

$\mathrm{R}=\mathrm{Me}$ or $\mathrm{Ph}$
46a-f/AgSbF 6 (2-5 mol\%) $\mathrm{CH}_{2} \mathrm{Cl}_{2}, 15-18 \mathrm{~h}$,

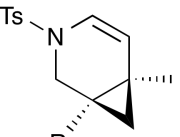

R

$50-85 \%$ yield $0-80 \%$ ee
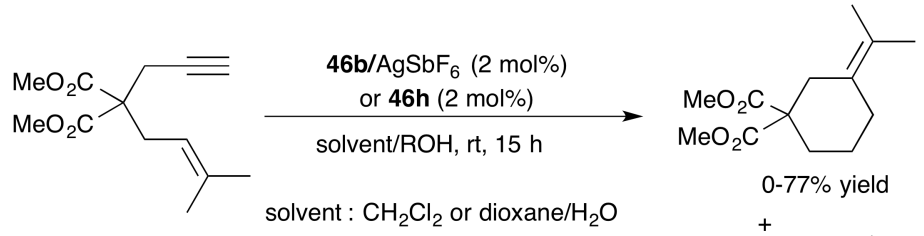

$0-77 \%$ yield

$\mathrm{R}=\mathrm{Me}, \mathrm{Bn}, \mathbb{P r}$ or $\mathrm{H}$

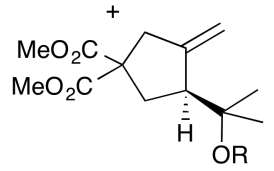

7- >99\% yield $46-94 \%$ ee

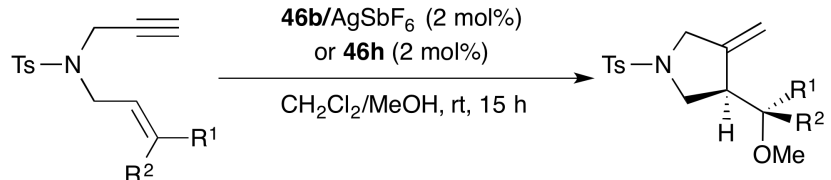

$R^{1}=R^{2}=$ Me or

$\mathrm{R}^{1}=\mathrm{Ph}, \mathrm{R}^{2}=\mathrm{Me}$

$58-79 \%$ yield

$84-88 \%$ ee
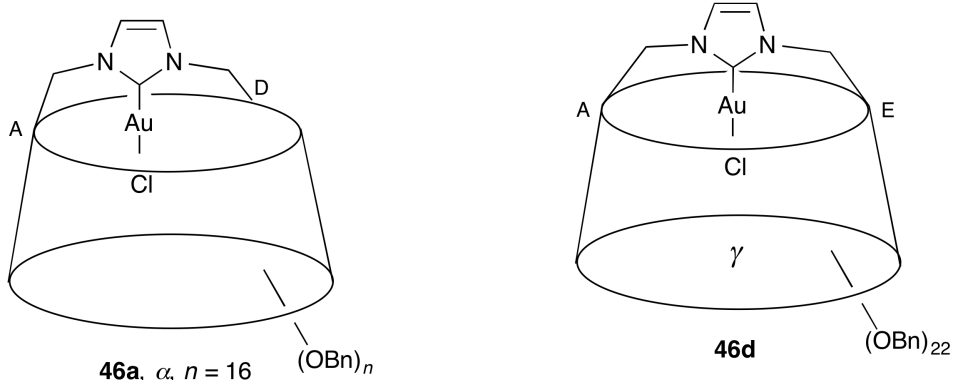

46b, $\beta, n=19$

46c, $\gamma, n=22$
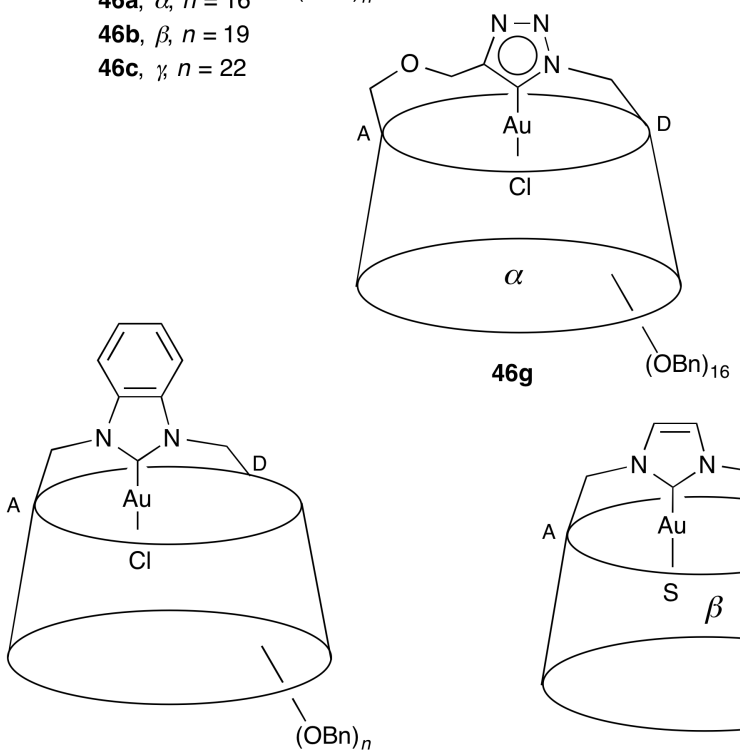

46e, $\alpha, n=16$

46f, $\beta, n=19$

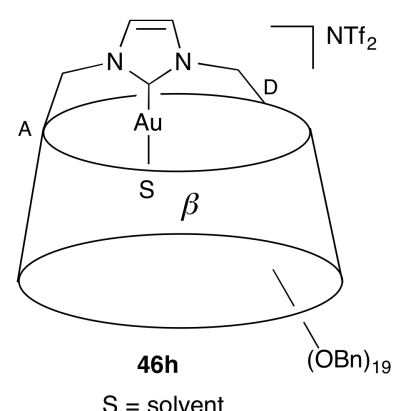

Scheme 27. $\mathrm{Au}(\mathrm{I})$ complexes derived from perbenzylated NHC-capped CDs as asymmetric catalysts in the asymmetric cycloisomerization and alkoxycyclization of 1,6-enynes. 
Copper(I) complexes of the same perbenzylated NHC-capped CDs [60] were used as precatalyts (47a-e) in the cavity-controlled asymmetric hydrosilylation of a range of prochiral ketones, in particular acetophenone (Scheme 28). $\alpha$-CD-based precatalysts, which involve a tighter fit between the substrate and the cavity, gave rise to significantly higher ee values (35$87 \%$ ee) than their $\beta$-CD counterparts $(10-63 \%$ ee). Starting from prochiral $\alpha, \beta$-unsaturated ketones as substrates with the same copper(I) precatalysts, the reaction was chemoselective as well as being enantioselective. Remarkably, the chemoselectivity of the reaction proved to be highly dependent of the cavity size of the NHC catalyst. While $\alpha$-CD-based precatalyst $\mathbf{4 7 d}$ led to 1,2-reduction with a wide range of ee values (8-85\% ee) and no formation of the saturated alcohol even in the presence of an excess of silane, its $\beta$-CD-based analog 47e promoted 1,4-reduction followed by carbonyl reduction when using an excess of silane with lower enantioselectivity $(6-51 \%$ ee). In the case of $\alpha$-CD-based analogs, the active monomeric copper-hydride catalyst (47f) is remarkably stable and could be isolated. DFT theoretical studies have shown that the discrimination between the two types of reduction (1,2- vs. 1,4-reduction) in both $\alpha$ - and $\beta$-CD catalysts is due to a combination of attractive noncovalent interactions within the cavity and steric hindrance imposed by the topography of the pocket. 

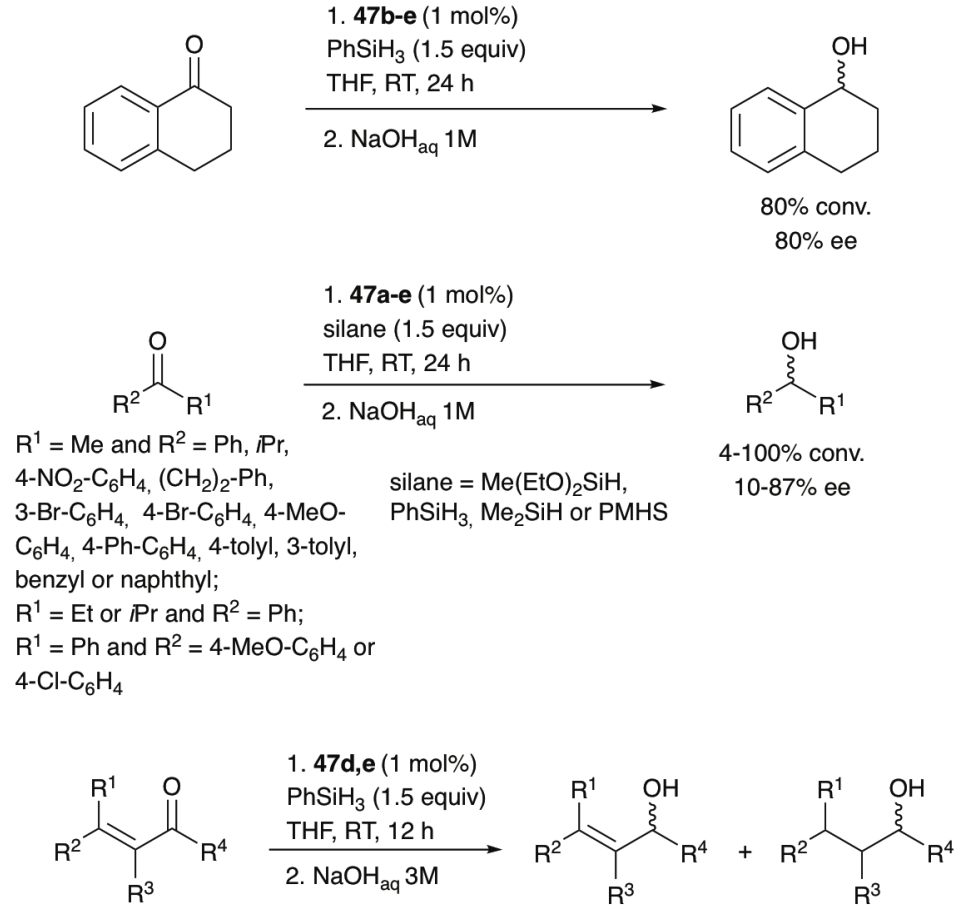

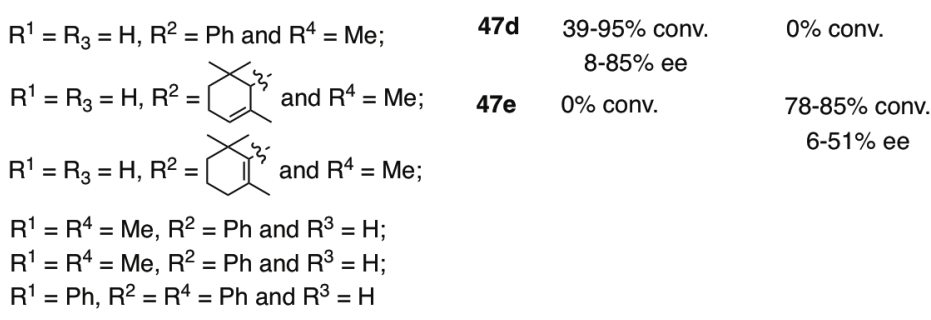<smiles>CC(=O)/C=C/c1ccccc1</smiles>
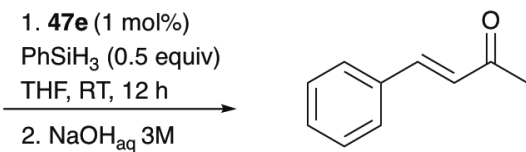

$45 \%$ conv.

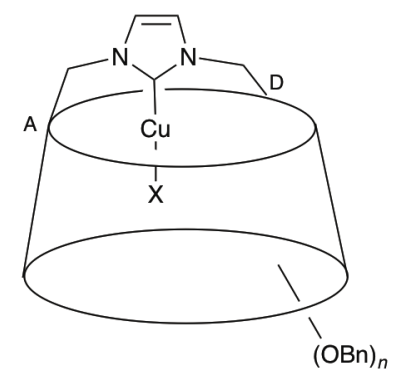

47a, $\alpha, n=16, \mathrm{X}=\mathrm{F} . \mathrm{HF}$

47b, $\alpha, n=19, \mathrm{X}=\mathrm{OH}$

47c, $\beta, n=19, \mathrm{X}=\mathrm{OH}$

47d, $\alpha, n=16, \mathrm{X}=\mathrm{Cl}$

47e, $\beta, n=19, \mathrm{X}=\mathrm{Cl}$

47f, $\alpha, n=16, \mathrm{X}=\mathrm{H}$

Scheme 28. Cavity-controlled asymmetric hydrosilylation of prochiral ketones including $\alpha, \beta$-unsaturated ones.

\section{Chiral ligands comprising other covalent cavities}

In 1999, Jablonski synthesized enantiopure salen-type macrocyclic ligands (48a-e) possessing a well-defined cavity which resembles that of calixarenes, hence the name « calixsalen » that was used to describe these macrocycles [61]. They comprise two chiral salen coordinating units capable of coordinating simultaneously two $\mathrm{Mn}^{3+}$ metal cations. These dinuclear Mn(III) 
catalysts were tested in Jacobsen epoxidation of styrene using $\mathrm{NaOCl}$ as terminal oxidant (Scheme 29). Various proportions of anti-Markovnikoff chlorinated products (chloroether or chlorohydrin) and epoxides were obtained depending on the ligand and the presence or not of methanol in the reaction mixture with ee values not exceeding $52 \%$, a figure that is comparable to those obtained with acyclic analogs. The fact that enantioselectivity generated by the macrocyclic $\mathrm{Mn}(\mathrm{III})$-calixsalen systems appears unrelated to the steric requirements of the alkyl substituents on the ortho position of the phenol in the salen skeleton suggests that enantiodiscrimination is controlled by host-guest intra-cavity interactions, in stark contrast with their acyclic analogs.

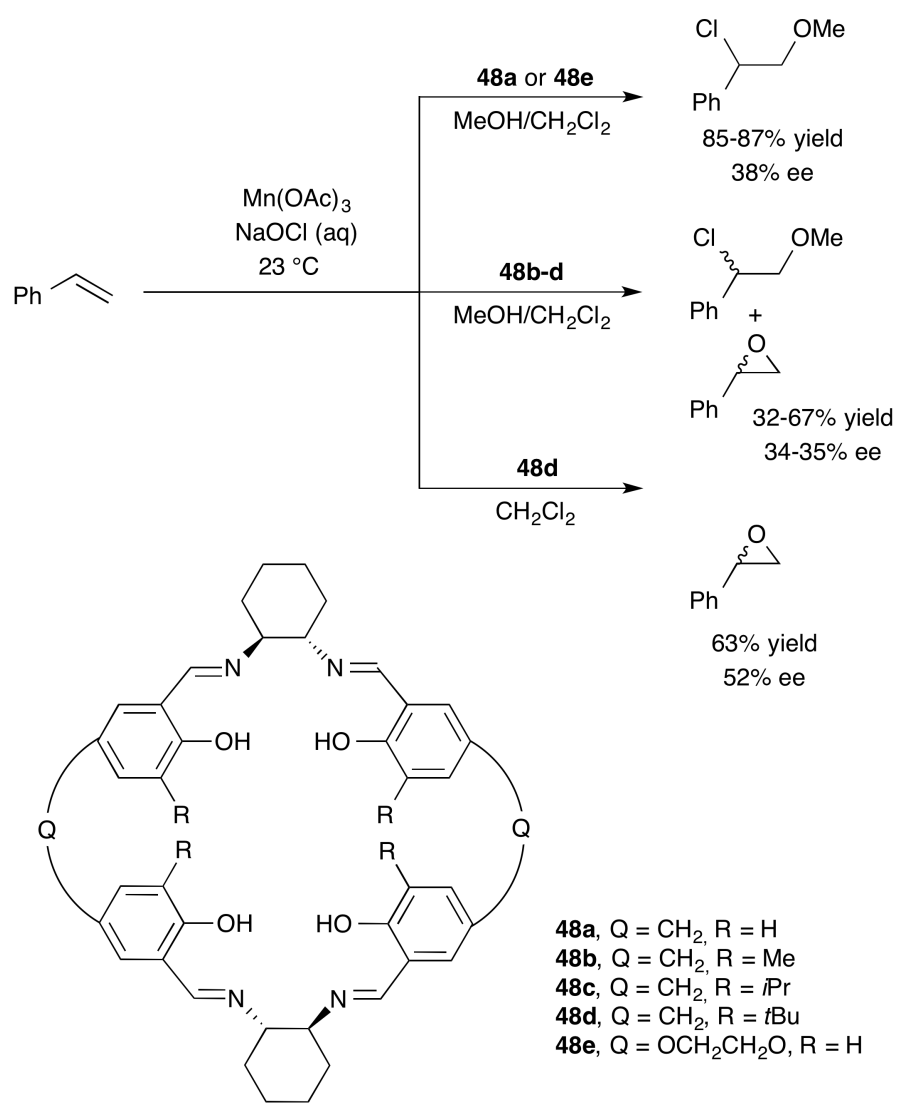

Scheme 29. Macrocyclic Mn(III) salen complexes as asymmetric catalysts for styrene epoxidation.

In 2017, Martinez performed asymmetric oxidation of various aromatic thioethers with the bowl-shaped oxido-vanadium complex 49a as catalyst (Schemes 30 and 31) [62]. 


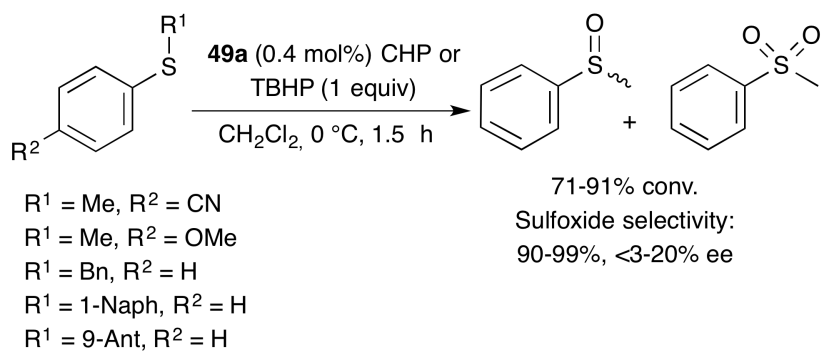

Scheme 30. Asymmetric oxidation of bulky sulfides using oxido-vanadium(V) cage catalysts.

Although enantioselectivity remains low (up to $20 \%$ ee) when using 1 equiv of cumene hydroperoxide (CHP) or tert-butyl hydroperoxide (TBHP) as terminal oxidants, the system is remarkably more active (24-, 9-, and 301-fold faster than respectively $49 b, 49 c$ and 49d) as well as more enantioselective than its diastereomeric counterpart $49 \mathrm{~b}$, hemicryptophane analog 49c [63] and cavity-free 49d (Scheme 31). Upon metal complexation, ligand 49a is the only one to adopt a bowl-shaped conformation capable of hosting the substrate as confirmed by $2 \mathrm{D}$ NMR COSY and ROESY experiments. The metallohost exhibits enzyme-like Michaelis-Menten kinetics and no product inhibition, resulting in very large TONs (up to $8.6 \times 10^{4}$ after 7 days). Although initial oxidation of the sulfide into sulfoxide is a directly enantioselective process, once the sulfoxide is formed, kinetic resolution takes place upon additional oxidation into the sulfone with an excess of hydroperoxide. Indeed, the ee value of remaining sulfoxide (around 15\% sulfoxide $v s .85 \%$ for the sulfone at the end of reaction) increased from $18 \%$ to $42 \%$ during this second oxidation process. 

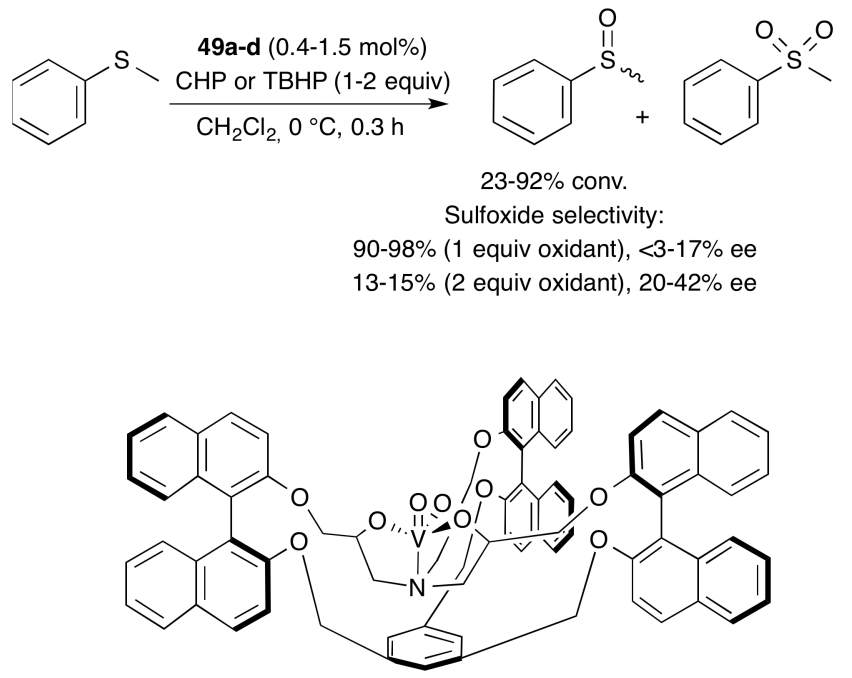

49a $(S S S-R R R)$

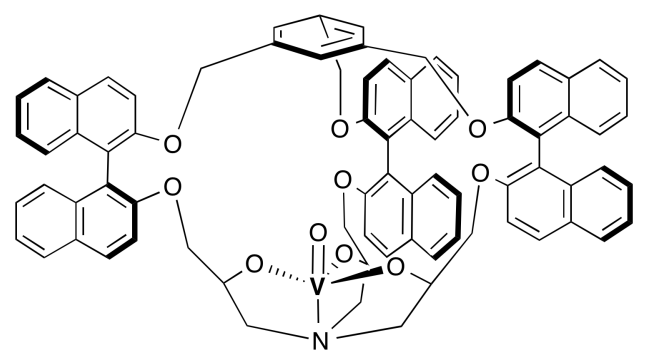

49b (SSS-SSS)

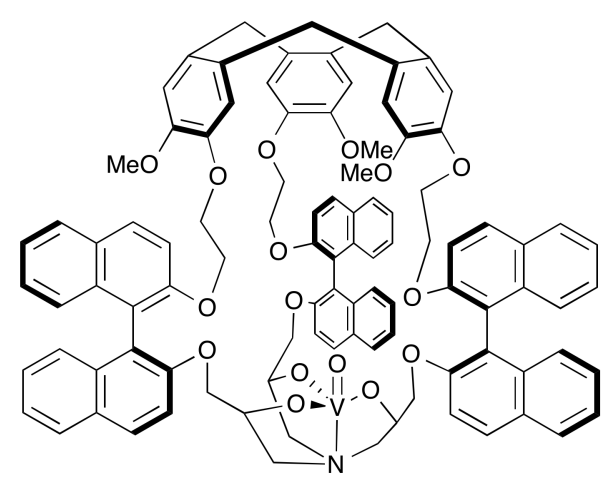

49c (M-SSS-RRR)

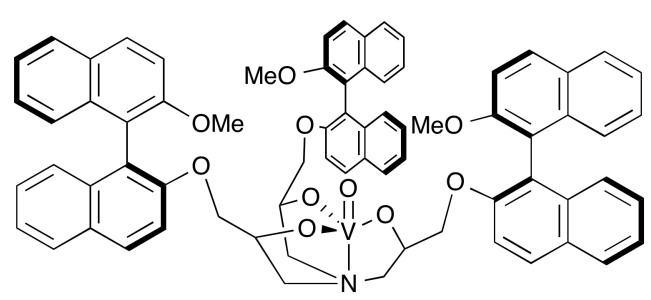

49d $(S S S-R R R)$

Scheme 31. Oxido-vanadium(V) cage catalysts for the asymmetric oxidation of sulfides. 
Unlike their calix[4]arene counterparts, there are only a few examples of ligands incorporating a resorcin[4]arene platform that have been used in metal asymmetric catalysis. In 2001, Hunter reported enantiopure, distally-bridged resorcin[4]arenes with alkyl chains of various length at the lower rim (50a-c) [64]. The chiral, diamino bridging unit was introduced onto the resorcin[4]arene platform via two Mannich reactions. The three ligands were tested in the asymmetric addition of diethylzinc to benzaldehyde (Scheme 32). The aminomethylphenol functionnality present in the macrocyclic structure is believed to form zincoxamines intermediates that act as templates for catalysis. All macrocyclic ligands produced the $(R)$ enantiomer with moderate ee values $(12-52 \%)$ as the major product unlike the acyclic, configurationally analogous ligand 51, which gave the $(S)$ enantiomer with low enantioselectivity (16\% ee). This, together with the fact that longer alkyl chains at the lower rim gave significantly higher ee values, point to a very different stereodifferentiation process between acyclic and macrocyclic versions, which is in line with a direct involvement of the cavity in the catalytic process in the case of 50a-c. Capsular ligands having a similar diamino bridge, but with an additional ketal functionality in the middle were also synthesized and tested for the same catalytic reaction [65]. The nature of the central ketal group has a strong influence on enantioselectivity, which is significantly higher than when the ketal function is absent. While ketal 50d gave $(R)$-1-phenypropanol with 34\% ee, its dimethoxy analog 50e, which is equipped with the same methyl chains at the lower rim produced the $(S)$ enantiomer with $51 \%$ ee. These results are in line with a ketal group interacting strongly with zinc and again a catalytic process taking place within the cavity. 


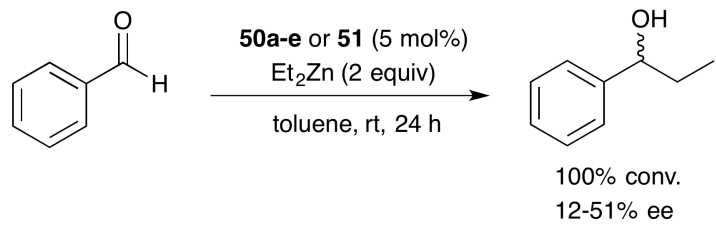

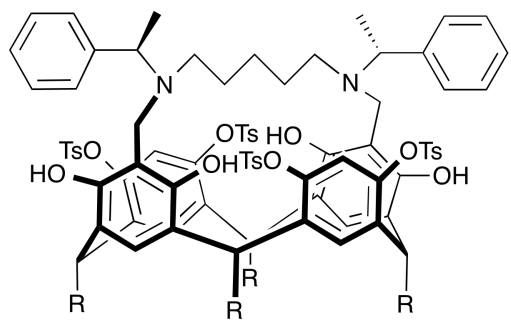

50a, $\mathrm{R}=\mathrm{Me}$

50b, $\mathrm{R}=\mathrm{C}_{5} \mathrm{H}_{11}$

50c, $\mathrm{R}=\mathrm{C}_{11} \mathrm{H}_{23}$

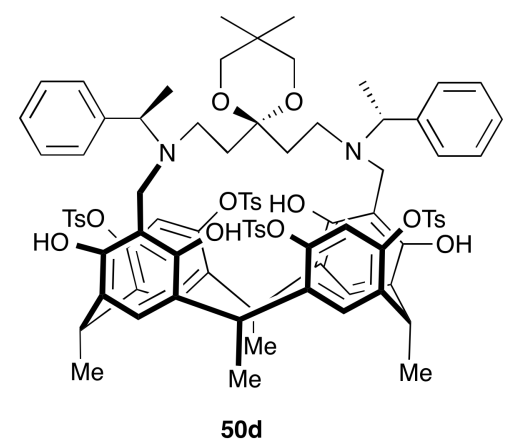

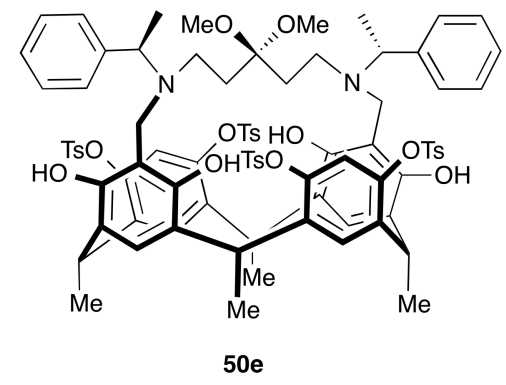

Scheme 32. Asymmetric addition of diethylzinc using bridged resorcin[4]arenes as ligands

Very recently, Echavaren prepared enantiopure Iwasawa-type cavitands [66,67] to perform gold(I)-catalyzed enantioselective alkoxycyclization on various 1,6-enynes, including bulky bio-relevant ones [68]. In these extended resorcin[4]arenes, one or two phosphoramidite units bearing either $S, S$ - or $R, R$-bis-(1-arylethyl)amino substituents are able to bind one or two gold(I) centers with the metal centers located either inside or outside the cavity (Scheme 33). While complexes with at least one metal center sitting outside the cavity (52a-g) performed rather poorly in terms of enantioselectivity (ee values between 2 and 36\%), dinuclear complexes 52h-n having both their metal centers inside gave rise to much higher ee values (48-78\% ee at $23{ }^{\circ} \mathrm{C}$ ) reaching $94 \%$ ee when performing the reaction with the best performing monocationic catalyst $\mathbf{5 2 1}$ at low temperature $\left(-50^{\circ} \mathrm{C}\right)$. Noteworthy, complex $\mathbf{5 2} \mathbf{m}$ $((R, R, R, R)$ enantiomer of 52l) was used to achieve the first total synthesis of (+)mafaicheenamine C. Its non-natural enantiomer was also synthesized using $\mathbf{5 2 1}$ as catalyst proving that such cavity-shaped catalysts are useful in the synthesis of structurally complex and bulky natural products. DFT calculations performed on catalyst $\mathbf{5 2 1}$ gave insight on the 
origin of the enantiodiscrimination process which involves attractive noncovalent interactions between the cavitand and the aromatic ring of the enyne and within the complex itself.
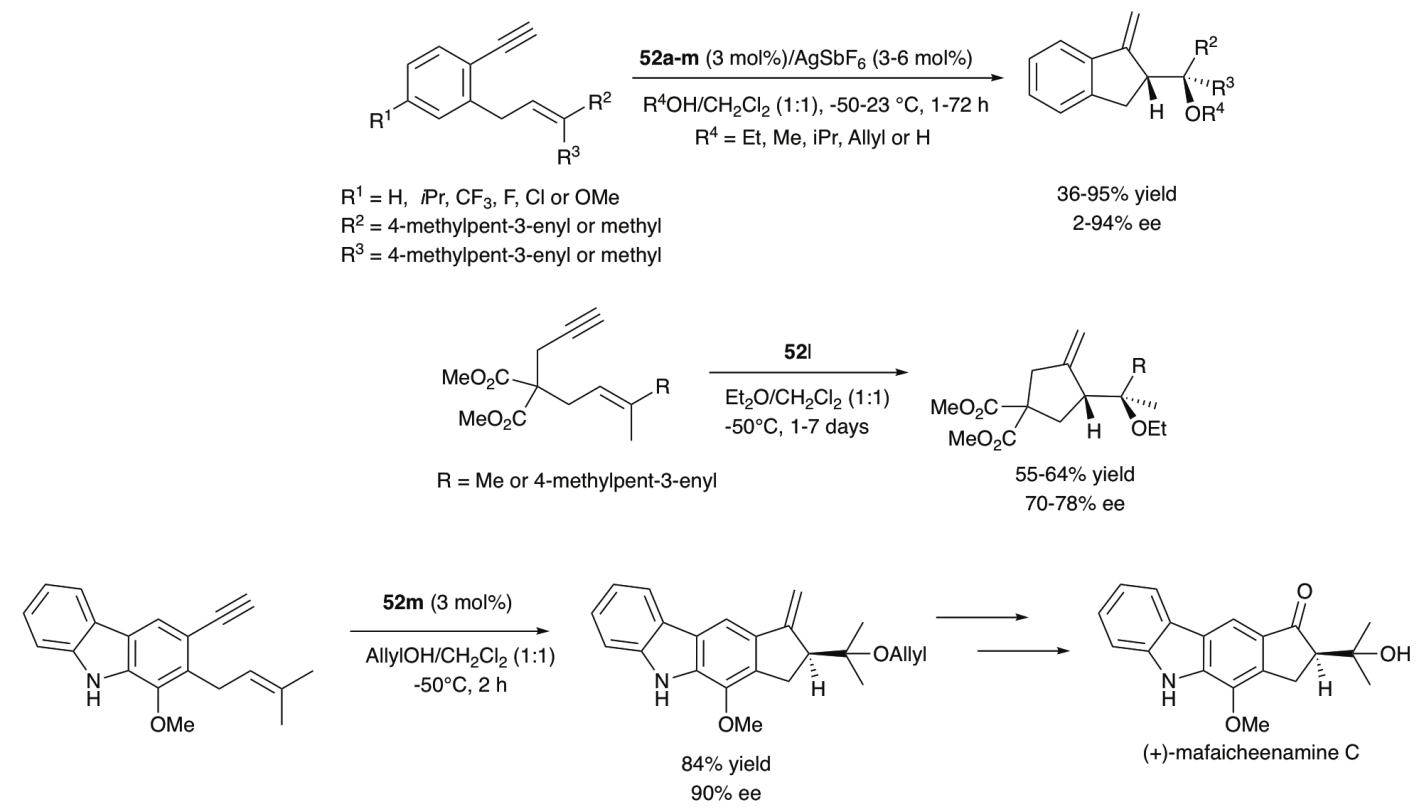

(+)-mafaicheenamine C

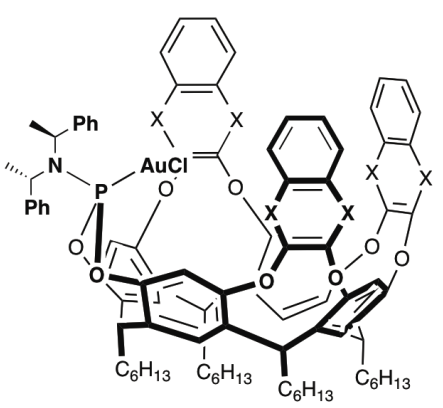

52a $(S, S), X=\mathrm{CO}$ $52 b(S, S), X=N$

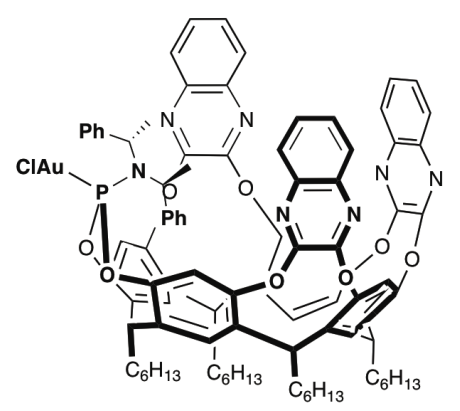

$52 \mathrm{c}(S, S)$

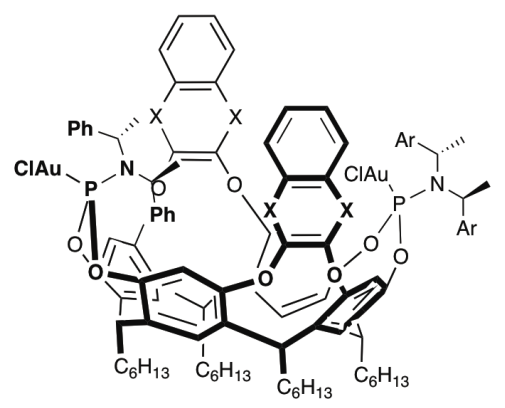

52d $(S, S), A r=P h, X=C O$

52e $(S, S), A r=P h, X=N$

$52 f(S, S), \operatorname{Ar}=1$-naphthyl, $\mathrm{X}=\mathrm{CO}$

52g $(S, S), A r=2$-naphthyl, $X=C O$

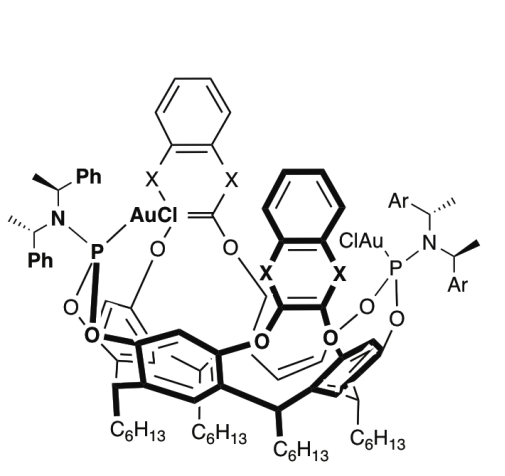

52h $(S, S, S, S), \mathrm{Ar}=\mathrm{Ph}, \mathrm{X}=\mathrm{CO}$ 52i $(S, S, S, S), A r=P h, X=N$ 52j $(S, S, S, S), A r=1$-naphthyl, $X=C O$ $\mathbf{5 2 k}(S, S, S, S), \operatorname{Ar}=2$-naphthyl, $X=C O$

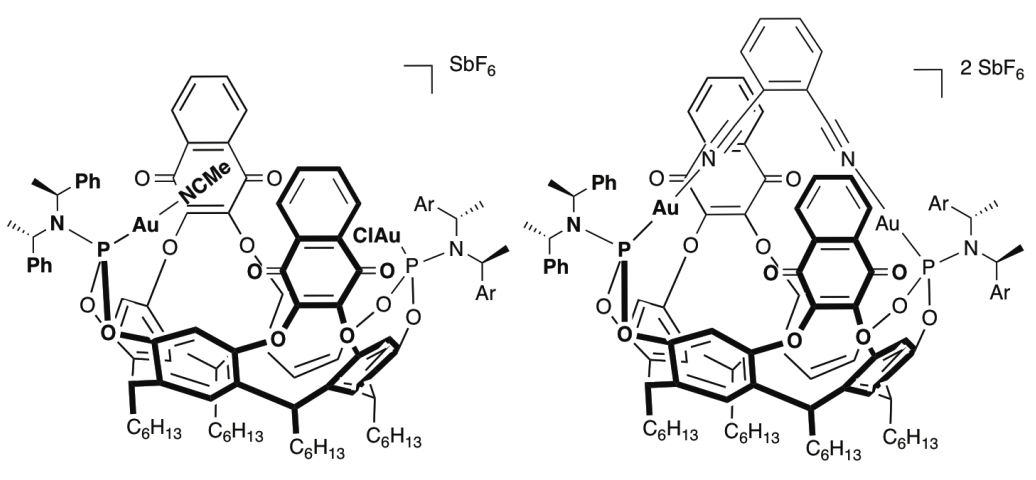

521 $(S, S, S, S)$

$52 \mathrm{~m}(R, R, R, R)$, not drawn

Scheme 33. Enantioselective alkocyclization of 1,6-enynes with gold(I) cavitands 50a-n. 
Inorganic and organometallic cycles and cages can be self-assembled via coordination bonds that make the construction of the cavity much simpler compared to their purely organic analogs. These designs have seen a tremendous development over the last decades. Despite these achievements, only one of these assemblies (53) [69] has so far been used as ligand in asymmetric metal catalysis. It consists of a rigid triangular coordination oligomer built from enantiopure 4,4'-bis(alkynyl)-1,1'-binaphthalene units coordinated to cis-( $\left.\mathrm{PEt}_{3}\right)_{2} \mathrm{Pt}$ corners (Scheme 34). Unfortunately, the presence of a well-defined cavity could neither be proven in the free ligand nor in the titanium complex used for catalyzing the addition of diethylzinc to aromatic aldehydes because of a lack of molecular structures. Ee values around $90 \%$ were measured with various aldehydes as starting materials when conducting the catalytic tests with the free ligand and a large excess of $\mathrm{Ti}(\mathrm{O} i \mathrm{Pr})_{4}(7$ equiv).

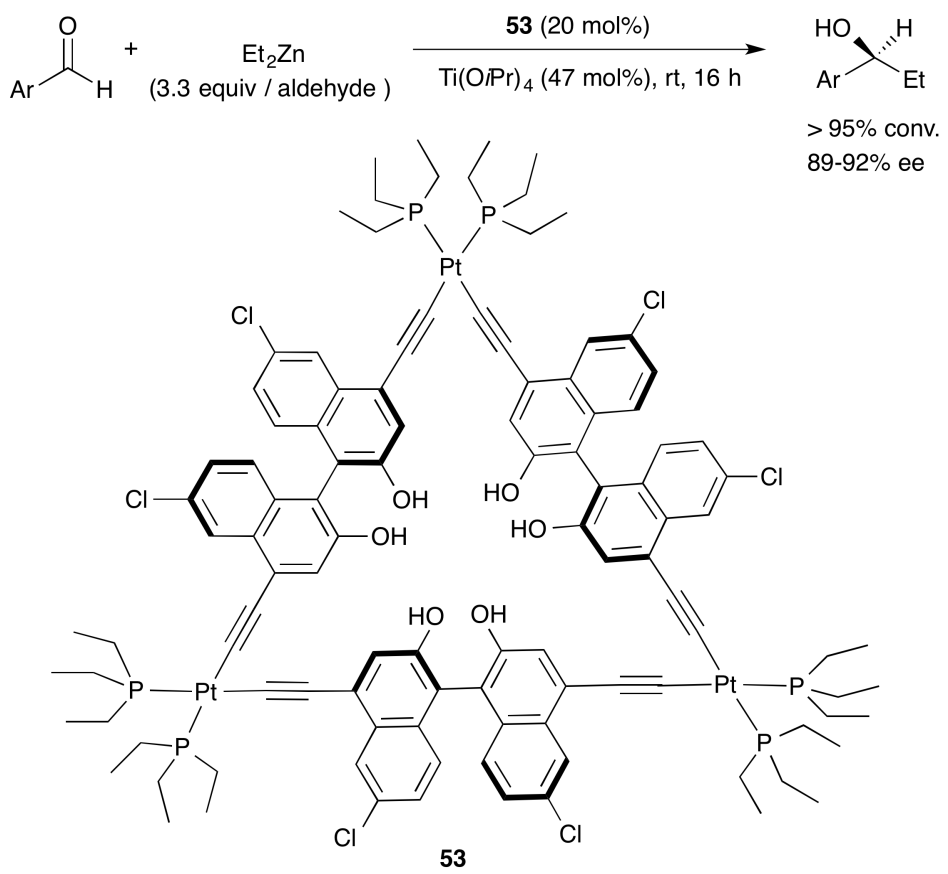

Scheme 34. Enantioselective diethylzinc additions to aromatic aldehydes catalyzed by an organometallic triangle.

A smaller dimeric version of the same ligand (54) was also prepared (Figure 7). Although this system possesses a well-defined cavity as established by an X-ray diffraction study, it is unable to coordinate the titanium metal center presumably because of steric congestion. 


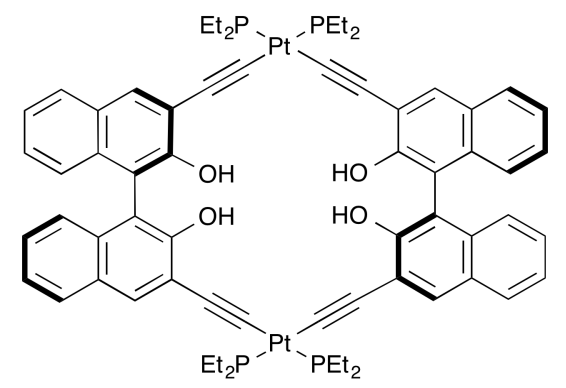

54

Figure 7. Dimeric analog (54) of the trimeric chiral metallocyclophane 53.

It is worth mentioning here that a similar dimeric metalloorganic macrocycle (55) in which the phenolic coordination groups point outside the cavity gave good results (ee values between 74 and 94\%) for the same asymmetric reaction even if the reaction does not take place in a confined space (Scheme 35) [70]. In this case, the macrocyclic structure helps to rigidify the metal coordination sphere. Unfortunately, this seems to be detrimental to enantiodiscrimination as the catalyst has a much more narrow substrate scope than acyclic analogs, which gave much higher ee values with smaller aromatic aldehydes. Although, the presence of a metal confining cavity could not be established in these metallomacrocyclic systems, they constitute the basis for the later development of very successful MOF-like asymmetric catalysts in which metal confinement is a key factor for effective enantioselectivity [12-16],[71-73].
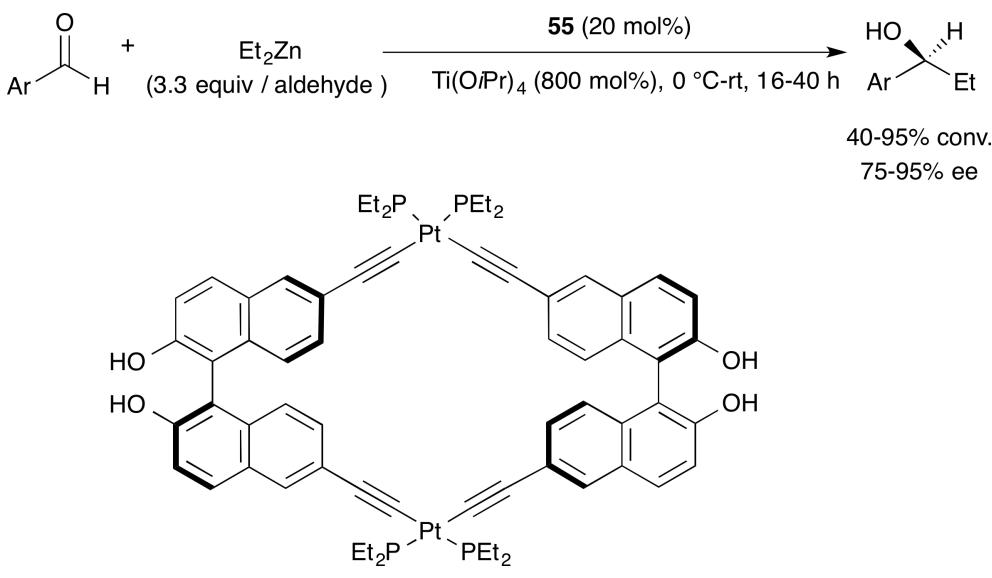

$75-95 \%$ ee

55

Scheme 35. Metallocyclophane analog of $\mathbf{5 4}$ with outward-pointing phenolic coordinating groups (55) used in the asymmetric diethylzinc addition to aldehydes.

Note that a number of metallocages displaying excellent enantioselectivities (up to $99.9 \%$ ee) in asymmetric metal catalysis have been constructed since from enantiopure metallo-organic 
units $[74,75]$. These will not be included in this review as the incorporation of the catalytic center takes place on coordinating building blocks devoid of cavity.

\section{Chiral cavity-shaped supramolecular assemblies with metal coordinating ability}

In recent years, non covalent approaches have been developed, notably by Reek [76], to create a cavity-like environment around the metal center. Compared to their molecular counterparts, these supramolecularly assembled ligands are in principle easier to prepare thanks to the modular strategy at stake. Structural variations are also facilitated and their dynamic properties provide opportunities for guest exchange. The first supramolecularly assembled cage-like chiral ligand developed by Reek consists of two planar bis[Zn(salphen)] units 56 separated by two chiral dipyridyl pillars each equipped with a binaphthyl containing phosphoramidite coordinating unit (57) (Figure 8) [77].
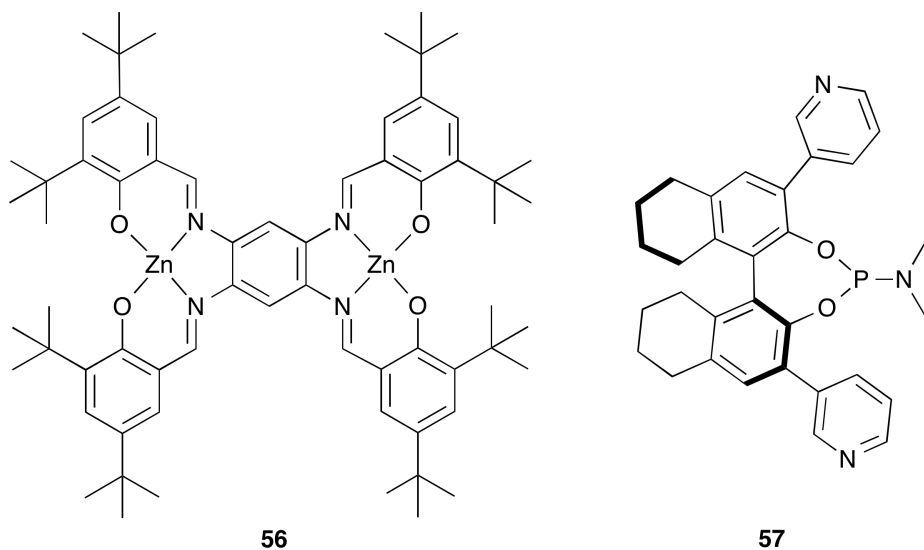

Figure 8. Building blocks used for assembling ligand 57.

The two P(III) atoms in the $2+2$ assembly $\mathbf{5 8}$ face each other and are ideally placed for chelating a $\mathrm{Rh}$ (acac) unit within the chiral box (Scheme 36). The $\mathrm{Rh}(\mathrm{I})$ complex 59 (Figure 9) was tested in the notoriously difficult asymmetric hydroformylation of internal olefins, particularly trans- and cis-2-octenes. It systematically outperformed (56-86\% ee) analogous $\mathrm{Rh}(\mathrm{I})$ complexes derived from dipyridyl ligand $\mathbf{5 6}$ (Figure 8) as well as other chiral P(III)based rhodium catalysts commonly used in hydroformylation $(R, R$-Chiraphite and $S, S$-DIOP) even at elevated temperatures (up to $40^{\circ} \mathrm{C}$ ), reaching a record-breaking ee of $86 \%$ in the hydroformylation of (Z)-2-octene for the innermost aldehyde (2-ethylheptanal), however with a modest activity (20\% conversion after $84 \mathrm{~h}$ reaction time at room temperature). Furthermore, compared to the same standard catalysts, reversed regioselectivity in favor of 2ethylheptanal (regioisomeric ratio of 70/30) was found to take place with 59. The same trend in terms of regio- and enantioselectivity was observed for other internal olefins. Surprisingly, 
lower ee values ( $46 \%$ ee) were measured in the case of styrene, which is sterically bulkier than aliphatic olefins.

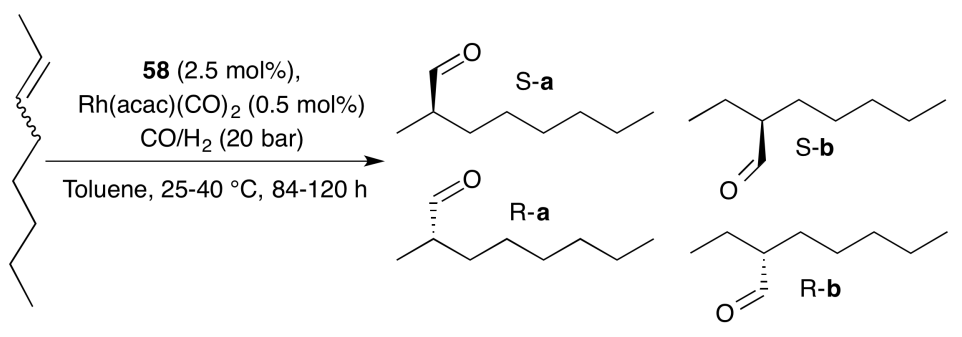
(E)-2-octene:
(Z)-2-octene:
$10-36 \%$ conv.
$20-79 \%$ conv.
regioisomeric ratio (b:a): $42: 58-57: 43 \%$
$58-72 \%$ ee (regioisomer $\mathbf{b}$ )
regioisomeric ratio (b:a): $65: 35-70: 30 \%$
$76-86 \%$ ee (regioisomer b)

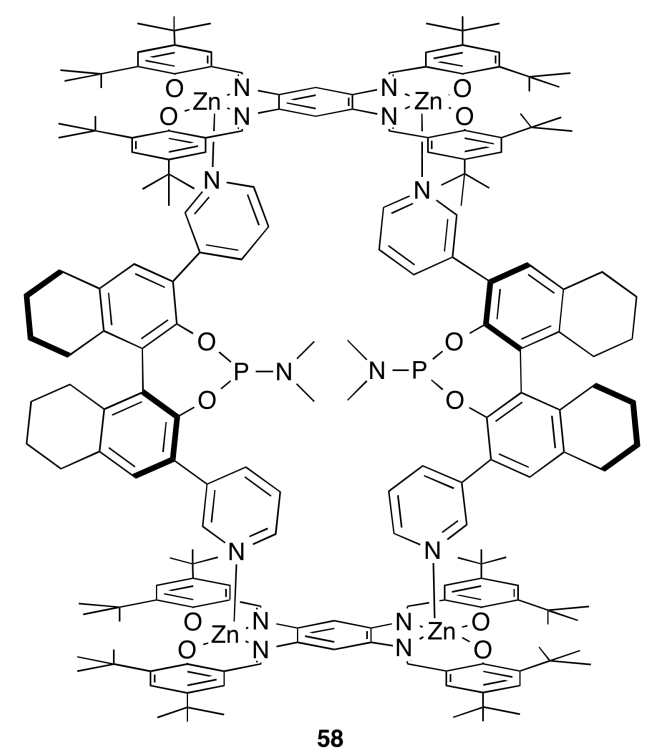

Scheme 36. Asymmetric Rh(I)-catalyzed hydroformylation of unfunctionalized alkenes using a chiral supramolecularly assembled ligand (58). 


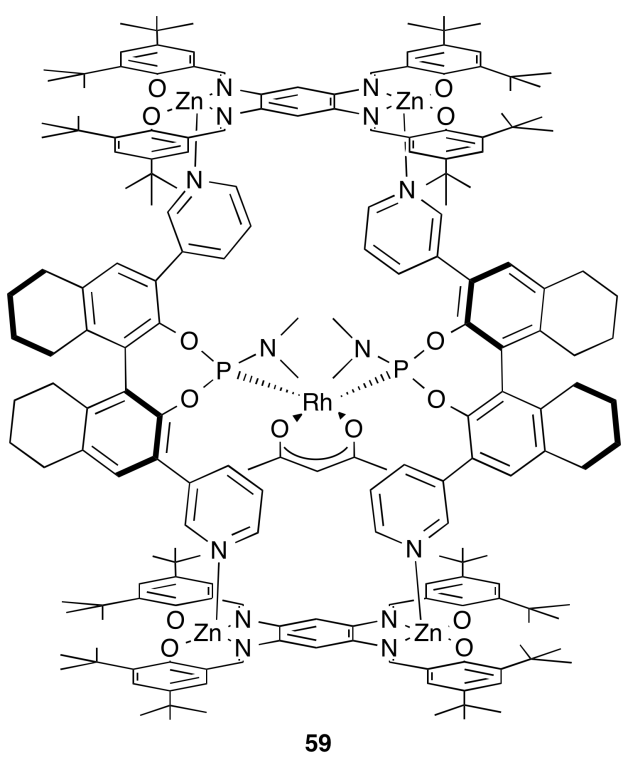

Figure 9. Rh(acac) complex (59) of ligand 58.

In the same vein, other supramolecularly assembled asymmetric hydroformylation catalysts (60a-c) were designed by Costas, Ribas and Reek in 2015 [76]. They involve an atropoisomeric phosphoramidite ligand held within a nonchiral tetragonal cage (61) resulting from metal directed self-assembly (Figure 10).
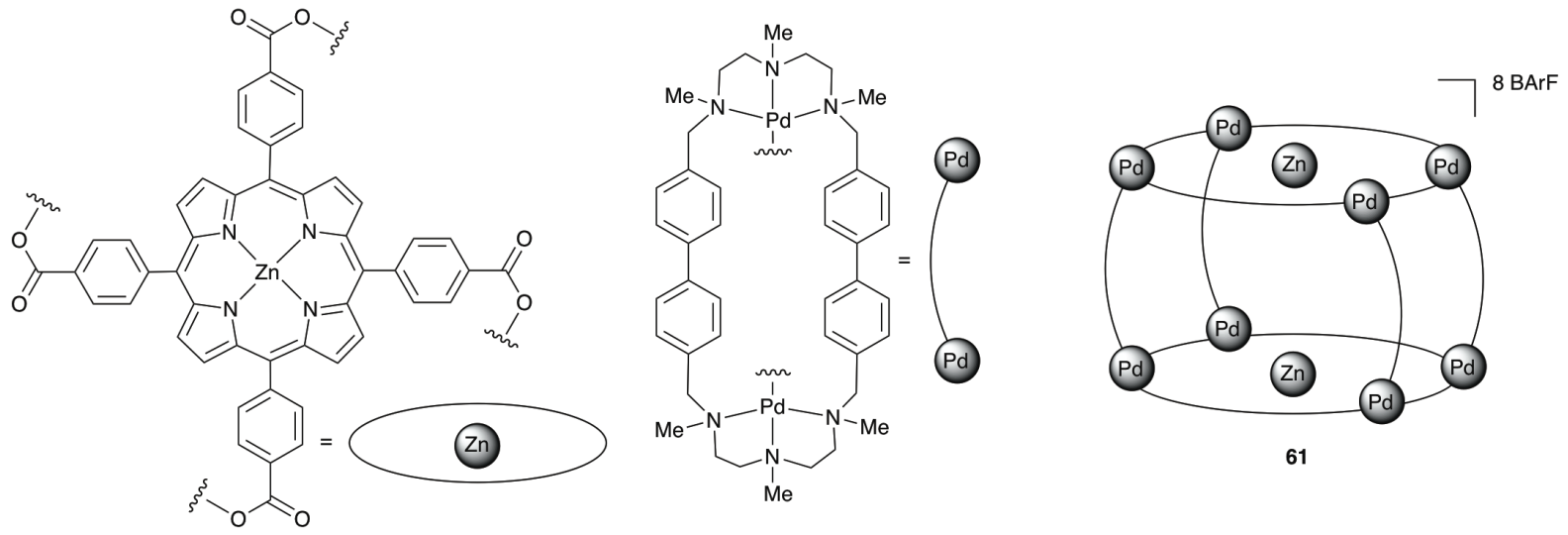

Figure 10. Tetragonal prismatic nanocapsule $\mathbf{6 1}$ and its building blocks.

Compared to their non encapsulated analog 62, 60a-c lead to much higher ee values (up to $79 \%$ for $\mathbf{6 0 b} v s$. only $16 \%$ for $\mathbf{6 2}$ ) and is more active and robust (TON $=308$ for $\mathbf{6 0 b} v s .215$ for 62 ) even if activity remains very low (only $6 \%$ conversion with $\mathbf{6 0 b}$ and $32 \%$ (TON $=$ 1600) for the most active $60 \mathrm{a}$ after $96 \mathrm{~h}$ reaction time under 20 bar $\mathrm{CO} / \mathrm{H}_{2}$ at standard rhodium load (0.02 mol\%) and room temperature) (Scheme 37). 

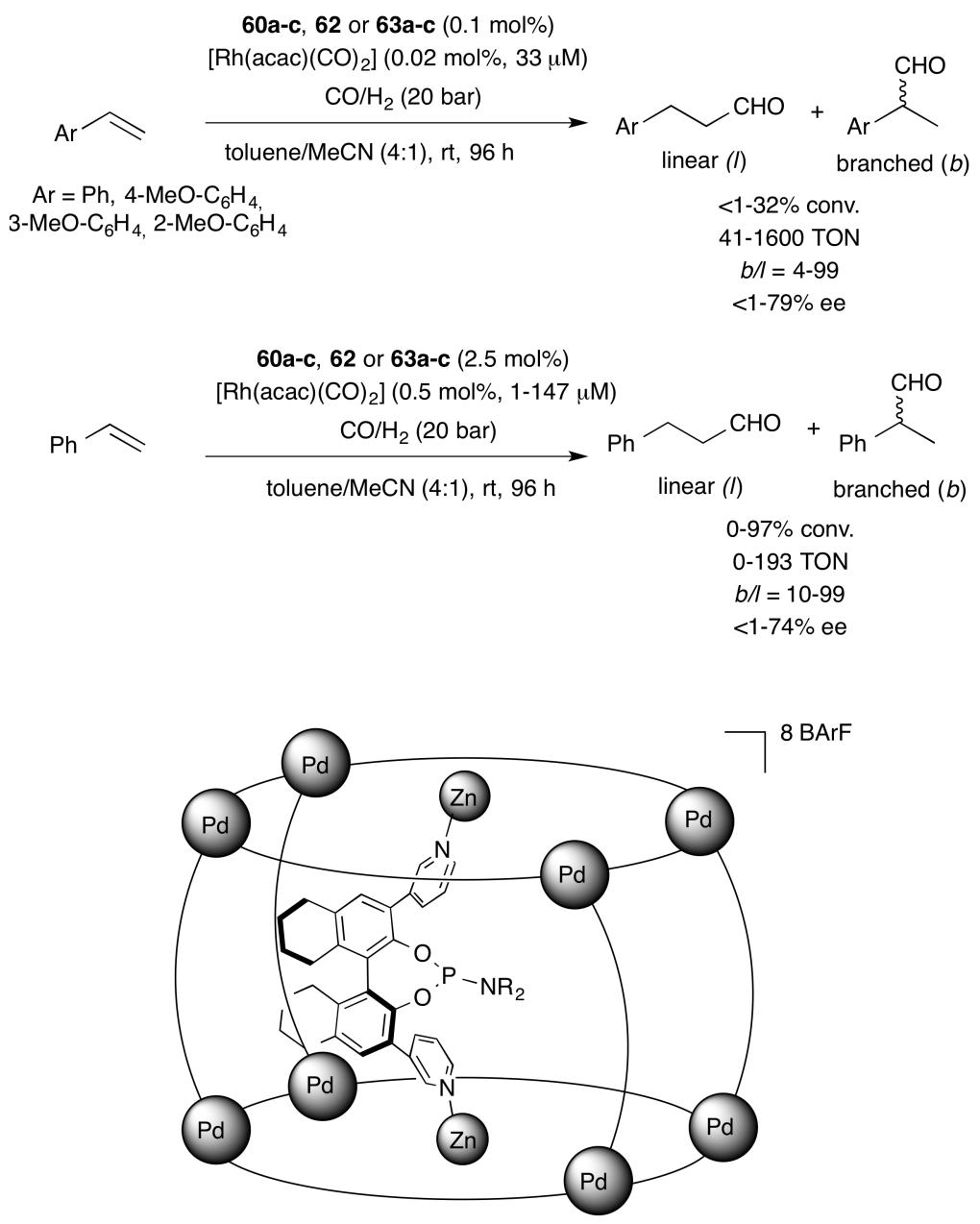

60a, R = methyl

60b, R = ethyl

$60 c, R=$ ipropyl

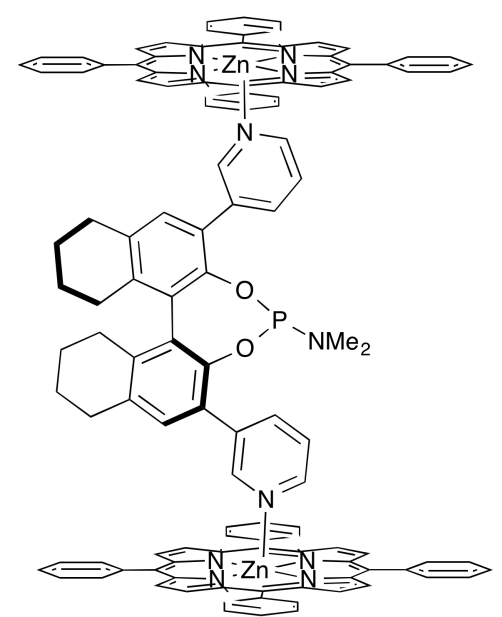

62

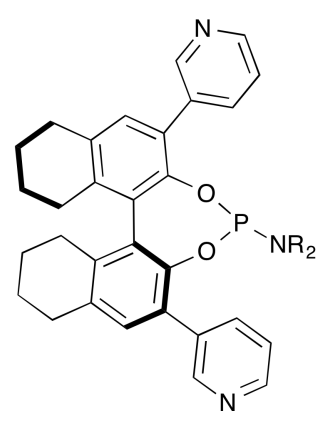

63a, $R=$ methyl

63b, R = ethyl

63c, $\mathrm{R}=$ ipropyl

Scheme 37. Asymmetric hydroformylation of styrene using $\mathrm{Rh}(\mathrm{I})$ catalysts derived from supramolecular metallocages. 
The large difference in enantioselectivity cannot be ascribed purely to encapsulation but also to the fact that the dipyridyl guest is less prone to decoordination when encapsulated in a metallocage, knowing that the rhodium complexes derived from free dipyridyl phosphoramidite 63a-c are poor chiral inductors and display very low activity as a result of the competition between free pyridine ligands and substrate for the rhodium catalytic center (up to $6 \%$ conversion and $8 \%$ ee). Very recently, Reek designed other self-assembled chiral capsules. Although not macrocyclic, the nonchiral tris-3-pyridylphosphine 64 forms capsulelike ligands when coordinated to metalloporphyrins (65a-e) (Scheme 38) [78].
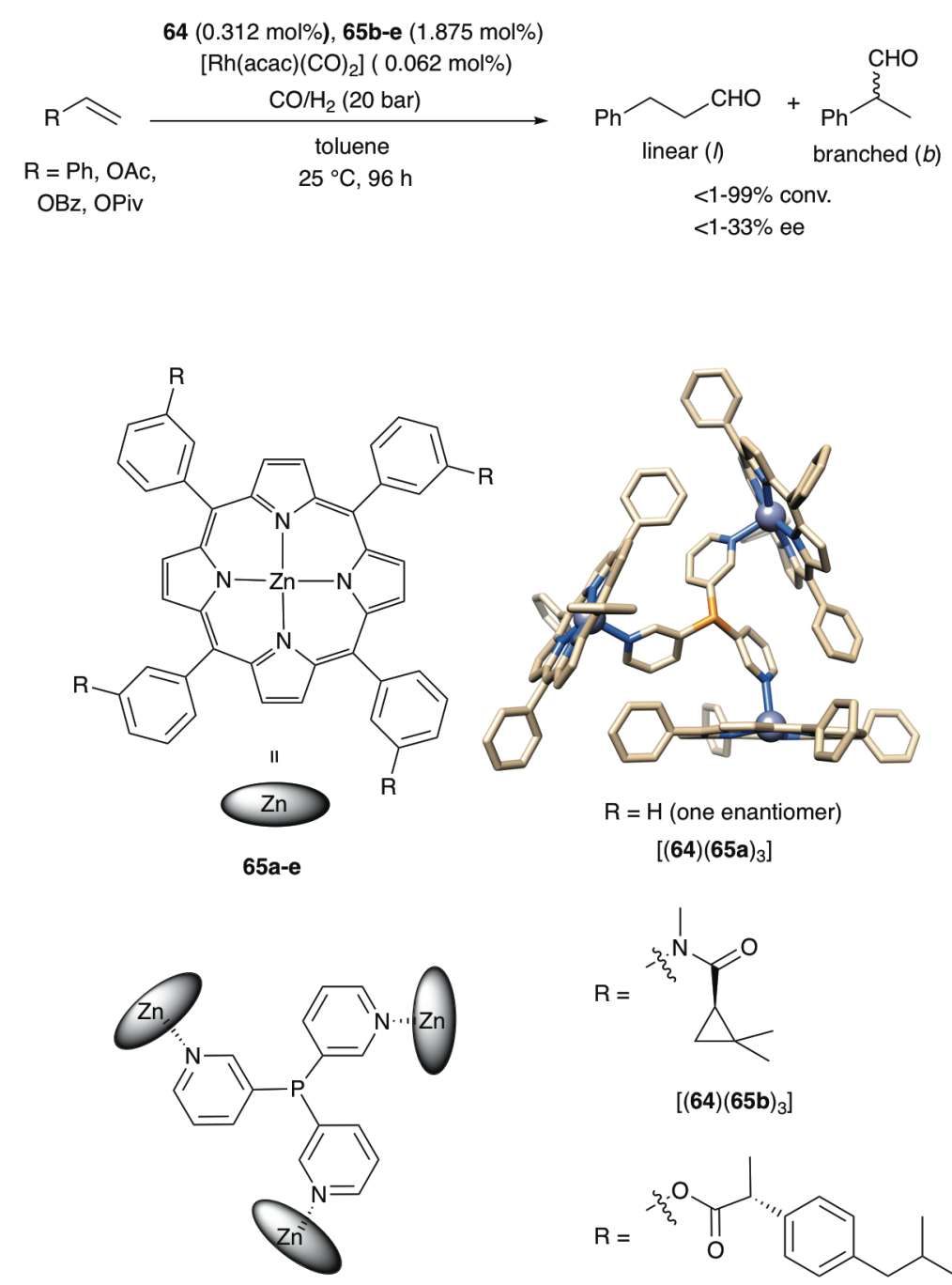

$\left[(64)(65 b)_{3}\right]$<smiles>CC1(C)C2CCC1(C(=O)O[13CH3])OC2=O</smiles><smiles>CC(C)Cc1ccc([C@@H](C)C(=O)O[AsH])cc1</smiles>

$\left[(64)(65 c)_{3}\right]$

$\left[(64)(65 e)_{3}\right]$<smiles>CCOC(=O)C(C)CC</smiles>

Scheme 38. Capsular, supramolecularly assembled monophosphine ligands for Rh(I)-catalyzed asymmetric hydroformylation of functional olefins. 
In the presence of chiral functionalities as in $\mathbf{6 5 b} \mathbf{b}-\mathbf{e}$ at the periphery of the zinc porphyrins, the P(III) ligand at the heart of the capsule can adopt two diastereomeric forms, one of them being lower in energy by $3 \mathrm{kcal} / \mathrm{mol}$ according to calculations. It is believed that the source of chiral induction during the rhodium-catalyzed hydroformylation of various olefins is not the outwards pointing chiral substituents, but the conformation of tris-3-pyridylphosphine together with the chiral shape of the porphyrin capsule. Because of the weak pyridine-zinc bond, a large excess of chiral metalloporphyrin ( 6 equiv) has to be added during catalysis to guaranty the integrity of the metallocapsule around the P(III) ligand. Such a bulky capsular ligand ensures the exclusive formation of a monophosphine-coordinated rhodium species under hydroformylation reaction conditions according to operando FTIR studies, which in turn leads to the chiral branched regioisomeric aldehyde only, during the hydroformylation of styrene and other vinyl arenes. Up to $33 \%$ ee was achieved for the asymmetric hydroformylation of vinylacetate with the best performing chiral capsule $\left[(\mathbf{6 4})(\mathbf{6 5 b})_{3}\right]$. However, only $13 \%$ ee was reached in the case of styrene with the same ligand. Asymmetric hydroformylation of 1-octene was also carried out, but attempts to separate the branched product enantiomers failed.

\section{Conclusion}

Cavity-shaped ligands have attracted increasing interest in the field of asymmetric metal catalysis because of their capacity to control the first coordination sphere of metals and alter their reactivity both in terms of activity and selectivity, in particular enantioselectivity. So far, the cavity in most of these catalytic systems acts as a preorganization platform in order to bring rigidity and better control access of the substrate(s) to the metal center. Recent studies have shown that even better enantiodiscrimination can be achieved when the metal is forced to reside in the cavity, which is reminiscent of the way metallo-enzymes works. Although very high ee values have to date been reached for notoriously challenging asymmetric catalytic reactions in particular those taking place at the backside of the metal-ligand bond as in gold(I) catalysis, most of these cavity-shaped systems do not follow Michaelis-Menten kinetics and therefore often suffer from poor activity as a result of the confinement of the active site and product poisoning. Only by ensuring true enzyme-like behavior, which involves transition state stabilization, effective substrate uptake and product expulsion from the catalyst inner space can one hope to match the exceptional catalytic properties of enzymes, but without their drawbacks, in particular their structural complexity, lack of 
robustness, and limited scope. The host-guest properties of cavity-shaped catalysts will undoubtedly play a key role in the future in achieving such desirable properties. Another limitation of some of these catalytic systems is the impossibility to get hold of both enantiomers in the case of naturally occurring receptors like the CDs. However with the advent of powerful regioselective multifonctionalization methods, it is now possible to alter the environment of the catalytic center within the cavity at will, thus providing opportunities for accessing both enantiomeric products for a given asymmetric reaction.

\section{Conflicts of interest}

There are no conflicts to declare.

\section{Acknowledgements}

ZK would like to thank the Algerian "Ministère de l'Enseignement Supérieur et de la Recherche Scientifique" for a PNE fellowship. We thank Dr. D. Matt and Dr. S. T. Jung for critical discussion and suggestions.

\section{References}

[1] W.S. Knowles, Angew. Chem. Int. Ed. 41 (2002) 1998-2007.

[2] R. Noyori, Angew. Chem. Int. Ed. 52 (2013) 79-92.

[3] K.B. Sharpless, Angew. Chem. Int. Ed. 41 (2002) 2024-2032.

[4] H.B. Kagan, T.-P. Dang, J. Am. Chem. Soc. 94 (1972) 6429-6433.

[5] R.H. Holm, P. Kennepohl, E.I. Solomon, Chem. Rev. 96 (1996) 2239-2314.

[6] R. Gramage-Doria, D. Armspach, D. Matt, Coord. Chem. Rev. 257 (2013) 776-816.

[7] T. Iwasawa, Tetrahedron Letters 58 (2017) 4217-4226.

[8] S.H.A.M. Leenders, R. Gramage-Doria, B. de Bruin, J.N.H. Reek, Chem. Soc. Rev. 44 (2015) 433-448.

[9] V. Mouarrawis, R. Plessius, J.I. van der Vlugt, J.N.H. Reek, Front. Chem. 6 (2018) 623.

[10] C. Tan, D. Chu, X. Tang, Y. Liu, W. Xuan, Y. Cui, Chem. Eur. J. 25 (2019) 662-672.

[11] Y. Tang, Y.i. He, Y. Feng, Q. Fan, Prog. Chem. 30 (2018) 476-490.

[12] B. Kesanli, W. Lin, Coord. Chem. Rev. 246 (2003) 305-326.

[13] H.L. Ngo, W. Lin, Top. Catal. 34 (2005) 85-92.

[14] L. Ma, C. Abney, W. Lin, Chem. Soc. Rev. 38 (2009) 1248-1256.

[15] W. Lin, Top. Catal. 53 (2010) 869-875.

[16] J.M. Falkowski, S. Liu, W. Lin, Isr. J. Chem. 52 (2012) 591-603.

[17] J. Dong, X. Han, Y. Liu, H. Li, Y. Cui, Angew. Chem. Int. Ed. 59 (2020) 13722-13733.

[18] C.D. Gutsche, Muthukrishnan, J. Org. Chem. 43 (1978) 4905-4906.

[19] C.D. Gutsche, Calixarenes Revisited in Monographs in Supramolecular Chemistry, Royal Society of Chemistry, Cambridge, 1998.

[20] L. Mandolini, R. Ungaro, in: Calixarenes in Action, Imperial College Press, London, 2000.

[21] A. Dalla Cort, L. Mandolini, C. Pasquini, L. Schiaffino, New J. Chem. 28 (2004) 11981199.

[22] G.E. Arnott, Chem. Eur. J. 24 (2018) 1744-1754. 
[23] C. Dieleman, S. Steyer, C. Jeunesse, D. Matt, J. Chem. Soc., Dalton Trans. (2001) 2508-2517.

[24] A. Marson, Z. Freixa, P.C. Kamer, P.W. van Leeuwen, Eur. J. Inorg. Chem. 2007 (2007) 4587-4591.

[25] N. Khiri, E. Bertrand, M.-J. Ondel-Eymin, Y. Rousselin, J. Bayardon, P.D. Harvey, S. Jugé, Organometallics 29 (2010) 3622-3631.

[26] N. Khiri-Meribout, E. Bertrand, J. Bayardon, M.-J. Eymin, Y. Rousselin, H. Cattey, D. Fortin, P.D. Harvey, S. Jugé, Organometallics 32 (2013) 2827-2839.

[27] A. Karpus, O. Yesypenko, V. Boiko, R. Poli, J.C. Daran, Z. Voitenko, V. Kalchenko, E. Manoury, Eur. J. Org. Chem. (2016) 3386-3394.

[28] L. Monnereau, D. Sémeril, D. Matt, L. Toupet, Adv. Synth. Catal. 351 (2009) 16291636.

[29] N. Natarajan, M.-C. Pierrevelcin, D. Sémeril, C. Bauder, D. Matt, R. Ramesh, Catal. Commun. 118 (2019) 70-75.

[30] C. Floriani, R. Floriani-Moro, Metal Reactivity on Oxo Surfaces Modeled by Calix [4] arenes, in: Calixarenes 2001, Springer, 2001, pp. 536-560.

[31] C. Gaeta, M. De Rosa, M. Fruilo, A. Soriente, P. Neri, Tetrahedron: Asymmetry 16 (2005) 2333-2340.

[32] P. Nandi, A. Solovyov, A. Okrut, A. Katz, ACS Catal. 4 (2014) 2492-2495.

[33] M.E. Amato, F.P. Ballistreri, A. Pappalardo, G.A. Tomaselli, R.M. Toscano, D.J. Williams, Eur. J. Org. Chem. (2005) 3562-3570.

[34] C. Bonaccorso, G. Brancatelli, F.P. Ballistreri, S. Geremia, A. Pappalardo, G.A. Tomaselli, R.M. Toscano, D. Sciotto, Dalton Trans. 43 (2014) 2183-2193.

[35] G. Crini, Chem. Rev. 114 (2014) 10940-10975.

[36] F. Macaev, V. Boldescu, Symmetry 7 (2015) 1699-1720.

[37] J.M. Benito, J.M. García Fernández, Cyclodextrin Chemistry via Selective Protecting Group Manipulations in: S. Vidal (Ed.) Protecting Groups: Strategies and Applications in Carbohydrate Chemistry, Wiley-VCH, Weinheim, 2019, pp. 371-393.

[38] A. Molnár, ChemCatChem 13 (2021).

[39] L. Weber, I. Imiolczyk, G. Haufe, D. Rehorek, H. Hennig, J. Chem. soc., Chem. Commun. (1992) 301-303.

[40] M. Bonchio, T. Carofiglio, F. Di Furia, R. Fornasier, J. Org. Chem. 60 (1995) 59865988.

[41] H. Sakuraba, H. Maekawa, J. Inclusion Phenom. Macrocyclic Chem. 54 (2006) 41-45.

[42] A. Schlatter, M.K. Kundu, W.D. Woggon, Angew. Chem. Int. Ed. 43 (2004) 67316734.

[43] S. Tilloy, C. Binkowski-Machut, S. Menuel, H. Bricout, E. Monflier, Molecules 17 (2012) 13062-13072.

[44] M. Jouffroy, D. Armspach, D. Matt, Dalton Trans. 44 (2015) 12942-12969.

[45] M. Sawamura, K. Kitayama, Y. Ito, Tetrahedron: Asymmetry 4 (1993) 1829-1832.

[46] Y.T. Wong, C. Yang, K.-C. Ying, G. Jia, Organometallics 21 (2002) 1782-1787.

[47] É. Engeldinger, D. Armspach, D. Matt, L. Toupet, M. Wesolek, C. R. Chim. 5 (2002) 359-372.

[48] S. Guieu, E. Zaborova, Y. Blériot, G. Poli, A. Jutand, D. Madec, G. Prestat, M. Sollogoub, Angew. Chem. Int. Ed. 49 (2010) 2314-2318.

[49] M. Jouffroy, D. Sémeril, D. Armspach, D. Matt, Eur. J. Org. Chem. 2013 (2013) 60696077.

[50] M. Jouffroy, R. Gramage - Doria, D. Armspach, D. Sémeril, W. Oberhauser, D. Matt, L. Toupet, Angew. Chem. Int. Ed. 126 (2014) 4018-4021. 
[51] M. Jouffroy, R. Gramage-Doria, D. Sémeril, D. Armspach, D. Matt, W. Oberhauser, L. Toupet, Beilstein J. Org. Chem. 10 (2014) 2388-2405.

[52] M. Jouffroy, D. Armspach, D. Matt, K. Osakada, D. Takeuchi, Angew. Chem. Int. Ed. 55 (2016) 8367-8370.

[53] Z. Kaya, L. Andna, D. Matt, E. Bentouhami, J.-P. Djukic, D. Armspach, Eur. J. Org. Chem. (2019) 4528-4537.

[54] Z. Kaya, L. Andna, D. Matt, E. Bentouhami, J.P. Djukic, D. Armspach, Chem. Eur. J. 24 (2018) 17921-17926.

[55] X. Zhu, G. Xu, L.-M. Chamoreau, Y. Zhang, V. Mansuy, L. Fensterbank, O. BistriAslanoff, S. Roland, M. Sollogoub, Chem. Eur. J. 26 (2020) 15901-15909.

[56] H. Sak, M. Mawick, N. Krause, ChemCatChem 11 (2019) 5821-5829.

[57] M. Guitet, P. Zhang, F. Marcelo, C. Tugny, J. Jiménez - Barbero, O. Buriez, C. Amatore, V. Mouriès - Mansuy, J.P. Goddard, L. Fensterbank, Angew. Chem. Int. Ed. 52 (2013) 7213-7218.

[58] P. Zhang, C. Tugny, J.M. Suárez, M. Guitet, E. Derat, N. Vanthuyne, Y. Zhang, O. Bistri, V. Mouriès-Mansuy, M. Ménand, Chem 3 (2017) 174-191.

[59] C. Tugny, N. del Rio, M. Koohgard, N. Vanthuyne, D. Lesage, K. Bijouard, P. Zhang, J. Meijide Suárez, S. Roland, E. Derat, ACS Catal. 10 (2020) 5964-5972.

[60] G. Xu, S. Leloux, P. Zhang, J. Meijide Suárez, Y. Zhang, E. Derat, M. Ménand, O. Bistri-Aslanoff, S. Roland, T. Leyssens, O. Riant, M. Sollogoub, Angew. Chem. Int. Ed. 59 (2020) 7591-7597.

[61] Z. Li, C. Jablonski, Chem. Commun. (1999) 1531-1532.

[62] D. Zhang, J.-P. Dutasta, V. Dufaud, L. Guy, A. Martinez, ACS Catal. 7 (2017) 73407345 .

[63] D. Zhang, K. Jamieson, L. Guy, G. Gao, J.-P. Dutasta, A. Martinez, Chem. Sci. 8 (2017) 789-794.

[64] G.E. Arnott, P.C. Bulman Page, H. Heaney, R. Hunter, E.P. Sampler, Synlett 3 (2001) 412-414.

[65] G. Arnott, H. Heaney, R. Hunter, Philip C.B. Page, Eur. J. Org. Chem. 2004 (2004) 5126-5134.

[66] N. Endo, M. Kanaura, M.P. Schramm, T. Iwasawa, Eur. J. Org. Chem. 2016 (2016) 2514-2521.

[67] N. Natarajan, E. Brenner, D. Sémeril, D. Matt, J. Harrowfield, Eur. J. Org. Chem. 2017 (2017) 6100-6113.

[68] I. Martín-Torres, G. Ogalla, J.-M. Yang, A. Rinaldi, A.M. Echavarren, Angew. Chem. Int. Ed. 60 (2021) 9339-9344.

[69] S.J. Lee, A. Hu, W. Lin, J. Am. Chem. Soc. 124 (2002) 12948-12949.

[70] H. Jiang, A. Hu, W. Lin, Chem. Commun. (2003) 96-97.

[71] W. Lin, J. Solid State Chem. 178 (2005) 2486-2490.

[72] C. Wang, M. Zheng, W. Lin, J. Phys. Chem. Lett. 2 (2011) 1701-1709.

[73] J. Dong, X. Han, Y. Liu, H. Li, Y. Cui, Angew. Chem. Int. Ed. 59 (2020) 13722-13733.

[74] J. Jiao, C. Tan, Z. Li, Y. Liu, X. Han, Y. Cui, J. Am. Chem. Soc. 140 (2018) 2251-2259.

[75] C. Tan, J. Jiao, Z. Li, Y. Liu, X. Han, Y. Cui, Angew. Chem. Int. Ed. 57 (2018) 2085 2090.

[76] C. García-Simón, R. Gramage-Doria, S. Raoufmoghaddam, T. Parella, M. Costas, X. Ribas, J.N. Reek, J. Am. Chem. Soc. 137 (2015) 2680-2687.

[77] T. Gadzikwa, R. Bellini, H.L. Dekker, J.N.H. Reek, J. Am. Chem. Soc. 134 (2012) 2860-2863.

[78] L.J. Jongkind, J.N.H. Reek, Chem. Asian J. 15 (2020) 867-875. 


\section{Captions to Figures}

Scheme 1. Asymmetric alkylation and hydrogenation of functional olefins catalyzed by diphosphines based on chiral calix[4]arene platforms.

Scheme 2. Use of enantiopure calix[4]arene-based diphosphites in asymmetric hydrogenation of prochiral olefins.

Scheme 3. Asymmetric hydrogenation of a dehydroamino acid methyl ester by a calix[4]arene bonded to a P-chirogenic aminophosphane phosphinite Rh metallo-organic unit.

Scheme 4. Use of P-chirogenic mono- and diphosphines built on a calix[4]arene platform for Pd-catalyzed asymmetric allylic substitution.

Scheme 5. Use of enantiopure mono-and di(ferrocenylphosphine)-calixarenes in asymmetric Pd-catalyzed Suzuki-Miyaura cross coupling and allylic substitution.

Scheme 6. Use of calix[4]arene-diphosphite rhodium complexes in asymmetric olefin hydroformylation.

Scheme 7. Use of diphosphites based on upper rim substituted calix[4]arenes in asymmetric Rh-catalyzed hydroformylation of styrene.

Scheme 8. Asymmetric aldol reactions catalyzed by Ti(IV)-complexed calix[4]arenes substituted with enantiopure amino acid and pinene-like units at the lower rim.

Scheme 9. Asymmetric MPV reduction of chloroketones with chiral Al(III)-calix[4]arene complexes.

Scheme 10. Al(III)-catalyzed asymmetric MPV reduction with enantiopure calix[4]arenes ligands having distally positioned chiral substituents.

Scheme 11. Enantiopure (salen)Mn(III) complexes containing a calix[4]arene as catalysts for enantioselective epoxidation reactions.

Scheme 12. Enantioselective epoxidation of alkenes by enantiopure (salen)Mn(III) calix[4]arenes.

Scheme 13. Photocatalytic oxygenation of a racemic $\alpha$-pinene mixture by cyclodextrin-linked porphyrins.

Scheme 14. Asymmetric oxidation of thioanisole in the presence of $\beta$-CD-based nitrogen ligands.

Scheme 15. Enantioselective oxidation of sulfides catalyzed by chiral $\mathrm{Mo}(\mathrm{V})$ and $\mathrm{Cu}(\mathrm{II})$ complexes of catechol-functionalized $\beta$-CD derivatives.

Scheme 16. Ru(II)-catalyzed asymmetric reduction of ketones using monosubstituted CDs $\mathbf{2 7} \mathbf{a}, \mathbf{b}$ as ligands.

Scheme 17. Ru(II)-catalyzed asymmetric reductions of aromatic methyl ketones using monosubstituted CDs 27a-h as ligands. 
Scheme 18. $\beta$-CD-based diphosphine 31 and corresponding $\mathrm{Rh}(\mathrm{I})$ complex 32 for $\mathrm{Rh}(\mathrm{I})$ catalyzed asymmetric hydrogenation of functional olefins.

Scheme 19. Diphosphite functionalized $\alpha$-CDs in Rh catalyzed hydrogenation.

Scheme 20. $\mathrm{Pd}(0)$ catalyzed Tsuji-Trost substitution using pseudo-enantiomeric diphosphine CD ligands 35a-c.

Scheme 21. Phosphane-phosphite chelators on an $\alpha$-CD scaffold and application in Rh(I)catalyzed hydrogenation and hydroformylation of olefins

Scheme 22. $\mathrm{Rh}(\mathrm{I})$-catalyzed hydroformylation of styrene using CD-based monophosphine complexes 39a,b.

Scheme 23. Cationic Pd(II) allyl monophosphine complexes for the asymmetric polymerization of styrene.

Scheme 24. $\mathrm{Au}(\mathrm{I})$ complexes derived from CD-based monodentate P(III) and NHC ligands for the asymmetric cycloisomerization of 1,6-enynes.

Scheme 25. NHC-capped $\alpha$ - and $\beta$-CDs 44a,b for asymmetric gold catalysis.

Scheme 26. NHC-appended $\beta$-CD 45 for asymmetric gold catalysis.

Scheme 27. $\mathrm{Au}(\mathrm{I})$ complexes derived from perbenzylated NHC-capped CDs as asymmetric catalysts in the asymmetric cycloisomerization and alkoxycyclization of 1,6-enynes.

Scheme 28. Cavity-controlled asymmetric hydrosilylation of prochiral ketones including $\alpha, \beta$ unsaturated ones.

Scheme 29. Macrocyclic Mn(III) salen complexes as asymmetric catalysts for styrene epoxidation.

Scheme 30. Asymmetric oxidation of bulky sulfides using oxido-vanadium(V) cage catalysts.

Scheme 31. Oxido-vanadium(V) cage catalysts for the asymmetric oxidation of sulfides.

Scheme 32. Asymmetric addition of diethylzinc using bridged resorcin[4]arenes as ligands.

Scheme 33. Enantioselective alkocyclization of 1,6-enynes with gold(I) cavitands 50a-n.

Scheme 34. Enantioselective diethylzinc additions to aromatic aldehydes catalyzed by an organometallic triangle.

Scheme 35. Metallocyclophane analog of 52 with outward-pointing phenolic coordinating groups (53) used in the asymmetric diethylzinc addition to aldehydes.

Scheme 36. Asymmetric Rh(I)-catalyzed hydroformylation of unfunctionalized alkenes using a chiral supramolecularly assembled ligand (56). 
Scheme 37. Asymmetric hydroformylation of styrene using $\mathrm{Rh}(\mathrm{I})$ catalysts derived from supramolecular metallocages.

Scheme 38. Capsular supramolecularly assembled monophosphine ligands for $\mathrm{Rh}(\mathrm{I})$ catalyzed asymmetric hydroformylation of functional olefins.

Figure 1. Calix[4]arenes in a 1,3-alternate conformation with an enantiopure (salen)Mn(III) capping unit.

Figure 2. Schematic description of CDs

Figure 3. $\beta$-CDs substituted with a single aminoalcohol unit.

Figure 4. $\mathrm{Ru}(\mathrm{II})$ complexes of $\beta$-CDs substituted with a single amino alcohol unit.

Figure 5. Pseudoenantiomeric $\mathrm{Pd}(\mathrm{II})-\mathrm{CD}$ complexes.

Figure 6. CD-based monophosphines with an inward-pointing phosphorus atom.

Figure 7. Dimeric analog (52) of the trimeric chiral metallocyclophane 51.

Figure 8. Building blocks used for assembling ligand 55.

Figure 9. Rh(acac) complex (57) of ligand 56.

Figure 10. Tetragonal prismatic nanocapsule 59 and its building blocks. 
Graphical Abstract

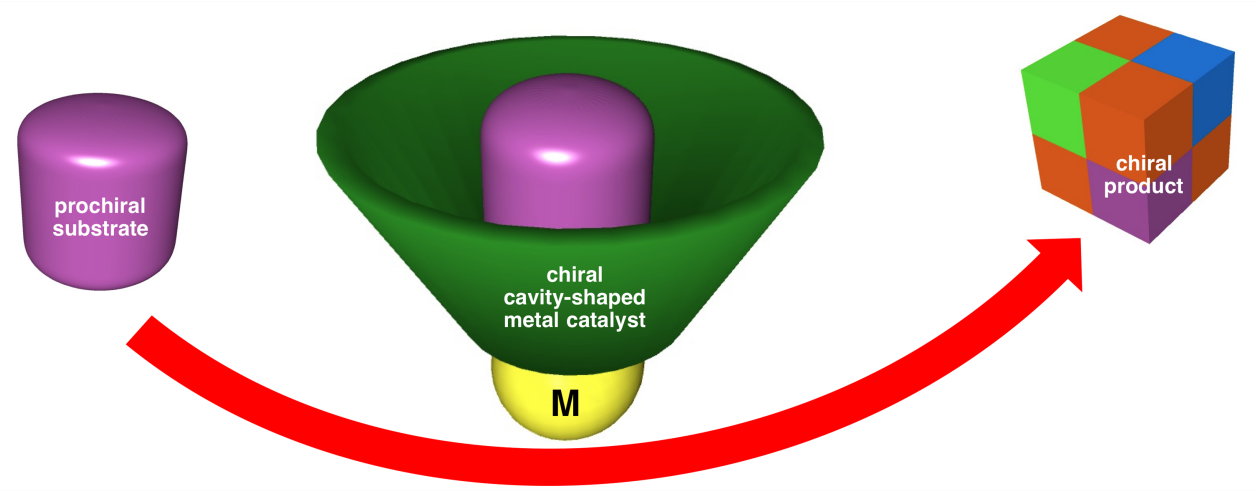

